\title{
Identity Performance and Negotiation of Multilingual English Language Teachers in New Zealand - A Multiple Case Study
}

By Apsara Kalpanie Wimalasiri

\author{
A thesis \\ submitted to the Victoria University of Wellington \\ in fulfillment of the requirement for the degree of \\ Master of Arts \\ in Applied Linguistics
}

Victoria University of Wellington

2021 


\section{Dedicated to Appachchi}

for bringing me up to be multilingual in a highly monolingual background,

and

for foreseeing my academic life way before I started the journey 


\begin{abstract}
Identity is constituted in and through language (Norton, 2005) demonstrating social, political and cultural ideologies of individual selves in interaction. Exploring identities of individuals as language users, learners and teachers allows linguistic and applied linguistic researchers to disclose meanings behind complex language related behaviours. This supports insights for the development of language education.

In the current study, I explore identity performance and identity negotiation of multilingual English language teachers (MELTs) in New Zealand (NZ). I define MELTs as English language teachers who speak any other language(s) in addition to English. Exploring how MELTs perform and negotiate their identities in NZ is important due to several factors. First, people in society have various ideological assumptions regarding multilingual teachers involved in teaching English in an English speaking country; therefore, MELTs are required to negotiate their linguistic and social identities to suit the expectations of the institutions and students they serve. Secondly, there is no known study in NZ focused on MELT identities, even though the population of NZ is diverse, comprised of multilingual communities. Thirdly, revealing identity negotiation of MELTs supports language teacher educators to understand language teacher identities with regard to classroom realities. This provides insights to develop language teacher education programmes accordingly.
\end{abstract}

I employed four different research methods: semi-structured narrative interviews, identity portraits and classroom observations followed by stimulated recall sessions to explore how MELTs perform negotiated identities in the classroom (RQ 1) and what ideological and interactional functions are served when they perform negotiated identities (RQ 2). Data from narrative interviews provided insights to understand teacher identities revealed through their biographies and classroom stories. In addition, teachers' narratives revealed how teacher identities are constructed and positioned while being negotiated in their stories. Identity portraits and the recorded interactions provided insights to understand how teachers make semiotic links to various linguistic and social identities they perform as English language teachers, providing various indexical meanings to those identities. I observed how teachers perform negotiated identities in interaction with students through classroom observations. I also conducted 
stimulated recall sessions to investigate teacher responses for classroom scenarios. Triangulated data from all the sources generated themes answering the two research questions.

The findings of the study show that MELTs perform multiple negotiated identities in interaction with students and myself with reference to the micro and macro social contexts in which they are situated. MELTs also demonstrate positive and negative identity practices in the classroom based on their English language and English language teaching ideologies. Furthermore, MELTs' identity performances were observed to serve various ideological and interactional functions in the classroom. For instance, their negotiated identities support them practicing either monolingual or multilingual friendly language teaching. Moreover, some MELTs employ their negotiated linguistic identities to translanguage in the classroom, catering to the language needs of multilingual students. They also negotiate their teacher identities based on contextual factors. Thus, the findings of my study support language teacher educators, researchers and administrators to understand the contribution of MELTs towards English language education in New Zealand. 


\section{Acknowledgements}

I express my gratitude to my supervisor, Dr Corinne Seals for her guidance throughout the completion of this research. Thanks for your encouragement to bring out the best researcher self in me.

I take this opportunity to thank my participants for their valuable time and contribution in my research. Dory, Olga and Cindy, thanks for your humbleness.

I would like to thank the most humble academic staff and colleagues in LALS for their constant support. Thanks Mohammed for the useful academic insights and inspiration during the initial phase of the research. Thanks Anna, Mark and Natasha for the best friendship and emotional support provided when it was needed most. Thanks Priska and Xin from the welcoming neighbourhood and Aini and Jenny for partnering the conference tour. Thanks Janet, Bernie, Matthew, Patrick and Alastair for all the support throughout last year.

I extend my thanks to João and Harisu for being the family in New Zealand. Thanks João for the technical assistance provided. Thanks Hiroshika and Baligh for bearing me at Maru.

Thanks Sri Lankan Wellingtonians, Erandi, Chethana and Rasika for including me in their circle. Thanks Hesadi and the Victoria Sri Lankan group for "ourness".

My heartiest thanks to Kethaki, Ms Mihiri, Dr. Shreemali, Raji, Osanka, Thilini and Charu for our virtual meetings and discussions.

Thanks UOC group: Cha, Mela, Ksha, Tsha, Ud and Upex for love and friendship extended via virtual spaces.

Finally, thanks my two moms, and three sisters for bearing my long silence due to academic commitments. Thanks Miyasiya for managing my research time line with constant reminders, being patient on my academic moods and committing one whole year of our family life for this research. 


\section{Contents}

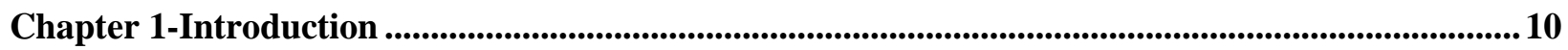

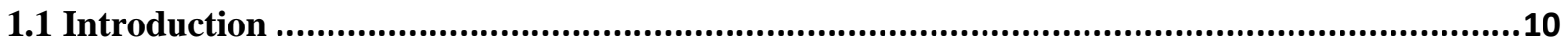

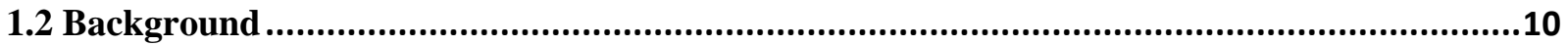

1.2.1 English Language Teaching (ELT) in New Zealand .............................................12

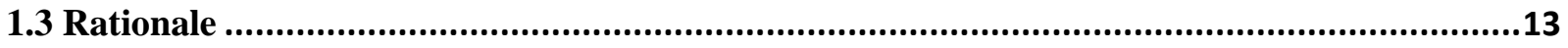

1.3.1 Research questions ....................................................................................................14

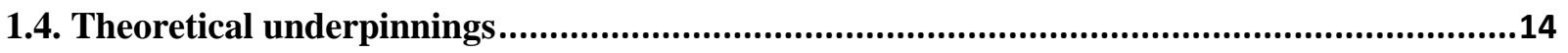

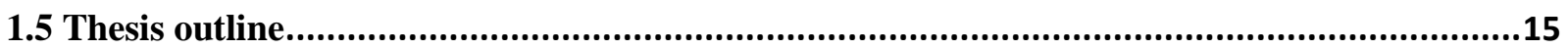

Chapter 2-Literature Review .........................................................................................................................18

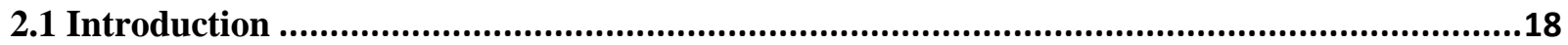

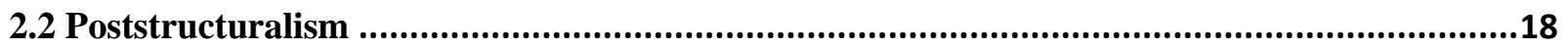

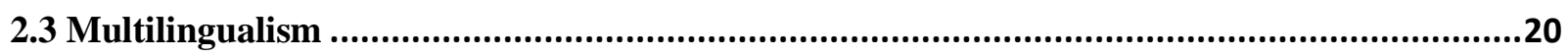

2.3.1 Translanguaging in the language classroom ..............................................................21

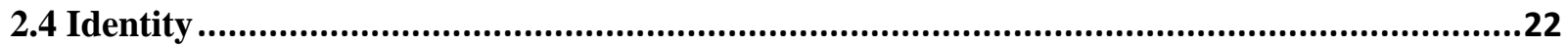

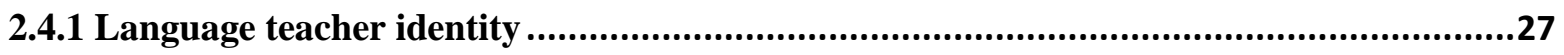

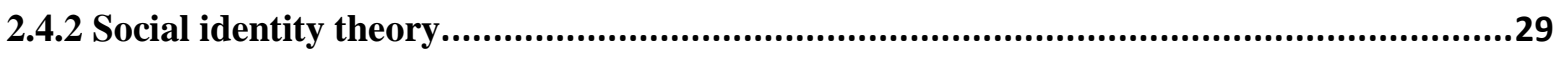

2.4.3 Linguistic identities of the language teachers ...............................................................31

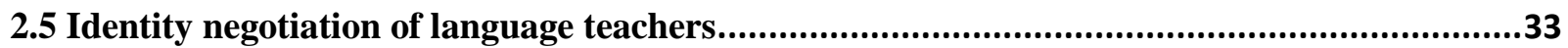

2.5.1 Identity negotiation as an investment by language teachers ......................................34

2.5.2 A conceptual framework for understanding Language Teacher Identity (LTI)..............36

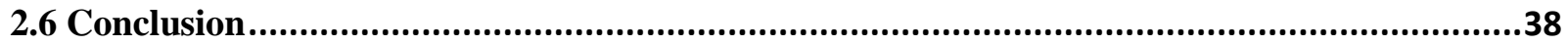

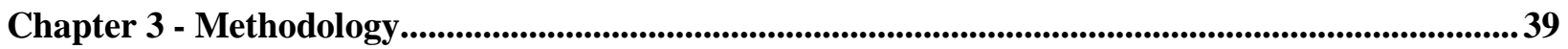

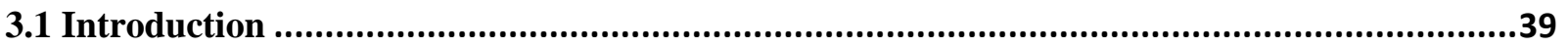

3.2 Employing a multiple case study research design to explore teacher identities .....................39

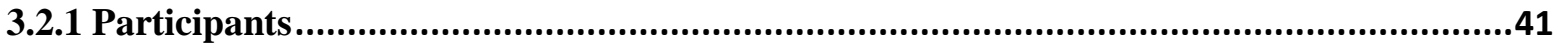

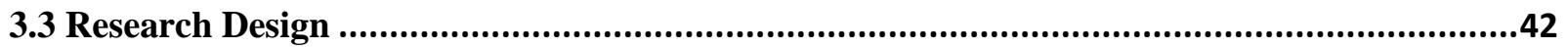

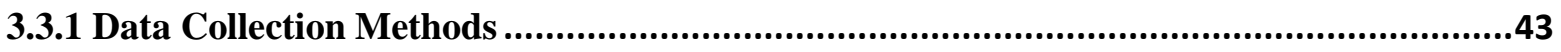

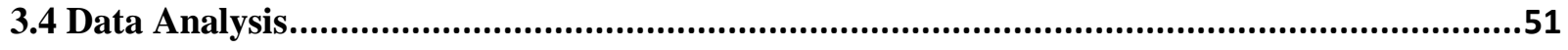

3.5 My engagement in collecting, reporting and analyzing data ..............................................53

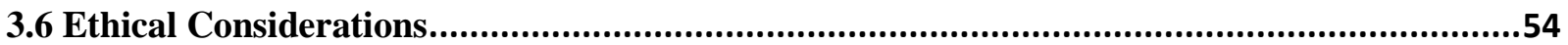

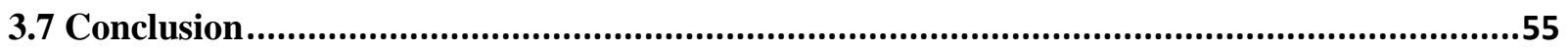


Chapter 4: Identity Performance of Multilingual English Language Teachers.....................................56

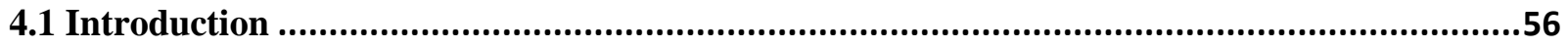

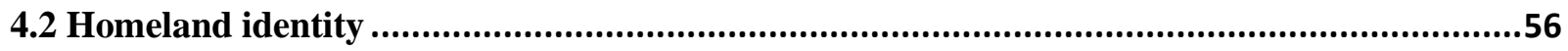

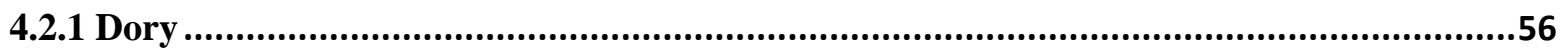

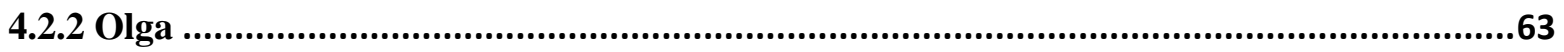

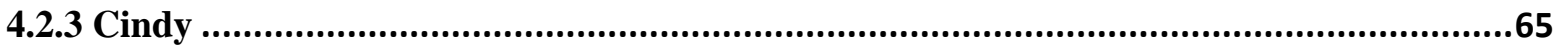

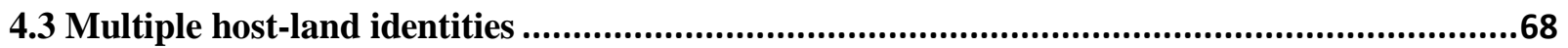

4.3.1 Negotiated host-land identities ................................................................................68

4.3.2 Multilingual identity of the MELTs.........................................................................72

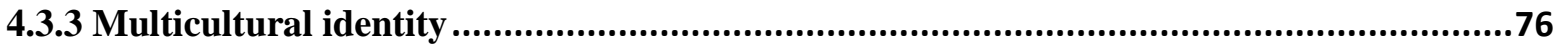

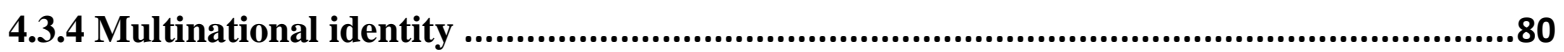

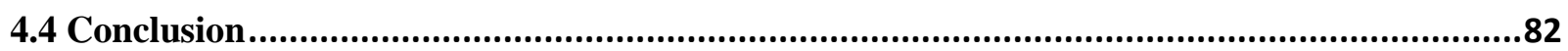

Chapter 5- Identity Negotiation of Multilingual English Language Teachers.......................................84

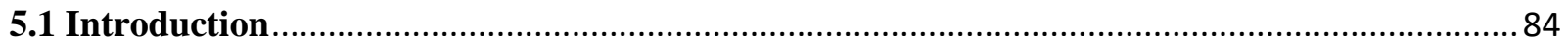

5.2 Investment in ELT: Identity, Ideology and Capital............................................................... 84

5.2.1 Ideology of monolingual practice in English language teaching .................................... 85

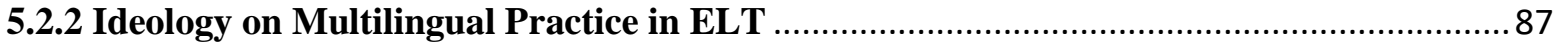

5.3 Identity Negotiation: a pedagogical advantage ................................................................ 91

5.3.1 ELT Classroom as a Community of Practice ............................................................. 91

5.3.2 Community of Practice: An advantage in the multicultural ELT classroom ................... 94

5.3.3. Translanguaging through negotiated multilingual identity ........................................... 95

5.4 Context dependent teacher identity negotiation................................................................. 101

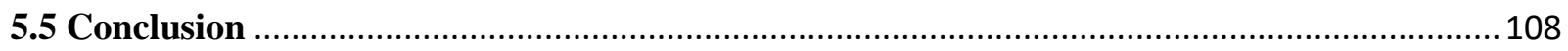

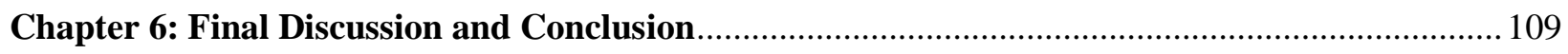

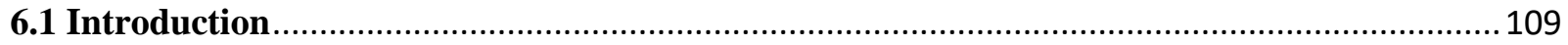

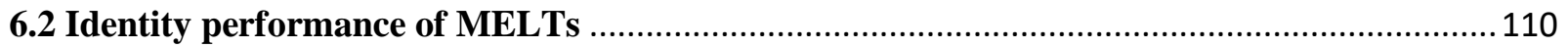

6.3 Ideological and interactional functions served at identity negotiation of MELTs ................111

6.4 Epistemological value to the field of LTI research .......................................................... 113

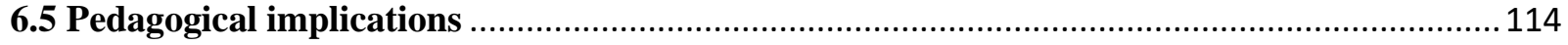

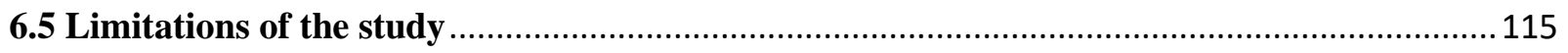

6.6 Recommendations for future research ........................................................................ 116

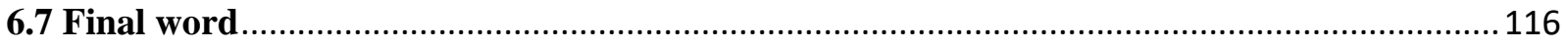




\section{List of Abbreviations}

NZ-New Zealand

ELT- English Language Teaching

MELT-Multilingual English language teachers

CofP- Community of Practice

TESOL-Teaching English to Speakers of Other Languages

LTI- Language Teacher Identity

NNESTs- Non-Native English Speaker Teachers

ESL - English as a Second Language

EFL- English as a Foreign Language

RQ- Research Question

SR-Stimulated Recall 


\section{List of Figures}

Figure 2.1-Model of investment (Darvin \& Norton, 2015)

Figure 2.2- A conceptual framework for understanding teacher identity (Yazan, 2018)

Figure 3.1- Research design

Figure 4.1- Dory's identity portrait

Figure 4.2- Olga's identity portrait

Figure 4.2- Cindy's identity portrait 


\section{Chapter 1-Introduction}

\subsection{Introduction}

This thesis elucidates the identity negotiation of multilingual English language teachers in New Zealand in terms of language, interaction, ideology and investment. I explore multilingual English language teacher identities with special reference to identity positioning, identity performance and identity negotiation. The thesis discloses multilingual English teachers' multiple identity performance and identity negotiation in interaction with myself throughout the research process as well as with students in the English language classroom. In this chapter, I present the background for the current research in terms of main theoretical underpinnings employed to understand language teacher identities. I also provide an account of English language teaching in New Zealand, with regards to its multicultural and multilingual macro social context. In addition, I state the rationale for my research, discussing the research gap identified in the literature. The introduction chapter concludes with a brief outline of the thesis.

\subsection{Background}

"People negotiate being and belonging in interaction with each other and with the settings in which they live, work and study" (Rudolph et al., 2020, p. 1). This is because individuals claim and are assigned different multiple identities (Norton, 2013), yet belong to communities in places where they live, work and study. These identities need to be negotiated for various interactional and ideological functions when they engage in interactions within the communities. Also, Rudolph et al. (2020) argue that negotiation of identity and community membership in interaction is not neutral. This is because the process of negotiation of identity is a struggle over positionality that includes "individuals and groups defining and patrolling and/or problematizing or destabilizing essentialized and idealized notions of 'language', 'culture', 'identity' and 'place' which can afford people validity, authority and agency and or strip it away from them" (Rudolph et al., 2020, p. 1). Higgins (2011) remarks that language education which involves interaction is a space where identities are negotiated. The reason for this is that the languages that are being promoted are considered a priority, marginalizing other languages (Rudolph, et al 2020), which is also considered linguistic imperialism (Phillipson, 1992). English is such a prioritized language due to its history involving colonialism; therefore, teaching and learning English to speakers of other languages is always an ideological and political practice. 
Traditionally, it was believed that native speakers teaching English language is more successful; however, in the recent past, this notion has been questioned by many researchers; for example, Ortega (2013), Higgins and Ponte (2017) and Dewaele et al. (2021), while critiquing the terms "native and non-native English speakers", as these terms can be marginalizing speakers of English. Relatedly, "native speaker fallacy" is a term introduced by Phillipson (1992) to refer to the idea that the ideal language teacher is a native speaker of that language. Sociolinguists and ELT researchers for instance, Braine (1999) and Canagarajah (1999), used this term to discuss Non-Native English Speaker Teachers (NNESTs)' right to teach English.

Also, Selvi (2018) argues that ownership of English is best understood in the context of debates on identity, legitimacy, and power. English has traditionally been the language of its gate keepers; however, identity researchers (Canagarajah, 1999; Norton, 1997) argue that language is owned by its speakers regardless of their ethnic identities. Norton (1997) also suggests that if English belongs to the speakers of English, despite labels such as native or non-native, English as a Second Language (ESL) or English as a Foreign Language (EFL) and standard or nonstandard, development of English during globalization is inevitable. However, with the rise of the discussion on World Englishes and English as a Lingua Franca, speakers of different varieties of English are recognized as contributing to the development of language rather than making mistakes. As a result, sociolinguists (Asadi et al., 2020; Dewaele et al., 2021; Dewaele \& Botes, 2020; Jenkins, 2017; Ortega, 2013; Seals et al., 2019) are researching applications of multilingualism and translanguaging as possibly more effective approaches to language teaching. Thus, I identify English teachers who speak other language(s) in addition to English, including myself, as Multilingual English Language Teachers (MELTs).

MELTs attempt to establish and negotiate their positioning and membership within their educational contexts in response to the "native speaker fallacy". This burden doubles when they teach in an English-speaking country where English is the dominant language. In such scenarios, their ethnic and multilingual identities are often questioned as part of their proficiency in English and experience in teaching English. As a result, MELTs make ideological choices to negotiate (or not) their identities. Yazan (2018) claims how language teachers understand the nature of language is "integral to their identities as language users and teachers because this understanding guides what they see as important in language instruction" (p.28). Also, Mohamed (2020) argues 
that the way in which language teachers use languages can serve to validate their membership within their teaching context or allow others to exclude them from affiliation. Thus, MELTs in my study, intentionally perform negotiated linguistic and social identities to validate their membership in the teaching contexts with which they are affiliated.

Additionally, Yazan (2018) reviews many studies on teacher identities and identifies five main commonalities with reference to conceptualizations of teacher identity: "teacher identity includes teachers' conceptions and beliefs about themselves as teachers, involves other's expectations and social positioning, dynamic and evolves constantly, is constructed and reconstructed in social contexts and interactions and develops through teachers' commitment to, participation, and investment in the profession" (p.27). This conceptualization of language teacher identity supports an understanding of language teachers' identity negotiation in relation to the contexts they are situated in and their interlocutors. Hence, the identity negotiations of the MELTs who participated in my study align with Yazan's conceptualization of teacher identity.

\subsubsection{English Language Teaching (ELT) in New Zealand}

Waite (1992) reports that there were increasing numbers of migrant adults in New Zealand who require ESL assistance, especially if they enter the country as refugees. According to Waite, it is important that the language needs of these adults are met for the wellbeing of themselves, their families and their communities because low levels of proficiency in English can limit their access to information and services, the labour market and NZ society. Waite also argues that English as a Second Language (ESL) programmes for these communities should be delivered to suit the needs of the students, preparing them for employment and transmitting cultural aspects of NZ. Furthermore, Waite remarks that it is significant that these ESL teachers show sensitivity to the cultural background and past experiences of these migrant students when designing and delivering lessons. Waite's account of teaching ESL in NZ provides insights to understand that English teachers employed in the institutions which cater to immigrants need subsequent knowledge and experience in managing language classrooms with immigrant learners. The current thesis explores identity performances and identity negotiation of multilingual English language teachers, revealing how these teachers negotiate their identities to suit their learners.

A more recent report on language teaching and learning in New Zealand by the Auckland Languages Strategy Working group (2018) mentions that a broader view of languages is required 
for NZ to fully benefit from investing in language learning and acquisition. the Auckland Languages Strategy Working Group (2018) also explains that language learning in Aotearoa New Zealand is often referred to only in the context of learning a second language rather than recognizing the different goals and needs of diverse language learners. Furthermore, this group argues that there are a number of areas where NZ needs to improve in order to achieve and fully benefit from NZ's multilingual society. For example, this report mentions that the education council does not record fluency levels in languages other than te reo Māori and English as of yet. They suggest the status of multilingualism can be raised through recording those fluency levels. Moreover, they argue that teachers' competencies in language(s) should be recorded as a signal of expertise and resources as part of teacher registration and practicing certificates.

Most importantly, the Auckland Languages Strategy Working Group (2018) identifies the multilingual teachers as resourceful for education and suggests that language proficiency of the teachers should be recognized. This report also argues that native speakers becoming teachers of languages without formal pedagogic training can be a disadvantage as these teachers can lack the range of resources and professional knowledge required for language teaching programmes. However, the Education Counts of the Ministry of Education, NZ confirmed (as an answer to my written request inquiring statistics of English language teachers in NZ) that statistics of language teachers have not been maintained in any of the potential administrative bodies in NZ at the time this thesis was written; therefore, statistics of English language teachers in NZ are not reported in this thesis. The current study, in line with the arguments of these two reports: Waite (1992) and the Auckland Languages Strategy Working Group, attempts to recognize how multilingual English language teachers can effectively be employed in language teaching in New Zealand, by exploring their identity performances and negotiation in the English language classroom.

\subsection{Rationale}

Many studies on English language teacher identities: Braine (1999); Canagarajah (1999); Huang and Varghese (2015); Liu (2012); Pavlenko (2003) have focused on the non-native identity of the language teachers rather than considering their multilingual identity. This has marginalized the MELTs, disregarding the multilingual resources they bring to the language classroom. As a result, less attention has been paid to exploring multilingual English language teacher identities and their identity negotiation. Also, multilingual English language teacher identity has not been a 
major focus of study in New Zealand. Thus, the current study addresses this gap in the literature by exploring the identity performance and negotiation of MELTs by answering the first research question mentioned below in Section 1.3.1.

In addition, teachers' identity performance and negotiation seem to be context dependent "allowing the researcher to uncover how a particular interaction is situated within micro- and macro- community, cultural, and social norms" (Seals, 2021). Identity performance and negotiation of MELTs are observed interactionally produced (Bucholtz \& Hall, 2005) between teachers and students in the classroom context as well as teachers and myself during the research process. Moreover, language ideologies of the teachers have an impact on how they perform multiple identities on different contexts with different interlocutors. Thus, I investigate what interactional and ideological functions are served when MELTs negotiate their identities answering the second research question mentioned below.

\subsubsection{Research questions}

1. How do multilingual English language teachers (MELTs) perform their negotiated identities in the classroom?

2. What ideological and interactional functions are served when MELTs negotiate their identities?

\subsection{Theoretical underpinnings}

I employ postructuralist identity theories (See Chapter 2) to understand identities of MELTs. Norton (2013) defines identity as "the way a person understands his or her relationship to the world, how that relationship is constructed across time and space and how the person understands possibilities for the future" (p. 4). According to postructuralist theorists, identity is seen as a multiple, dynamic and shifting phenomenon (Norton, 1997; Norton, 2000; Norton, 2010, 2013; Varghese et al., 2005) . They also view language as a site of social and linguistic struggle which is developed on the basis that languages are constructed by and through discourses (Norton, 2010; Pavlenko, 2002). Identity construction, positioning and negotiation are also seen as a socio cultural phenomenon that emerges in context of interaction (Bucholtz \& Hall, 2005; Qin, 2019). Aligning with these arguments, I use identity theories to interpret MELT identities in my study. 
In addition, the present study provides an in depth analysis of the multilingual English language teacher identities by employing predominantly qualitative research design. Triangulation of data from four methods: semi-structured narrative interviews, identity portraits and classroom observations followed by stimulated recall sessions have allowed for exploring teacher identities in different scenarios. For instance, data generated from narrative interviews supports understanding teachers' lived socio-linguistic histories (Barkhuizen, 2016) disclosing their previous language learning experiences and biographies which according to Yazan (2018), are of great importance in understanding language teacher identities. Furthermore, teachers' representation of the characters and tellership of the small stories (Bamberg \& Geogakopoulou, 2008) are used to analyze how they position themselves (Bucholtz \& Hall, 2005; Davies \& Harre', 1990) and how they want me to understand their identities. In addition, identity portraits (Krumm \& Jenkins, 2001; Nofal, 2020; Seals, 2017) allow the teachers to express their MELT identities making semiotic links to various indexicalities (Silverstein, 2003) of their social, cultural and linguistic identities, by also revealing their language ideologies. Moreover, classroom observations as well as the stimulated recall sessions (Gass \& Mackey, 2000; Ryan \& Gass, 2012) provide insights to understand teachers' identity performance and identity negotiation while interacting with the students in their classroom. This has revealed MELTs' participation in Communities of Practice (CofP) (Lave \& Wenger, 1991) in their language classrooms. Thus, the current study provides insights in terms of a complex, interwoven research design to explore teacher identities.

\subsection{Thesis outline}

In Chapter Two, I review literature to incorporate theoretical and empirical data related to postructuralism on language and society, identity theories in language teaching and learning as well as multilingualism in language education. More specifically, in the literature review, I present how postructuralist theories have been used to understand the role of language in human lives and social relations. My focus is specifically on MELT identities; therefore, I also discuss multilingualism in language teaching and learning in my literature review. In addition, I discuss employing identity theories to understand language teachers' identity negotiations by illustrating how other researchers have used identity theories in their research on teacher identities. 
Chapter Three in this thesis presents the methodological aspects of my study; including, the research design, recruiting participants, the participants' profiles, four data collection methods, data analysis methods, researcher reflexivity and ethical considerations. Moreover, I elaborate upon the rationale for using semi-structured narrative interviews, identity portraits and classroom observations followed by stimulated recall sessions to collect data from the three cases: three MELTs in New Zealand. Furthermore, I explain the use of discourse analysis methods including narrative analysis and the small stories approach for analyzing data collected by the semistructured narrative interviews and stimulated recalls. Finally, I acknowledge my subjective engagement in the research process which I consider as a social practice (Talmy, 2011) rather than collecting and analyzing data.

In Chapter Four, I present the first part of my data analysis addressing RQ 1: how multilingual English language teachers perform their negotiated identities. I present excerpts from their narrative interviews, recorded interactions while conducting identity portrait sessions, my field notes and the stimulated recall sessions along with identity portraits drawn by the participants to illustrate the negotiated multiple identities performed by the MELTs. I also elucidate how multilingual teachers negotiate their identity performance from one instance to another as language teachers. In other words, I examine how they perform different identities in different instances depending on the context and the interlocutors. I conclude the chapter highlighting the identities performed by the multilingual English language teachers who participated in my study, including homeland identities (identities they were assigned and they performed in their countries of origin) and host-land identities (identities they perform in NZ) including multilingual identity and monolingual identity, multicultural and multinational identity and migrant identity.

I present the second part of my data analysis in Chapter Five which addresses RQ 2: what ideological and interactional functions are served when multilingual teachers negotiate their identities. In this chapter, I discuss multilingualism and monolingualism practiced in English Language Teaching (ELT) classes as an ideological function that serves the identity negotiation of MELTs in my study. In addition, I report how MELTs maintain their ELT classes as a Community of Practice which serves as a pedagogical advantage for both teachers and learners. Moreover, I argue that translanguaging practices, which emerged in my data, are an interactional 
function that is served when MELTs negotiate their linguistic identities. Furthermore, I present how teachers negotiate their teacher identities based on contextual factors. I conclude the chapter by outlining the ideological and interactional functions that are served when multilingual teachers negotiate their identities.

In Chapter Six, I conclude the thesis summarizing the content of my study and outlining my findings. I also discuss the pedagogical implications of my study providing insights to develop English language teaching programmes and English language teacher education programmes paying special attention to identities of multilingual English language teachers. I also address the limitations of the study as well as recommendations for future research on language teacher identities. 


\section{Chapter 2-Literature Review}

\subsection{Introduction}

Language Teacher Identity (LTI) is an area of research that has recently been of an interest in applied linguistics research both locally and internationally. Since my study focuses on multilingual English language teachers specifically, this chapter presents a review of literature in exploring how sociolinguists and applied linguists have researched and interpreted language teacher identities and identity negotiation. In this chapter, I first review the theoretical background related to poststructuralism with the intention of identifying definitions of language use, language learning and language teaching related to identity theories. Secondly, I expand the focus to include multilingualism in language teaching to align with my focus of multilingual English language teachers' identities and their identity negotiation. Further in this chapter, I discuss how identity theorists have situated their studies of English language teacher identities and identity negotiation through New Zealand and other international contexts. The final section of the literature review identifies gaps in the literature and provides the rationale for the current study.

\subsection{Poststructuralism}

Poststructuralism, developed in the 1950s and 1960s by scholars such as Barthes, Derrida, and Foucault, is a philosophical and a linguistic movement associated with the development of literary, cultural, and discursive theories which offer rational and transformative perspectives that "challenge and/or supplement dominant paradigms" (Baxter, 2006, p. 34). Derrida (1987) remarked that postructuralism is a complex notion of how knowledge and every aspect of human experience are textually constructed and that our realities are created by the language we use. Moreover, poststructuralism focuses on "the social distribution of power associated with the construction of knowledge" (Harcourt, 2007, p. 27), and poststructuralist theories contest the traditional binaries which were largely fortified in structuralism, suggesting that such dichotomies of abstractions are "always independent and mutually contesting" (Baxter, 2006, p. 34). Block (2006) further remarks that poststructuralism was developed by social theorists and researchers who viewed structuralism as presenting an "oversimplified, one dimensional view of the world" (p.23). In addition, Block (2006) mentions that the poststructuralist view of social phenomena considers "both individual agency and social structures; however, it sees the two as inextricably linked and intertwined and as less stable and fixed over time" (p.23). 
Pavlenko (2003) defines postructuralism as follows: "an attempt to investigate and theorize the role of language in construction and reproduction of social relations, and the role of social dynamics in the processes of additional language learning and use" (p.282). Pavlenko, citing key scholarship, sums up that "the poststructuralist theory of SLA views language as symbolic capital and a site of identity construction and negotiation" (p. 283). Poststructuralism considers language as the "locus of social organisation, power, and individual consciousness" (Pavlenko, 2002, p. 282). It emphasizes that language constitutes "a social reality" rather than reflecting "an already given social reality" and that "meaning is produced within language rather than reflected by language" (Baxter, 2006, p. 36).

Furthermore, poststructuralist perspectives argue that signs within a given language are ascribed with social meanings that differ perhaps from one linguistic community to another or even within the same linguistic community (Norton \& McKinney, 2011 ). These perspectives also suggest the view of language as a site of identity construction. Accordingly, signs in linguistic communities are perceived not as having idealized meanings and being homogenous but as having conflicting claims of truth and power and being heterogeneous, thus emphasizing languages as sites of multiplicity, dynamicity, and conflict (Norton, 2010). This view of language as a site of social and linguistic struggle is developed on the basis that languages are constructed by and through discourses, which essentialise performance of different identities or subject positions and assign them different values (Pavlenko, 2002). This performativity perspective, originally coined by Butler (1988), denotes "it is not that people use language varieties because of who they are, but rather that we perform who we are by (among other things) using varieties of language" (Pennycook, 2003, p. 528). When identities are constructed and negotiated in social contexts, especially in multilingual contexts, there may occur tensions of identity politics which cause conflicts between self-chosen identities or agency and societal impacts or others' attempts to differently position oneself (Pavlenko, 2002).

The MELTs in my study are three migrants (living in an English speaking country) who speak other language(s) in addition to English. They can be identified and positioned by their different ethnic identities (different to the majority of the country) and multilingual identities (within majority of monolingual English speaker teachers) rather than by their professional identities (of English language teacher). Due to this, the MELTs can choose to perform multiple identities 
which are negotiated based on the context and interlocutor in order to earn acceptance and approval of the students, institutions and society, as poststructuralist theorists argue. Thus, I explore how MELTs perform their negotiated identities in multilingual ELT contexts in New Zealand. The next section of the literature review discusses multilingualism related to English language teaching and learning.

\subsection{Multilingualism}

Multilingualism has been popular world-wide due to "globalization, transnational mobility of the population and the spread of new technologies which are highly influential in different political social and educational contexts" (Cenoz, 2013, p. 4). Li (2008, p. 4) defines a multilingual individual as "anyone who can communicate in more than one language, be it active (through speaking and writing) or passive (through listening and reading)". The European Commission (2007) defines multilingualism as "the ability of societies, institutions, groups and individuals to engage, on a regular basis, with more than one language in their day-to-day lives" (p.6). Multilingual speakers can include speakers of minority indigenous languages or immigrants who speak their heritage languages, both of who are often required to learn the dominant state language in predominantly monolingual countries and cities. According to Cenoz (2013), some individuals also learn other language(s) in addition to their first language when they travel internationally for economic, political social and educational purposes.

Multilingualism is both an individual and a social phenomenon. An individual can acquire different languages simultaneously by being exposed to two or more languages from birth or successively by being exposed to second or additional languages later in life. However, the focus on the multilingual individual rather than on the languages spoken by the multilingual individual has resulted in interesting insights about the characteristics of language learning and language use by multilinguals (Kramsch, 2009; Todeva \& Cenoz, 2009).

The work of the French sociologist Pierre Bourdieu (1987) has been extremely influential in the development of poststructuralist critical approaches to the study of multilingualism. Bourdieu viewed linguistic practices as a form of symbolic capital. The form the different types of capital take "once they are perceived and recognized as legitimate" (Bourdieu, 1987, p. 4) is symbolic capital. Language varieties that are legitimated by the social groups in power are more valuable forms of symbolic capital. Bourdieu's theories have stimulated research that critically analyzes 
discourse practices so as to identify the sociopolitical implications of the use of different languages. Research in this area has proven that the use of linguistic resources can be constrained by institutional ideologies and how linguistic practices represent power relations (Gardner \& Martin-Jones, 2012; Heller, 2007). For instance, the MELTs in my research seemed to carry different language ideologies promoted by the institutions to which they are attached. An interesting feature of this line of research is that multilingualism has come to be seen as a socially constructed phenomenon where languages are sets of resources rather than as fixed linguistic systems.

Plöger and Putjata (2019, p. 217) argue that language is a particular form of cultural capital because "languages and linguistic varieties have different market values within a society that correspond to hierarchical power relations". Therefore, they argue that the individuals who speak minority languages or dialects in a society acquire only a low level of capital in most professional settings while individuals who speak a "socially legitimate majority language" (Plöger \& Putjata, 2019, p. 217) successfully convert that high cultural capital into economic capital. MELTs participated in my research support their multilingual migrant students to earn cultural capital, English language, so that the students can convert that into economic capital in the host country. In this process, some MELTs employ multilingualism enjoyed by both the students and the teachers for the benefit of the multilingual English learners in their classroom. However, there can also be instances where multilingual resources are not valued as capital in language education. For example, Higgins and Ponte (2017) reveal that there are anti-immigrant ideologies in North America towards languages spoken by multilingual children at home, viewing them as a burden on the system rather than as a benefit to a globalized society. However, they argue that these language ideologies are challenged by multilingual pedagogies by acknowledging these languages as linguistic resources in teaching and learning.

\subsubsection{Translanguaging in the language classroom}

Translanguaging, coined by Williams (1994), is "a theory, a pedagogy and an analytical approach centered around rejecting the monolingual bias" (Seals et al., 2019, p. 39). Further, Seals et al. (2019, p. 43) state that "translanguaging takes the position that people have linguistic repertoires with features that are socially constructed as belonging to a particular language". According to them, translanguaging allows people to use their repertoire flexibly with 
socio cultural competency. However, translanguaging takes an opposite position to institutional monolingualism. Traditionally, languages are believed to stand alone as languages are connected to power relations as discussed in earlier sections of this chapter. Therefore, Canagarajah (2013) claims translanguaging to be political and critical in linguistics, education and social beliefs.

Translanguaging has significant value in language teaching and learning. For instance, translanguaging challenges the belief that language has to be learned separated by subject, teacher or periods of time and suggests how students' linguistic and semiotic resources can be employed to help them to learn and engage with material being acquired (Lasagabaster \& García, 2014; Seals et al., 2019). In addition, translanguaging creates spaces for the learners to participate more in language lessons as students have access to their full linguistic repertoires (Garcia, 2009; Seals et al., 2019). Furthermore, (Seals et al., 2019, p. 43) illustrating the role of translanguaging in te Reo Maori and English, claims that "establishing a translanguaging space where teachers and students are able to move between and beyond socially constructed language ideologies and educational systems, structures and practices will help generate new configurations on language and education practices".

In relation to the current study, translanguaging was observed being used in the ELT contexts by the multilingual teachers and students in order to make sense of the discourse of their teaching and learning. Moreover, the MELTs have negotiated their multilingual identity to include the languages spoken by their students in their multilingual repertoire. In addition, some MELTs seem to encourage their adult students to use their multilingual repertoire as a resource in learning the target language. In such situations, translanguaging is promoted by the MELTs as a common trait shared by their ELT classroom as a Community of Practice (Wenger, 1998). This will further be elaborated in Chapter Five of this thesis. The next section of the literature review will further elaborate how identity has been viewed by theorists and applied linguists with reference to language, language use, language learning and language teaching.

\subsection{Identity}

Beijaad (1995) defines identity as various meanings that people can attach to themselves or the meanings attributed by others. Duff and Uchida (1997) further remark that identity is closely related to social, cultural and political context. Moreover, Norton (1997) claims that identity is not fixed or static. Instead, it is multiple, shifting and always in conflict. According to Bucholtz 
and Hall (2005, p. 586), "identity is a discursive construct that emerges in interaction". In addition, Norton (2013, p. 4) defines identity as "the way a person understands his or her relationship to the world, how that relationship is constructed across time and space and how the person understands possibilities for the future". Norton (2013, p. 4) also remarks upon the "contingent, shifting and context-dependent nature of identities" and emphasizes that identities are not merely given by social structures or ascribed by others, but are also negotiated by agents who wish to position themselves in social structures. Identities of the MELTs who participated in my study can be understood with these definitions of identity. In other words, identities performed by MELTs are multiple and shifting based on the context as well as emergent in interaction with different interlocutors. I will further discuss how identity theory has been elaborated upon by Varghese et al. (2005) and Norton (2013) in the following paragraphs.

Varghese et al. (2005, p. 23) depict three lines of identity theory. First, there is the multiple, shifting and conflictual nature of identity (Norton, 1997), as opposed to it being a fixed, stable, unitary and internally coherent phenomenon; therefore, they claim identity to be "transformational and transformative". Further, "the primacy of agency in identity formation" is a key factor which moves it away "from a structurally deterministic view of the fashioning of individuals to understanding individuals as intentional beings" (Varghese et al., 2005, p. 23). Second, they illustrate the contextual nature of identity with reference to one's social, cultural and political background, as well as interlocutors and institutional settings. Also, they identify the relationship between "assigned identity" - the identity imposed on an individual by others and "claimed identity" - the identity or identities an individual acknowledges or claims for oneself to be a crucial factor. Third, they state that identity is considerably constructed, maintained and negotiated through language and discourse.

Bucholtz and Hall (2005, p. 586)'s framework sees identity as a sociocultural and relational process. Moreover, they argue that identity is constructed through interaction. They introduce five principles underlying the investigation of identity: emergence, positionality, indexicality, rationality and partiality. The principle of emergence conceives of identity as "realized in and through social action rather than as pre-discursive and pre-existent phenomena in an individual's mind". 
Positionality indicates a complex view of identity as "encompassing macro-level demographic categories, local ethnographically specific cultural positions and temporary and interactionally specific stances and participant roles" (Bucholtz \& Hall, 2005, p. 592). In other words, Bucholtz and Hall (2005) remarks individuals assume temporary roles and orientations through discourse during interactions. Such interactional positions can be different from identity as conventionally understood. However, these temporary roles contribute to the formation of subjectivity and intersubjectivity in discourse. McEntee-Atalianis (2019) commenting on positionality, mentions that this principle also accounts for the shifting and multiple nature of identity performance while constructing "self" and "other" in and through discourse. As the identity positions of the MELTs is a major area of inquiry in my study, identity positions constructed within interaction will be further discussed in this chapter as they relate to empirical data.

Bucholtz and Hall (2005, p. 594) see the principle of indexicality as "the manner by which identity positions are constructed within the context of the interaction....... indexicality is also fundamental to the way in which linguistic forms are used to construct identity positions". Silverstein (1979) introduced index is a linguistic form that depends on the interactional context for its meaning. Moreover, the concept of indexicality also involves the creation of semiotic links between linguistic forms and social meanings (Ochs, 1992; Silverstein, 1979). Also, indexicality is dependent on larger ideological frames, cultural beliefs and values which are connected with different linguistic practices of the language users (McEntee-Atalianis, 2019). "Identity relations are indexed via multiple processes, including identity labels and categorizations, pragmatic implicature and presuppositions about subjective and intersubjective positions displayed evaluative and epistemic orientations to ongoing talk, as well as interactional footings and participant roles; and the use of linguistic forms associated with individuals or groups/communities" (Bucholtz \& Hall, 2005, p. 594). The MELTs in my study index their identity positions using various ideological and cultural frames, performing multiple identities. In other words, they use different indexicalities to show how they want to be understood while they interact with myself and their students.

Relationality according to Bucholtz and Hall (2005, p. 596) is "the tactics of intersubjectivity" which means the significance of considering the intersubjective dimensions of identity formation and the influence of culture, power and agency. McEntee-Atalianis (2019) remarks that 
relationality highlights the reasons for "doing" identity. Finally, the $5^{\text {th }}$ principle of the framework is partiality, which means the influence and constraints imposed by macro- and micro- structures on identity realization. Bucholtz and Hall (2005, p. 605) argue that all representations of culture are partial accounts. Furthermore, they argue that "identity is inherently relational, always partial, produced through contextually situated and ideologically informed configurations of self and other." In line with this argument, identity performance of the MELTs in my study demonstrates partialness to the contexts in which they are situated as well as their personal and institutional ideologies.

Norton's work on identity has been inspired by the postructuralists West (1992), Bourdieu (1977) and Weedon (1999). Following West (1992), Norton (1997) describes how identity relates to desire - desire for recognition, affiliation, security and safety. According to Norton and West, those desires are inseparably connected to material resources in society. One's access to power and privilege is dependent on their access to a wide range of resources, and this in turn has an impact on how they understand their relationship to the world and their possibilities for the future. As a result, one's identity may shift with regard to changing social and economic relations. Norton (1997) also agrees with Bourdieu (1977) who had similar views on identity and symbolic power. He argued that the value ascribed to speech cannot be understood apart from larger networks of social relationships. Also, Norton (1997) agrees with Bourdieu's (1977) claim of the "right to speak" and shows how the right to speak intersects with language learner identity. According to Bourdieu (1977, p. 648), "language is not only an instrument of communication or even of knowledge, but also an instrument of power. A person speaks not only to be understood but also to be believed, obeyed, respected and distinguished. Hence, the full definition of competence as the right to speech, i.e. "to the legitimate language, the authorized language which is also the language of authority" (Bourdieu, 1977, p. 648). Moreover, Norton has also been inspired by Weedon (1987)'s theory of subjectivity that integrates language, individual experience and social power. Norton depicts three defining characteristics of subjectivity: the multiple, non-unitary nature of the subject, subjectivity as a site of struggle and subjectivity as changing over time.

Norton (2013, p. 5) also highlights the relationship between identity and language: "identity is constituted in and through language". Use of a target language by learners in speaking, writing 
and reading, according to Norton (2013, p. 6), not only helps learners exchange information with members of the target language community but also serves to "organize and reorganize a sense of who they are and how they relate to the social world". This draws upon Vygotsky (1978)'s socio-cultural theory of mind. As a result, the learners are engaged in identity construction and negotiation. Even though my primary concern is language teachers, I cannot exempt language learning of my participant teachers because they are multilingual speakers who have been learning languages during different phases of their past and present. Therefore, I explore both their language learning and language teaching experiences in order to understand their multilingual English language teacher identities.

Norton (2013) also identifies the multiple nature of identity in introducing identity categories and their impact on language learning. Identity categories according to Norton are socially and historically constructed (within relations of power) relationships. She further claims that there are occasions when students or teachers may wish to assert their identities as homogenous and unitary, foregrounding a particular aspect of their experience such as gender, race, class, sexual orientation or religious affiliation. In addition, Wenger (1998) defines Language Teacher Identity (LTI) as "a nexus of multi membership" that brings together social memberships-identities one enjoys outside the teaching profession to inform one's professional practice. It is important to investigate how teachers perform different identities in language classroom within their relationships with students, institutional bodies and larger social world. Thus, inspired by Norton's views on identity construction and negotiation with reference to language, I employ postructuralist identity theory in my study to explore how multilingual English language teachers perform and negotiate their multilingual teacher identities in an English speaking country, NZ.

A significant relationship between identity and language teaching in the classroom has also been remarked upon by Norton (2013). For example, Mckinney and Norton (2008, p. 7) argue that "responding to diversity in the language classroom requires imaginative assessment of what is possible as well as critical assessment of what is desirable". Assessment of what is "possible" refers to the need for ongoing interaction between teachers, administrators and policy makers in preparing and updating teaching material that can serve to constrain or enable the range of identity positions available to students. Norton (2013) also identifies how diverse identities of learners assist teachers to better cater to language learners. The first way is by exploring which 
identity positions offer the greatest opportunity for social engagement and interaction, and then employing them in language teaching. For example, the multilingual teachers in my study intentionally perform negotiated host-land identities to model the kind of identity positions for the students to follow as English language learners. Multilingual and multicultural identities performed by some teachers in my study encourage the learners to negotiate their learner identities to fit in the host-land, NZ. The second way is by discovering the identity positions that silence students and addressing these marginalizing practices. I argue that these ongoing interactions between language teachers and students and the knowledge gained by teachers while being engaged in the student-teacher interactions can provide reasons and opportunities for the teachers to negotiate their teacher identities in favour of better language teaching. Therefore, my study explores how English language teachers negotiate their multilingual teacher identities in response to ongoing student-teacher interactions.

\subsubsection{Language teacher identity}

When exploring sociocultural and sociopolitical dimensions of teaching, many aspects of identity including matters of ethnicity, gender and sexual orientation have been taken into consideration. Varghese et al. (2005) claim that the teacher does not play a neutral role in the classroom. Johnson (1992)'s and Woods (1996)'s investigations into teacher beliefs, knowledge and attitudes revealed that "such attributes could not be seen atomistically but that it was the teacher's whole identity as a crucial component in determining how language teaching is carried out" (Varghese et al., 2005, p. 22). Furthermore, they argue that "a teacher's positionality can be determined in relation to her students and the broader context in which the teacher was situated" (Varghese et al., 2005, p. 23) I further discuss how teachers' positionality can be determined with reference to their students and the teaching context in the following paragraphs.

How language teachers' positionality is determined in relation to the context in which they are situated can be clearly identified through Stella's narrative as depicted in Bliss (2016). Stella was a Chinese teacher studying for a Master of Arts in TESOL (Teaching English for Speakers of Other Languages) degree in NZ. When she once went to a community school to volunteer in teaching English, the manager of the school told her that she did not think Stella could teach there because it was a speaking class, and according to the manager, students wanted "Kiwi English". Also, the manager used an example to show that Stella was not good at "Kiwi English" 
by checking whether Stella knew the meaning of the phrase "have an ear for English". When Stella was not successful in explaining the meaning of the term satisfactorily, the manager believed that she proved her point that Stella could not cater to the needs of the students for "Kiwi English". The first part of Stella's narrative reveals how English language teachers can be positioned in relation to the context because "Kiwi English" is a linguistic feature of the particular context. However, later she got the opportunity in the same institution to teach a large group of Chinese students and became a very popular teacher among the students and at the institution, which means her positionality as a multilingual English teacher was also influenced by the particular student group.

Additionally, Norton (2013) discusses how language teachers' conceptions of language and language teaching are broad in scope, drawing upon much research conducted in Mexico, China, South Africa, Uganda and the United Kingdom. She remarks that teachers conceive of language both as a linguistic system and social practice in which experiences are organized and identities are negotiated. In addition, teachers offer learners "multiple identity positions from which to engage in the language practices of the classroom" (p.17) when learners do not invest in language learning. Lee (2008), based on his research in a Canadian post-secondary institution, suggests that many language teachers struggle to enhance the range of future possibilities available to their students despite the disjuncture between the pedagogy as it is conceptualized by the teacher and practices adopted in the classroom. Therefore, teachers play a huge role in bringing justice to different language learner identities in the classroom. In this thesis, I explore how teachers strive to negotiate their own identities in providing learners with opportunities to invest in the English language classroom and how teachers' MELT identities are connected to the above process.

Furthermore, Hawkins and Norton (2009) argue that "language (or discourse) is the tool through which representations and meanings are constructed and negotiated, and a primary means through which ideologies are transmitted" (p. 32). Yazan (2017) in line with Norton's argument, discusses how power relations are produced, maintained, and subverted through language. $\mathrm{He}$ further claims that both language and meanings produced through language are not neutral. Also, he explains that whether and how language teachers understand this nature of language is integral to their identities as language users and teachers because this understanding guides what 
they see as important in language instruction and how they facilitate their students' language development. Therefore, language is not only the subject matter in language classrooms but the medium through which classroom conversations and identities are constructed and negotiated.

In line with these arguments, language teacher identity can be identified as a combination of linguistic identity and non-linguistic identity (i.e. social identity) of the teachers. The following sections explain how English language teacher identities have been interpreted employing social identity theory in the previous literature.

\subsubsection{Social identity theory}

According to social identity theory by Tajfel (1978), social identity refers to the relationship between the individual and the larger social world as mediated through institutions such as families, schools, workplaces, social services and courts. Norton (1997) comments upon this, further arguing that identity construction must be understood with respect to larger social processes determined by relations of power. In addition, Varghese et al. (2005) remark that social identity theory recognizes individuals' membership in many groups, of which membership in any one group at certain times can be more prominent than the membership in another group. For instance, Motha (2016) presents her own narrative to discuss how she had to convey authority, dignity and legitimacy (as an English teacher) to her interlocutors because of her South Asian appearing social identity, which led these interlocutors to question the legitimacy of her linguistic identity. Also, Canagarajah (2016) describes how his ethnic identity and linguistic identity were questioned in a multilingual teaching context.

These multiple identities which sometimes become conflicting within the membership of several groups can be illustrated in Marc's story depicted in Varghese et al. (2005). Marc is a Mexican teacher of English who had enrolled in a two year TESOL Masters in the United States. During an interview she revealed her inner tension due to her own need to be "ahead of.... students" in language proficiency. She had difficulty when she contacted her colleagues on language questions. She was worried that she should know better as an ESL teacher. Her membership in different groups: as a language learner, and as an ESL teacher, belonging to "NNESTs as opposed to more powerful and influential group of NESTs" (p.26), in a country where English is the dominant language, was almost always problematic due to how she was positioned by others. 
Furthermore, social identity theory according to (Varghese et al., 2005) can provide positive contributions to our understanding of language teacher experiences; however, these authors also highlight some limitations involved in its application. For instance, social identity theory does not support the understanding of evolving teacher identities, the way different groups interact to produce an understanding of self or the individual variations of identities. Therefore, Varghese et al. (2005) also evaluate another framework for understanding teacher identities through situated learning - as a process of becoming a part of a Community of Practice, a concept which was originally developed by Lave and Wenger (1991).

\subsubsection{Community of Practice}

Researchers who investigate teacher identity in Second Language Teacher Education often interpret teachers' participation in social context(s) in terms of a "Community of Practice" (Yazan, 2018). Wenger et al. (2002, p. 4) defines Communities of Practice (CofPs) as "groups of people who share a concern, a set of problems, or a passion about a topic and who deepen their knowledge and expertise in this area by interacting on an ongoing basis" (p.4). Also, one's relationship to a CofP involves both participation and non-participation; therefore, one's identity can be understood in relation to both. The concept of CofPs has been widely used in identity research by sociolinguists and applied linguists; for example, Holmes and Marra (2002) and Vine and Marra (2017) in identity in work place research, Revis (2017) and Nofal (2020) in identity in heritage language research and Mantero (2004), Tsui (2007), Trent (2017) and Yazan (2017) in research in teacher identities.

Mantero (2004), Tsui (2007) and Trent (2017) argue that becoming a teacher means negotiating and acquiring membership in a Community of Practice, which can only happen through participation in the activities of this community. Furthermore, Singh and Richards (2006) conceptualize acquiring membership in a CofP and L2 teacher identity formation as two interrelated processes. They remark that becoming a member of a new community is not just about learning a new context but also acquiring new practices, values and ways of thinking which enable particular identities to be realized. However, the CofPs these researchers discuss are the academic communities that the teachers acquire membership while studying to be a language teacher. With regard to my study, all three multilingual teachers are migrant teachers 
with a recent heritage background from elsewhere. They reveal their membership in different CofPs.

On the other hand, one MELT expresses her membership in an imagined community of people in the urban city she lives in New Zealand. "Imagined communities," originally introduced by Benedict Anderson with regard to nationalism, refers to groups of people, not immediately tangible and accessible, with whom we connect through the power of the imagination (Anderson, 1991). Moreover, Pavlenko and Norton (2007) state that humans are capable of perceiving connections with people beyond their immediate social networks through imagination. Norton and Toohey (2011, p. 422), interpreting the term, state that "in imagining ourselves allied with others across time and space, we can feel a sense of community with people we have not yet met; and with whom we may never have direct dealings". Related to my study, the MELT who expresses her membership in an imagined community of residents in an urban city in NZ, emphasizes her host-land identity by making connections to this imagined community in contrast to other participants who express their membership in the Communities of Practice in their language classrooms highlighting their teacher identity.

\subsubsection{Linguistic identities of the language teachers}

Many researchers argue that language teachers' linguistic identities have been recognized through their native and non-nativeness of the language and that these binaries have been used to position or marginalize them inside and outside the classroom. For example, Yazan (2018) argues that the current or future identity of language teachers highly depend on how language teachers position themselves and how they are positioned by others within the discourse of "nativeness". He also claims that these value-laden discourses assign strengths and weaknesses to "native" and "non-native" language teachers, respectively.

Varghese et al. (2005) argue that many teachers experience professional and social marginalization both inside and outside schools. They also describe instances where the positionality of "non-native speakers" who teach language world-wide have been marginalized, which requires a critical analysis of "hegemonic relations between native speaker and non-native speaker teachers in many contexts" (p.23). Such analyses have been carried out in studies by Braine (1999), Liu (2012) and Pavlenko (2003). Moreover, further studies conducted by Edstam (2001), Johnston (1997) and Varghese (2004) explore how the professional position of Teachers 
of English to Speakers of Other Languages (TESOL) in particular and language teachers in general have been questioned. Relatedly, Hawkins \& Norton (2009) lead the discussion of positionality and marginalization of language learners and claim that language teachers can address the inequality in education since they work with individuals who are marginalized in wider society as well as they offer language-the subject matter they teach- that has the ability to both empower and marginalize individuals.

Furthermore, Swan (2015) argues that the global spread of English has been acknowledged as affecting the dominance of so called "native speakers", who have needed to accept that the English language does not belong to them exclusively and that "non-native" speakers have an increasingly important role in how the language is used and taught. Norton (1997) also supports this idea, claiming that the mandate of TESOL is the teaching of English; therefore, English should belong to the people who speak it. Despite positioning them as native or non-native, ESL or EFL, standard or non-standard, the expansion of English will possibly better contribute to its global spread. Moreover, Zhang (2016), based on a case study of an English-Arabic bilingual "Sarah", argues for the need to legitimize translingual teacher identities rather than deficit, nonnative English speaking teacher identities. Thus, English should be taught without positioning or marginalizing the learners or the teachers while recognizing both teachers' and learners' multilingual identities as a resource in language teaching and learning process. Therefore, I recognize teachers of English who speak other languages in addition to English, as "multilingual English Language teachers (MELTs)" in my study.

Canagarajah (2016) further explains how multilingual teacher identities are being challenged by institutional policies and social ideologies that value monolingualism and homogeneity. Also, the students who are being influenced by such ideologies demand "normative and instrumentalist forms of teaching that go against the values and beliefs of multilingual teachers" (Canagarajah, 2016, p. 65). As a result, multilingual teachers can feel insecure about representing their multilingual identities in English teaching. Further, Kubota (2016) argues that in critical pedagogy, teacher identity is often located where teachers and students struggle to negotiate their ideological differences. Also, in such situations, positive or negative identity practices (Barr \& Seals, 2018; Bucholtz, 1999) may come into play in language teaching classrooms in order for an 
individual's survival in the given context. Bucholtz (1999) defines positive and negative identity practices as follows:

.....NEGATIVE IDENTITY PRACTICES are those that individuals employ to distance themselves from a rejected identity, while POSITIVE IDENTITY PRACTICES are those in which individuals engage in order actively to construct a chosen identity. In other words, negative identity practices define what their users are NOT, and hence emphasize identity as an intergroup phenomenon; positive identity practices define what their users ARE, and thus emphasize the intragroup aspects of social identity" (p.211212)

Such positive and negative identity practices based on the context the teachers are situated in and the interlocutors they interact with are evident in identity practices of MELTs in my study. For example, they seem to negotiate their teacher identities to suit the ideologies carried out by the institutions they are affiliated with. According to Canagarajah (2016), inquiries into how multilingual teachers practice and negotiate their multilingual identities can contribute to our knowledge of how teachers modify or revise their teaching practices and identities to address the expectations of the respective institutions, society and students.

\subsection{Identity negotiation of language teachers}

"In critical pedagogy, teacher identity is often located in a site where teachers and students struggle to negotiate their ideological difference" (Kubota, 2016, p. 176). For instance, Cummins (2015) explains how Lisa Leoni, an ESL teacher, expressed her process of identity negotiation how she had to discover the linguistic and cultural background of each and every student who stepped into her language classroom. According to Cummins, such negotiations are required because the interactions among teachers, students and communities can never be neutral. However, my study is also evidence that some MELTs are willing to negotiate their linguistic

and social identities to open themselves to accommodate learners with different linguistic and social identities.

Mantero (2004) further explains that L2 teacher's identity construction and negotiations that occur when they actively participate in the language classroom, the profession, the curriculum and the community. For example, Stella's narrative in Bliss (2016) provides valuable insights to 
understand a multilingual English language teacher's identity construction and negotiation in NZ. Stella was once rejected as a volunteer English teacher in a community center; however, later her multilingual identity as an ESOL teacher of Chinese origin led to an opportunity to teach in a multilingual context. Her narrative also reveals how she first evaluated her own success as a teacher based on students' marks which can be due to her experiences in China where there is dominant focus on exams. However, she later presents herself as a competent teacher in NZ based on how popular she was among students and other teachers. Thus, her identity negotiation happened in relation to the context of teaching and the community.

Bliss (2016) also discusses identity negotiation of ESOL teachers in her study, related to cultural factors. For example, Maggie's narrative discloses how she had to align herself with the Japanese culture while teaching English in Japan. Also, both narratives of Ged and Maggie reveal how they had to adjust their classroom activities to suit gender divisions in Japanese culture. In addition, Duff and Uchida (1997) also researched how language teachers' sociocultural identities, understandings and practices are negotiated in relation to context. They found that the cultural context includes not just a body of knowledge, but also implicit assumptions, dynamic processes and negotiated relationships.

\subsubsection{Identity negotiation as an investment by language teachers}

Identity negotiation of the language teachers can also be understood as an investment made by teachers in teaching language. Norton's construct of investment (inspired by Bourdieu (1991)) is based on language learners. She argues that language learners have complex, multiple identities, changing across time and space, and reproduced in social interaction. According to Norton (2013), learners invest in a language because it will help them acquire a wider range of symbolic and material resources, which will in turn increase the value of their cultural capital and social power. In other words, learner investment can be understood as "language learning commitment". Darvin (2016, p. 24) points out that researchers question "to what extent are students and teachers invested in the language and literacy practices of a given classroom and community?". Language teachers also invest in their language classrooms to better cater the students' language learning. One way language teachers invest in the classroom can be negotiation of identities to suit the requirements of the institutions and the students. The model of 
investment introduced by Darvin and Norton (2015) supports understanding how identity, ideology and capital intersect on one's investment in language learning and teaching.

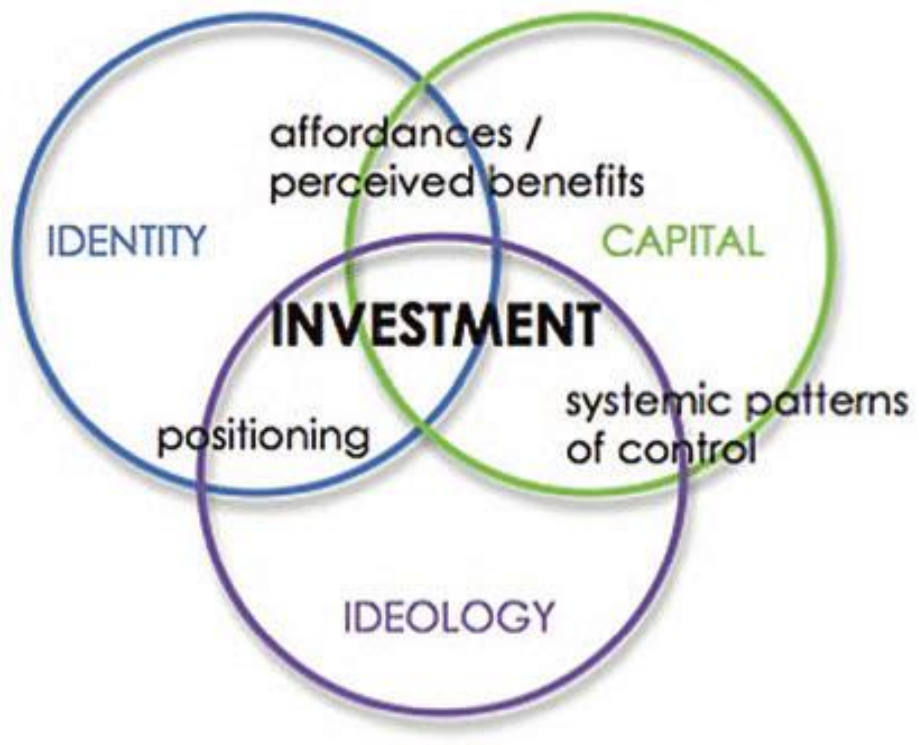

Figure 2.1: Model of investment by Darvin \& Norton (2015)

According to Darvin (2016, p. 25),

“As learners move across spaces, ideologies collude and compete, shaping learners' identities and positioning them in different ways. The value of a learner's economic, cultural or social capital shifts as it travels across time and space. It is subject to but not completely constrained by the ideologies of different groups or fields that determine how the capital of learners is 'perceived and recognized as legitimate' (Bourdieu, 1987, p. 4), or transformed into symbolic capital. To what extent teachers recognize the linguistic or cultural capital of learners - their prior knowledge, home literacies, and mother tongues - as symbolic capital can impact the extent to which learners will invest in the language and literacy practices of a given classroom. A closer examination of the three central constructs of the model (identity, ideology, and capital) provides further insight into this expanded theory of investment, with the caveat that these constructs are not mutually exclusive, but have common overlapping characteristics" (p.25) 
Even though this model has been used to interpret language learners' investment in language learning, I argue that this model can also be employed in understanding language teachers' investment in teaching languages with regard to their identity, ideology and capital. For instance, I discuss how MELTs in my study report to have earned new capital in host-land, $\mathrm{NZ}$, to invest in language classroom. Teachers' choice to earn new capital seems to intersect with their language ideologies and self-identity positioning. Also, they have negotiated their linguistic identity in terms of the new symbolic capital they earn and use in language classroom.

\subsubsection{A conceptual framework for understanding Language Teacher Identity (LTI)}

Yazan (2018) develops a conceptual framework for understanding language teacher identity (LTI). This framework (See Figure 2.2) depicts how teacher identity and teacher learning are interrelated with reference to teacher biographies, teacher cognition, teachers' participation in Communities of Practice, and teacher emotions. Yazan also highlights that this process can be understood in relation to contextual factors.

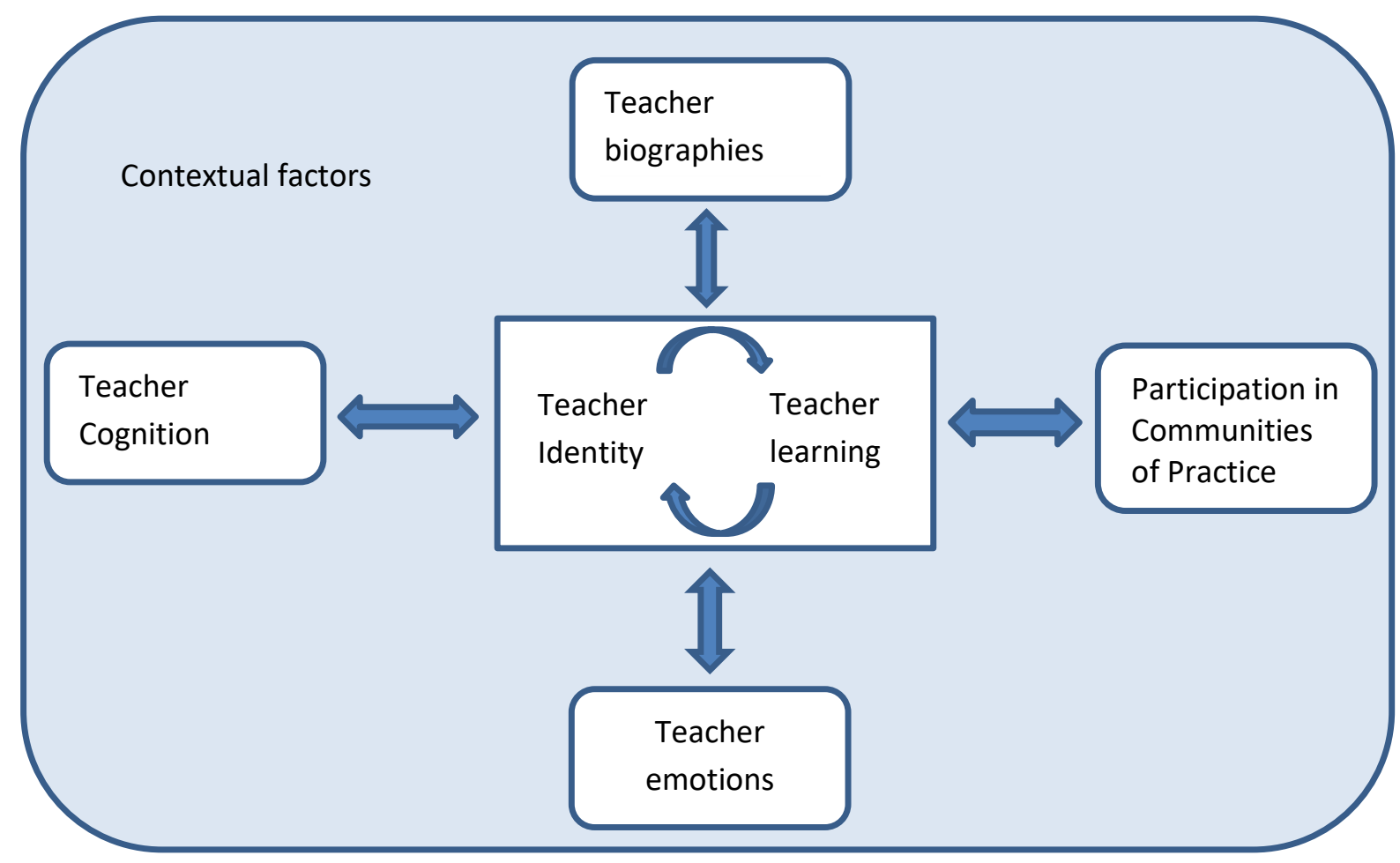

Figure 2.2: A conceptual framework for understanding teacher identity (Yazan, 2018) 
In contrast to traditional approaches which see teacher learning as an individual cognitive issue (Burns \& Richards, 2009), Yazan (2018) adopts sociocultural understandings of L2 teacher learning as "theorizing teacher practices which foregrounds practitioner knowledge and inquiry, reflection in and on practice, and critically reviewing, elaborating and revising personal pedagogical theories" (p. 30). In addition, Yazan introduces teacher cognition (in his framework) based on Borg (2003, p. 82), as 'teachers' constellations of beliefs, knowledge, theories, attitudes, images, assumptions, metaphors, conceptions, perspectives about teaching, teachers, learning, students, subject matter, curricular, materials, instructional activities and self". Moreover, he elaborates how teachers' participation in a CofP (Lave \& Wenger, 1991) and their memberships in these communities influence their learning and negotiation of identity. Teacher biographies are identified as "personal histories or biographical trajectories" (Yazan, 2018, p. 36) of language teachers which has a major role in constructing and reconstructing their teacher identities. Yazan also depicts how emotions (both positive and negative) experienced by teachers as a result of human interactions in teaching and learning, influence their identity negotiations. Yazan (2018, p. 34) defines context as "the set of circumstances and dynamics that shape the setting for teacher learning and teaching practices both at micro and macro plans". Thus, he argues that language teacher's identity negotiation occurs within contextual factors in relation to other factors introduced in his framework. Yazan's conceptual framework is based on his review of teacher identity research and pre service teacher identities of his 2017 study. However, identity negotiations of MELTs in my study align with the phenomena discussed by Yazan (2018) in his conceptual framework.

Urban New Zealand, where my study is conducted, is a multicultural context which is home to many migrants who have moved for education and work. However, English is the dominant language used here. Therefore, the multilingual identities of these migrants are not always recognized as a resource they have brought from their home countries (Greenbank, 2019). Thus, English proficiency is highly demanded from them for both educational and professional purposes (Waite, 1992). Consequently, number of migrants enrolled in ELT courses offered by universities and other private institutions seems to be increasing. There are both monolingual and multilingual English teachers employed to teach multilingual students. However, I focus on multilingual teachers, as their identities are required to be negotiated considerably due to teachers' own learner identity as second language learners of English, their migrant identity, 
ethnic identity different to the majority of the context (New Zealand) and ideological preferences of institutes and students they teach.

\subsection{Conclusion}

Social identity theory and poststructuralist identity theory have been widely used by applied linguists in researching LTI, both locally and internationally. Further, these theories have provided valuable insights to understand social, linguistic and professional identities of English language teachers. Moreover, most of the studies have focused on how English language teacher identities are constructed and negotiated as well as positioned and marginalized in different contexts in relation to their "nativeness" or "non-nativeness" of English. However, I recognize English language teachers who speak other languages in addition to English as multilingual English language teachers and that multilingualism is a positive trait in language pedagogies. Also, multilingualism is significant to my research in three ways: New Zealand being a superdiverse multilingual context, the teachers who participated in my study and their students are multilingual individuals from multilingual backgrounds, and, their ELT classes are multilingual contexts. Therefore, I included a brief discussion on multilingualism and translanguaging in the literature review. Furthermore, I discussed how the conceptual framework to understand LTI introduced by Yazan (2018) and the model of investment by Darvin and Norton (2015) can be employed to interpret identity negotiations of language teachers. There has been relatively less research conducted explicitly on MELTs in both New Zealand and international contexts. Consequently, my study, which explores how MELTs perform and negotiate their English language teacher identities, and what ideological and interactional functions are served when MELTs negotiate their identities, will hopefully contribute towards encouraging multilingualism in language education as a positive asset, both in New Zealand and potentially beyond. 


\section{Chapter 3 - Methodology}

\subsection{Introduction}

In this chapter, I present the rationale for my research design, specifically, a multiple case study to explore multilingual English language teacher identities and their identity negotiation in New Zealand. I further discuss the use of four different data collection methods: a semi-structured narrative interview, classroom observations, identity portrait sessions, and stimulated recall to generate a wide range of qualitative data. This range of data allowed me to analyze how multilingual English language teachers in New Zealand perform negotiated identities in the classroom (RQ1) as well as what ideological and interactional functions are served through this negotiation of identities (RQ2). I also discuss the data analysis methods utilized to analyze the narratives, identity portraits and classroom observations. How I addressed ethical requirements while collecting and reporting data is also presented in this chapter. I conclude the methodology chapter by elaborating on my engagement in the research through researcher reflexivity.

\subsection{Employing a multiple case study research design to explore teacher identities}

According to Stake (1995), a qualitative case study is "a study of the particularity and complexity of a single case, coming to understand its activity within important circumstances" (p. ix). Moreover, Merriam (1998) defines a case study as "an intensive, holistic description and analysis of a bounded phenomenon such as a programme, an institution, a person, a process or a social unit" (p. xiii). Yin (2003) also specifies that the case study is an empirical inquiry that investigates the case or cases by addressing "how" or "why" questions concerning the phenomenon of interest. According to Yin (2003, p. 13), “A case is a contemporary phenomenon within its real-life context, especially when the boundaries between phenomenon and context are not clearly evident and the investigator has little control over the phenomenon and context". Furthermore, Yin (2003) says that a case can traditionally be an individual; however, the case can also be some event or entity that is less well defined than a single individual. In addition, Merriam (1998, p. 27) interprets a case as "a thing, a single entity, a unit around which there are boundaries". Moreover, Stake (1995, p. 2) introduces a case as "a specific complex, functioning thing, more specifically, an integrated system which has a boundary and working parts". Duff (2014) also mentions that a case can either be an individual or a small number of individuals on their own or in a group. Cases in my study are individuals, specifically, multilingual English language teachers in New Zealand. The main inclusion criterion for the participants were 
teaching English in NZ and speaking any other language(s) in addition to English. The monolingual teachers who teach English in NZ were excluded from my study due to the required scope of the study.

I employed a multiple case study to explore the identity negotiation of MELTs in NZ. A multiple case study contains more than a single case (Baxter \& Jack, 2008) and allows the researcher to analyze within each setting and across settings. The particularity and the complexity of the cases studied, remarked by Stake (1995), can be understood in relation to multiple identities performed by the teachers in my study, for instance: their homeland identities (identities connected to their countries of origin), host-land identities (identities connected to their host country, New Zealand), migrant identities and multilingual and multicultural identities.

Merriam (1998) remarks that case studies are descriptive, yielding a rich and thick account of the phenomenon under study. Duff (2014) supports this view, mentioning that the in-depth study of cases provides an understanding of an individual's experiences, issues, insights, developmental pathways or performance within a linguistic, social or educational context. Moreover, Duff mentions that the main goal of case study research is to gain a thorough understanding of the phenomenon being studied, of which the case is an exemplar. For example, I explored phenomena such as identity, identity negotiation, English language teaching and multilingualism, utilizing different cases. Thus, case study is "a type of research design and written report that highlight cases" (Duff, 2014, p. 95).

Stake (1995) states that case studies are holistic because they consider the interrelationship between the phenomenon and its context. Even though teachers are individuals, the study of teachers' identities is an intensive and holistic description and analysis of a bounded phenomenon (Merriam, 1998) as they are situated in particular macro and micro social contexts (New Zealand as a macro social context, and the English language institute they serve and the classrooms as micro social contexts). The teachers in my study revealed through narrative interviews how they situate themselves in New Zealand, in the institute where they work and in the classroom. In addition, I explored how they understand and express their identities in relation to these micro and macro social contexts through identity portraits, and I observed how they perform their identities in the classroom. Therefore, employing a multiple case study approach assisted me to explore their multilingual teacher identities in relation to both the micro and 
macro contexts they are situated in. In the current study, I employed three cases (three MELTs) in order to study in depth realities of the selected individual cases. The following sections introduce my cases in more detail.

\subsubsection{Participants}

\section{Cindy}

Cindy is an English language teacher employed at a private English language teaching institute in NZ. She identifies herself as a multilingual English language teacher who speaks Mandarin and English. She is originally from Taiwan, and she lived in the United States for two years when she studied for her Masters degree before coming to New Zealand. She had been in NZ for seven years at the time data was collected. Her husband is Taiwanese, and she is a mother of two children.

Cindy reported that she studied history for her Bachelor's degree at a Taiwanese university. As she revealed in her interview, she preferred studying English, but she was not able to get selected for the English degree programme offered at the university. However, later she obtained her TESOL Masters degree in the United States, which included both coursework and a teaching practicum. During this particular teaching practicum, she taught migrant students in the USA. She migrated to NZ because her husband got a job there. After arriving in NZ, she volunteered with an English language teaching organization as an assistant to English teachers. She believes this volunteer work and her educational qualifications helped her to find a job as an English teacher in her current workplace.

\section{Dory}

Dory is an English language teacher employed at an English language teaching organization partly funded by the NZ government to teach refugees. She identifies herself as a multilingual English language teacher who speaks Thelungu, English, Tamil, Hindi, Spanish and Arabic. She is originally from India, and she had been in NZ for 15 years by the time data was collected. She is a mother of a 30 year old daughter, as she highlighted in her interview, and she lives with her extended family in NZ. She was recruited for the study through a friend. 
Dory studied English and English literature for both her Bachelor's and Master's degrees at an Indian University. She also completed her $\mathrm{PhD}$ at an Indian University. She worked in different schools and colleges in India while she was studying for her Master's degree and $\mathrm{PhD}$. As soon as she completed her $\mathrm{PhD}$, she migrated to $\mathrm{NZ}$ because her extended family lives there. After arriving in NZ, she was advised to study a related degree in NZ in order to be more qualified to be an English teacher in NZ. Therefore, she completed her Master's in TESOL at a NZ university. Afterwards, she was able to find an English teaching job in a private institute in NZ.

\section{Olga}

Olga is an English language teacher employed at the same English language teaching organization as Dory. She identifies herself as a multilingual English language teacher who speaks Russian, English, French, Belarussian, Serbian and Ukrainian. She is originally from Russia, and she had been in NZ for nine years when she was interviewed. Her husband is Russian, and she is the mother of two children. Olga was recruited for the study through a friend.

Olga studied English, French and translation methods for her Bachelor's degree, followed by a Master's degree in teaching at a Russian university. She also taught English in Russia before coming to NZ. She came to NZ for her PhD in Linguistics. After completing her PhD, Olga started teaching English, and she had two years of English teaching experience in NZ when she was interviewed. She had been in NZ for nine years by the time data was collected. She mentioned that her experience in teaching English to students from multicultural backgrounds (when she was tutoring while studying for her $\mathrm{PhD}$ ) was helpful in addition to her educational qualifications when she was interviewed for her teaching job.

\subsection{Research Design}

I employed four data collection methods: semi-structured narrative interviews, identity portraits, classroom observations, and stimulated recall sessions (from three cases) within three phases of my research design. First, I recruited participants for my research and obtained their written consent. Then, I conducted the semi-structured narrative interviews. During the second phase, I conducted classroom observations with the consent of the institutions where each participant is employed and the students in their classrooms. At the end of classroom observations, I conducted stimulated recalls which were used to ask the teachers about any incident I observed in class. The 
final phase included identity portrait sessions in which participants were asked to draw their identity portraits. This was a recorded interactive session. Figure 3.1 shows my research design in brief.

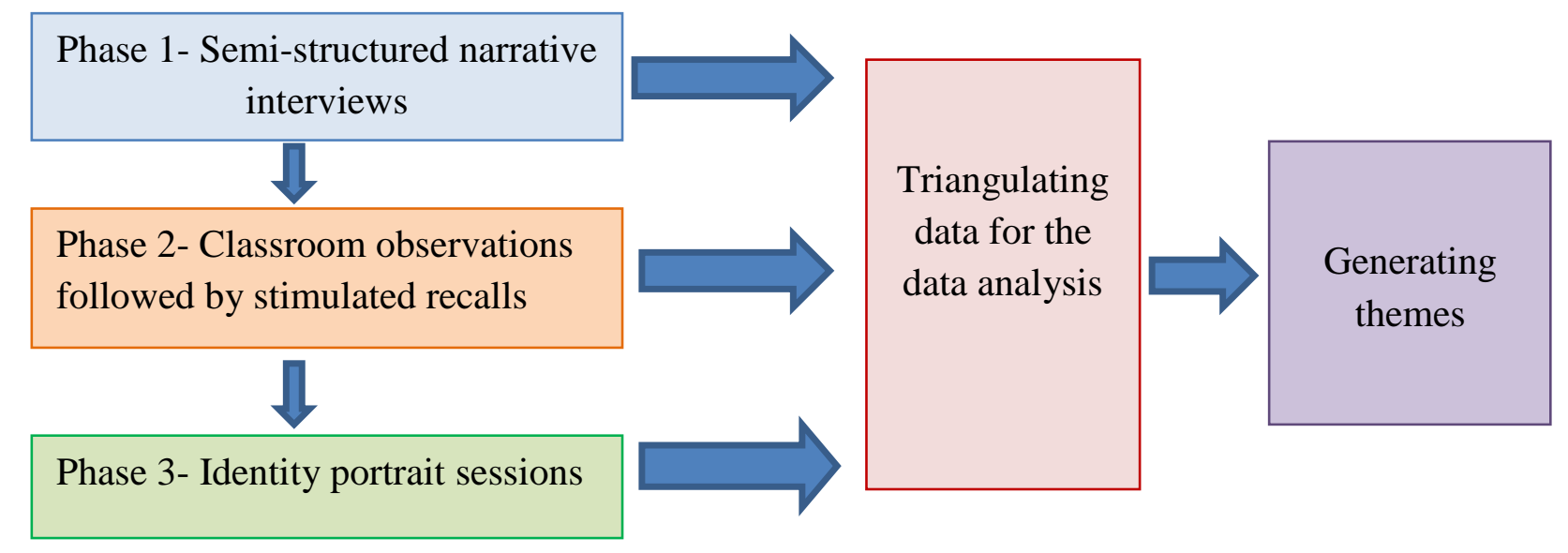

Figure 3.1 Research design

The data collection process lasted for three months from $25^{\text {th }}$ of May 2020 to $15^{\text {th }}$ of September 2020. The multiple methods for data collection allowed for data triangulation, and I drew upon all of the data when generating themes for the analysis. The following sections elaborate on the rationale for using these methods to explore multilingual teacher identities and their identity negotiation. Afterwards, I will discuss how the data was analyzed and how the themes were generated.

\subsubsection{Data Collection Methods}

\subsubsection{Employing Narratives in Identity Research}

Analyzing participant narratives in qualitative research (Barkhuizen, 2016) has been popular over several decades. Barkhuizen (2016) discusses this as a narrative turn in TESOL and applied linguistics research. He further remarks that these stories are "our experiences of life- the meaning we make of the events we live or imagine in our future lives" (p. 28). In addition, Kramp (2004) mentions that stories support human beings in adding meaning to their life experiences through preserving our memories, prompting our reflections and connecting us to our past and present while assisting us to envision our future. I came across such reflective stories in my research, such as those narrated by Dory who had more than 30 years of English teaching experience in different countries. She seemed to have reflected on her English language 
teacher identity through her past and present experience, which she narrated as long descriptive life stories in her interview with me. These experiences according to Barkhuizen (2016, p. 28) become narratives when they are told to an audience, and these narratives become part of narrative inquiry "when they are examined for research purposes and generated to report the findings of an inquiry”.

Barkhuizen (2016) also argues that narrative research is a much broader turn towards qualitative research which transforms the assumption that psychological, social and educational phenomena should be investigated similarly to the way that natural phenomena are investigated by hard scientists. He also mentions that the interest in narratives reflects postmodern concerns with the self, identity and individuality. Furthermore, narratives are a resource to understand how individuals construct their identities in relation to the world. The stories they narrate assist the researchers to understand "the ways they situate themselves and their activities in the world" (Barkhuizen, 2016, p. 29). For example, the multilingual English language teacher participants in my research narrated stories from their past and present, which reflect who they are and how they relate to the micro and macro societies they have connections to.

The traditional approach to narrative analysis is also called "big stories", an "autobiographical model" and the "narrative canon" (Bamberg \& Geogakopoulou, 2008). These big stories have been critiqued for "creating an illusory idea of identity as a solid marker of our existence" (Watson, 2007, p.372). Bamberg and Geogakopoulou (2008) focus on how individuals use small stories in their interactive engagements to construct a sense of self in contrast to the big stories which analyze the stories as representations of the world and identities. The following section elaborates more on employing the small stories approach in conducting and analyzing narrative interviews.

\section{Employing small stories approach}

According to Bamberg and Geogakopoulou (2008, p. 379), small stories are both literally and metaphorically termed because they tend to be brief stories and are woven around "micro, fleeting aspects of lived experience". In contrast, Bamberg and Geogakopoulou (2008) introduce traditional narratives as "big story research" which are more of an inquiry into tellers' 
representations of past events and how these tellers make sense of "self" with regard to these past experiences.

Small stories are narratives produced in everyday talk and "tend to be short, fleeting in nature and interactionally contingent" (Ives \& Juzwick, 2015, p.77). Furthermore, small stories are relatively less polished and coherent because they are produced interactionally (Qin, 2019). I realized that my participants and I generated such small stories during the narrative interviews while discussing their experiences in the classroom. In addition, I also came across small stories produced by the teacher and the students during classroom observations. Furthermore, some of the small stories were reported by the participants while they were narrating their past experiences. Qin (2019) used small stories to analyse classroom discourse and demonstrates how "small stories are often unobstructively narrated in classroom talk, functioning as pedagogical stories for teaching and learning, performative resources for identity and powerful discursive texts that construct normative ways of being, acting and learning” (p.192).

Bamberg and Geogakopoulou (2008) discuss employing small stories in analyzing identity research in terms of the "model of positioning" introduced by Davies and Harre' (1990). This model as used by Bucholtz and Hall (2005) allows the researchers to view self at two levels, as the representation of the character in the story and the tellership of a storytelling event. This model specifically shows how individuals position themselves in their stories. For instance, MELTs in my study used small stories to position themselves in their multiple identities in the host-land, New Zealand. Moreover, Bamberg and Geogakopoulou (2008) describe "how we are able to analyze the way the referential world is constructed with characters in time and space as well as a function of the interactive engagement" (p. 380). They further explain that the former refers to how the teller wants to be understood or what sense of self they index. Bamberg and Geogakopoulou (2008) extend the discussion of small stories by arguing that we can investigate "concrete sites of engagement in which small stories are negotiated and empirically scrutinize the procedures (repertoires) use by tellers in their talk in order to establish a particular sense of self" (p.380).

My focus in this study is to explore how MELTs perform and negotiate their identities in language classroom and other wider social contexts. Even though this is about the current scenario in their teaching career, it was also essential to explore the lived sociolinguistic histories 
of the multilingual teachers in order to understand how they have negotiated their identities from past to present. In other words, my participants who were migrants to New Zealand shared stories from both their homeland and host-land. Stories that emerged as related to their past experience are mostly big stories, and the stories which were interactionally produced between the teachers and myself are small stories. This way, I identified both big stories and small stories in the data generated by the participants of my study. However, interestingly, one participant, Cindy, only produced small stories, which were the result of interactions between her and me. In contrast, the other two participants, Dory and Olga, narrated both types of stories. Dory produced more big stories from her past academic and professional life in her homeland and host-land with some small stories from her classroom experiences, while Olga produced relatively more small stories than big stories. As a result, I have analyzed both big stories and small stories in my study.

\subsubsection{Use of Identity Portraits to uncover the multilingual teacher identities}

Identity portraits (also called reflective drawing (Molinie, 2009), language portraits (Krumm \& Jenkins, 2001) and linguistic reflective drawings (Nofal, 2020; Seals, 2017) - the mapping of one's language and social make up on a body template - were utilized to explore English language teachers' self-understanding of their multilingual English language teacher identities. Employing identity portraits has recently been popular among identity researchers to explore linguistic and social identities of language learners and teachers.

I provided an empty white A4 sheet and asked my multilingual English teacher participants to draw and colour their portraits in order to reflect their respective multilingual English language teacher identities. I interviewed them individually while they were drawing their portrait to inquire about the meanings and purposes of their selection of colours and symbols in the portraits. The sessions varied in terms of the time each participant spent drawing their portraits, specifically from 2.30 minutes to 15 minutes. The sessions were audio recorded and transcribed.

Bres (2017) mentions that this method supports rich and complex descriptions of linguistic repertoires and is useful for exploring personal, imaginative, subjective and emotional aspects of people's relationships to language. For example, the English teachers participating in my research clearly expressed their multilingual identities through their drawings. They used the portrait, colours, and symbols to index their connections to different languages they know/speak. 
Furthermore, they reflected on their own identities in relation to the language(s) they know/speak and language they teach. Moreover, they used identity portraits to express their multiple identities, for instance: homeland and host-land identities, multilingual identities, multicultural identities and teacher identities.

Identity portraits revealed additional feelings, emotions and beliefs of participants which were not revealed through other types of data collection methods used. For example, the expression of languages in their multilingual repertoires in different types of data varied. Interestingly, they did not represent all the languages they know/speak (as revealed in narratives and used in the classroom) in their identity portraits. They were careful to use only some languages out of the languages they know, specifically focusing on their heritage language and the languages they teach as well as speak in New Zealand, in their identity portraits. Also, one participant did not refer to any language she speaks or teaches in her identity portrait but instead reflected on her language teacher identity in relation to her students from multicultural backgrounds. Therefore, the use of identity portrait helped me to understand how multilingual English teachers perform some identities in relatively more dominant ways for different purposes. This will further be elaborated in data analysis chapters of the thesis (Chapters 4 and 5).

\subsubsection{Classroom observations}

Canagarajah (2016) suggests that research should be conducted to explore how teachers negotiate competing identities, in order to provide useful directions for multilingual teachers. He further remarks that classroom based studies can reveal how teachers negotiate these challenges in their instruction. Moreover, he explains the need to inquire into how teachers' practice and their identities are modified or revised in addressing the expectations of the institutions, society and students. Thus, he recommends classroom-based studies as one of the reliable methods to research how multilingual teachers negotiate their identities.

I employed classroom observations as one of my data collection methods that support the data generated by the other three methods: narrative interviews, identity portraits, and stimulated recall. Narrative interview data included the telling of past stories by teachers as well as interactionally produced small stories by the teachers and myself, and identity portraits focus on teachers' reflective drawings of their identities. In contrast, data from classroom observations 
(field notes and audio recordings) supported me in analysing how teachers perform their identities while they interact with students in the classroom.

I conducted 18 hours of classroom observations, which included six hours for each participant. I took notes of everything I observed in addition to all my reflections. The last classroom session of each participant was audio recorded with their consent. Scheduling the classroom observations was problematic due to the Covid-19 lockdown period in NZ. All institutions transferred to online classes due to restrictions on face-to-face interactions during different lockdown levels. Consequently, my research timeline was rescheduled several times. However, I finally managed to observe the classes when they returned to face-to-face classes.

\section{Cindy's classes}

Cindy conducted classes every week day from 9.00 a.m. to 12.p.m. in the institute where she works. During our initial discussion, she suggested observing one and half hour sessions (from 9.00 a.m. to $10.30 \mathrm{am}$ ) before the break. Therefore, four (one and half hours each) sessions were observed, for a total of six hours. I was warmly welcomed to the institution as well as the classroom. Cindy explained to me that the attendance of students can be low because it was the start of the face-to-face classes after two months of online classes due to the Covid-19 lockdown in New Zealand.

I was introduced to the class at the beginning, highlighting the fact that I am a student of Victoria University of Wellington. Afterwards, I was given time to talk to the students and explain the reason why I was observing their classes. I used this time to explain to them my research objectives and ask for their consent to observe the class. Adult students of this class were very keen to know about my background and my studies at the university. On the first day, there were five students in the class and one of them was a Sri Lankan. He recognized my Sri Lankan identity from my name and explained that to the other students who were from Asian countries, including India, Myanmar and China. At the beginning, it was a new experience for them to have an outsider sitting in the class, but eventually they started considering it to be normal and included me in their discussions, as well as asking me further questions about the university, my research, life in Sri Lanka, and what I was writing in my notebook. They also asked me clarification questions while negotiating the meanings of the words at times when Cindy was 
away. During the following classroom sessions, more students (who were absent during the first session) joined, and I introduced myself before the session started. The fourth day, Cindy had to combine her afternoon class with the morning class which I observed, and the afternoon class consisted of students from a refugee background. I had to introduce myself again to the students who joined the session that day and get the consent from them.

Olga's classes

Olga's classes were held at a library of a community center every Monday and Tuesday morning from 9.00 a.m. to 11.00 a.m. At our initial discussion, Olga and I agreed I could observe three sessions (two hours each). Her students were women from refugee backgrounds, specifically from Syria, Ethiopia and Iran. There were two volunteer teacher assistants working with Olga: one was an English monolingual from NZ who assists the students on Mondays. The other teaching assistant was an Arabic-English bilingual (who has been in NZ for several years) who comes on Tuesdays. They engaged in supporting the students who need help in understanding and following the instructions. Olga introduced me as a student from Victoria University of Wellington and an English teacher (she had prior knowledge that I was an English teacher in Sri Lanka) on the first day I observed the class. Afterwards, the students gave me consent to observe the class. My presence in class did not seem to have too much of an impact from the beginning because of my identity also as a woman. Also, they identified "sara"- a part of my first nameApsara as a common name in Arabic, which was a first language for most of them. They accepted my presence in the class as a help because they were used to have different volunteer teacher assistants in the class. They were very interactive with each other and communicated in Arabic and English. They seemed to enjoy each other's company as well as that of Olga and the volunteer teaching assistants.

Dory's classes

Dory's classroom observation schedule had to be postponed several times due to the second Covid-19 level 2 restrictions in NZ in September 2020. However, both of us discussed and agreed to observe online classes due to time constraints of the research. Dory conducted her online classes through Zoom platform. I sent the consent forms to the students through Dory and they completed the forms online. The session started by Dory greeting the students in their own 
languages and encouraging the students to greet each other using their interlocutors' language. I was asked to introduce the greeting in my language and they repeated it. Afterwards, she invited me to introduce myself and my research. Her class consisted of adult refugee students who study English for work. The classroom discussions were based on work related topics such as meeting employers, filling forms at work and learning work ethics in New Zealand. However, Dory had to often encourage her students to talk and appear herself in the screen to bring live experience to the class. The two online sessions seemed to be less interactive than the third session during which they went back to face to face interaction. 


\subsubsection{Stimulated Recall Sessions}

Stimulated Recall (SR) is a type of introspective research methodology that involves the verbalisation of cognition retrospectively rather than concurrently (Gass \& Mackey, 2000; Ryan $\&$ Gass, 2012). It is a method used to generate qualitative data relating to the "thought processes associated with performing an action or participating in an event" (Ryan \& Gass, 2012, p. 2). Furthermore, Ryan and Gass (2012) explain that recalling these thought processes can be assisted by a stimulus. Moreover, such stimuli can enable the participant to relive the situation. Stimulated Recall has most often been used to explore "aspects of cognition that lie behind the participants' decisions and actions; for example, it has been used to explore teacher cognition" (Ryan \& Gass, 2012, p. 2).

In my study, I employed stimulated recall sessions following classroom observations to ask my teacher participants about classroom incidents I observed. This was helpful for me to clarify some of the behaviours of the teachers and students, their reactions to situations and most importantly some of the classroom discourses which I could not understand as I was an outsider to their language classes. For example, during my discussion with Olga's students to explain my research background, I realized students consider Olga to be a multilingual speaker and they are aware of the languages spoken by Olga (field notes-27/07). Later, during the stimulated recall session with Olga, I asked her how students are aware of her multilingual repertoire and how they respond to that. Her answers to these questions generated important data regarding how she negotiates her multilingual identity in the language classroom in order to perform a linguistic identity favoured by her multilingual students. This will further be discussed in Chapter 4 of this thesis. In summary, stimulated recall sessions conducted with all three teachers who participated in my study generated data that connected the classroom incidents and discourses with teacher cognition.

\subsection{Data Analysis}

I transcribed the interview data as soon as the interviews were conducted. Full recordings of the three semi-structured interviews with Cindy, Dory and Olga were transcribed for analysis, whereas recordings of the last session of classroom observations were transcribed based on the relevance of data with regard to my research questions, as determined by coding. 
I used NVivo 12 Plus qualitative data analysis software for coding, triangulating and analyzing data. First, the transcriptions of semi-structured narrative interviews, field notes of the classroom observations, identity portraits and recordings of identity portrait sessions, stimulated recall and the transcriptions of recorded classroom sessions were uploaded to the software. Then, the data was coded using a mixed inductive and deductive qualitative coding method. I initially coded the data for pre-determined themes based on the research questions, such as identity performance and identity negotiation. However, new themes such as language teacher ideology, indexicality, and translanguaging were generated inductively from the data. Then, I revisited the initial coded scheme to change some of the themes which were identified to be more suitable for the themes that emerged later in the coding process.

Semi-structured narrative interviews, as mentioned earlier, consisted of both big stories and small stories (Bamberg \& Geogakopoulou, 2008). The content of the big stories was analyzed to explore the lived socio-linguistic histories (Barkhuizen, 2016) of the multilingual teachers. In contrast to big stories, small stories served different functions in analyzing multilingual teacher identities, for instance the 'teller's announcement of the story, the subsequent withdrawal, pretelling negotiations with the interlocutor and story content as a function of interactional engagement" (Bamberg \& Geogakopoulou, 2008, p. 377). As a result, I was able to analyze how multilingual English teachers position themselves with regard to their students, personal ideologies and ideologies of the institutes while negotiating their multiple identities on different occasions.

Identity portrait sessions involved two types of data: the drawing and the interview (while they were drawing) data. The drawing provided semiotic links to their identity performance, whereas the interactional discourse (between the teachers and myself) while drawing supported my understanding of the indexical meanings (Nofal, 2020) of their drawings. These indexical meanings they expressed further assisted me to uncover their identity positioning and how they want me to understand their multilingual English language teacher selves related to the macro and micro social contexts in which they are situated.

I analyzed classroom observation data (field notes and audio recordings) employing interactional sociolinguistics (Heller, 2007). The interactions between the teacher and the students, teacher and the voluntary teacher assistants (when they were present in the class), teacher and myself, 
and the students and myself were analyzed with the intention of understanding how multilingual teachers perform their multiple identities in the classroom. The adult students' behaviours and their discourse practices in class; for example, their use of other languages in addition to English for interaction, provided reasons behind teacher's identity performance and negotiations. In one hand, classroom observation data provided evidence for teacher's identity performance and negotiations in interaction with the students. On the other hand, I could identify different identities performed by the MELTs (which were not revealed through narrative interviews) in the language classroom.

Stimulated recall sessions supported understanding the teachers' explanations to some of the questions I had during classroom observations. The transcriptions of these data were analyzed using small stories approach and discourse analysis method.

All four types of data generated through narrative interviews, identity portrait sessions, stimulated recall sessions, and classroom observations allowed me to triangulate my analysis and generate themes. Multiple identity (identities and negotiated identities) performance of multilingual English teachers and the ideological and interactional functions of negotiated identities were the two macro themes identified. These themes will be further elaborated on in Chapter Four and Five of the thesis.

\subsection{My engagement in collecting, reporting and analyzing data}

I conducted the interviews knowing that my collaboration in producing data has several functions as follows. First, the similar identities shared by the participants and me supported me in engaging in the interview as a social practice rather than the interview as a data collection tool (Talmy, 2010) from the beginning. As Talmy (2010, p. 28) states, "analyzing not only the whats, or the product of the interview, but also the hows, or the process involved in the co-construction of meaning, has significant implications for the analysis of interview data". For example, Dory in her narratives always used the discourse marker "you know", which hints that she assumed shared socio-cultural background knowledge (Nofal, 2020) between us.

My multilingual speaker identity, English teacher identity and migrant identity helped my participants to relate to me as someone who has a similar background to them. Therefore, they openly shared their experiences with me. Also, the interviews were co-constructed and 
collaboratively produced (Talmy, 2010) between the participants and myself because we had similar experiences in terms of our multilingual and migrant identities in NZ. For instance, all three participants and myself had experiences of difficulties in understanding the locals in NZ due to a less commonly encountered English accent. We shared small stories related to those experiences during narrative interviews, which generated interesting data on how my participants negotiated their multilingual identities in NZ by investing in new cultural capital - becoming speakers of Kiwi English.

My identity as a research student at Victoria University of Wellington was always used both by myself and my participants in order to validate my research activities. For example, my studentship at the university was highlighted when requesting consent from the organizations and the students for classroom observations. Two of my participants, Olga and Dory, had previously studied at a NZ university and engaged in research activities. Therefore, they eagerly became a part of my research and supported obtaining consent from the organizations. Furthermore, this connection made building rapport with Dory and Olga easier. However, Cindy did not share common studentship experiences in NZ, so the interviewer-interviewee relationship between the two of us was different to the relationship I had with the other two participants. Cindy was contacted through the academic director of the institute where she works; therefore, the relationship between us was more formal, and she attempted at times to represent the institute instead of representing herself when discussing some aspects of her teacher identity.

Thus, I acknowledge my engagement in the research is not only visible in the data collection process but also in analyzing the data because my subjective decisions were involved in coding and analyzing data. I tried to be conscious to minimize misinterpreting data. Therefore, when some data was incomplete or confusing, I contacted my participants to confirm what they meant or what happened.

\subsection{Ethical Considerations}

I obtained approval from the Ethics Committee of Victoria University of Wellington prior to begin working with outside parties involved in the research. The information sheets for the organizations, teacher participants and students included detailed description of the research objectives and research design as well as the rationale for using each research method. The consent forms for the same parties explained how their anonymity and confidentiality would be 
ensured during data collection, data storing and data reporting. In addition, it elaborated on the space for them to withdraw from the study if they wanted to, and provided the contact details of the necessary administrative bodies. The consent forms also reported that they are allowed to receive transcribed copies of their respective interview data. None of the participants expressed the desire to read a copy of the transcribed data, but all the teacher participants mentioned in the consent forms that they were willing to read the final report of the study. I provided the respective information sheets for the participants and organizations before recruiting the participants. After explaining the process carefully, they signed the consent forms prior to the first phase of the data collection. The consent from the students was obtained during the second phase of the data collection, prior to the classroom observations. I used pseudonyms for my participants with their consent to ensure their identity is not revealed in my thesis. Some of the pseudonyms were suggested by them, whereas others were decided by me when they did not have any preference. Any information which might reveal the identity of the participants and the institutions was omitted. Furthermore, the collected data was stored ensuring confidentiality.

\subsection{Conclusion}

In this chapter, I presented the rationale for using a multiple case study to explore identity negotiations of multilingual English language teachers in New Zealand. In addition, I introduced my participants: Cindy, Dory and Olga with their biographical information relevant to the study. Furthermore, I discussed my research design, which involved four data collection methods: narrative interviews, identity portraits, classroom observations and stimulated recall, throughout the three phases of the data collection process. I also explained the data analysis methods: narrative analysis, which included both big stories and the small stories approach, the interactional sociolinguistics and discourse analysis method. I concluded the methodology chapter by reflexively explaining my engagement in the research process and ethical considerations. In the next chapter, I discuss how MELTs perform their negotiated identities, addressing the first RQ of the thesis. 


\section{Chapter 4: Identity Performance of Multilingual English Language Teachers}

\subsection{Introduction}

Identity performances of the multilingual English language teachers who participated in my research, "emerged in contexts of interaction" (Bucholtz \& Hall, 2005, p. 585). Furthermore, they performed multiple identities (Norton, 2013) in interactions with their students and me. The "contingent, shifting and context-dependent nature" (Norton, 2013, p. 4) of their identities is clearly visible, emphasizing that identities are not merely given by social structures or ascribed by others, but are also negotiated by agents who wish to position themselves in social structures. Thus, their identity practices seem to be in a constant state of negotiation, based on the situation, context and the interlocutors. Bucholtz and Hall (2005) introduce this scenario as an outcome of interactional negotiation. Varghese et al. (2005, p. 23) argue that "a teacher's positionality can be determined in relation to her students and the broader context in which the teacher was situated". In line with both arguments, MELTs in my study position themselves based on their micro and macro social contexts.

I identified multiple identities (Norton, 2013) performed by the multilingual teachers in their narrative interviews, identity portraits and classroom teaching. For example, they performed homeland identity as well as host-land identity along with multilingual, multicultural and multinational identities. This chapter, addressing the first RQ of my study, presents how multilingual English language teachers perform above mentioned multiple identities.

\subsection{Homeland identity}

The multilingual teachers, Cindy, Dory and Olga, express their homeland identities in various instances during the research process. Their homeland identity performance is visible in all the three data types: narrative interviews, identity portraits and field notes of the classroom observations. I observed Olga and Dory performing mostly positive homeland identity practices in contrast to Cindy whom I observed performing mostly a negative homeland identity (Bucholtz, 1999; Seals, 2017).

\subsubsection{Dory}

Dory positions herself as an Indian in New Zealand, emphasizing her homeland identity at the end of the narrative interview, when I asked whether she has anything to add to our discussion. 
She concludes stating how she performs her identity as an Indian and how she likes to perform her identity in NZ, as an Indian and as a teacher (See Excerpt 4.1).

\section{Excerpt 4.1-Dory positioning herself as an Indian (narrative interview)}

$\begin{array}{rll}1 & \text { Apsara: } & \text { ok (.) very } \uparrow \text { interesting } \downarrow \text { Is there anything more than this you think will be } \\ 2 & & \text { important for me that you } \uparrow \text { can add } \downarrow \text { like (.) about your multilingual English } \\ 3 & & \text { language teacher IDENTITY } \uparrow \text { how you negotiated your identity here } \downarrow \\ 4 & \text { Dory: } & \text { yeah I ALWAYS and my (.) I ask them where I am from and "teacher where } \\ 5 & & \text { are you from" (reporting what students ask her) "come on } \uparrow \text { look at me } \downarrow \text { look } \\ 6 & \text { at me } \downarrow \text { " I always tell my skin } \uparrow \text { colour and I NEVER regretted being an } \\ 7 & \text { Indian } \uparrow \text { and I know } \downarrow \text { I might have that Indian accent } \uparrow \text { and I am not ashamed } \\ 8 & \text { of it } \uparrow \text { and people treat me as I am } \uparrow \text { as a teacher } \uparrow \text { they don't care about where } \\ 9 & \text { I am from } \downarrow \text { all my employers also } \downarrow \text { they respect me they know who I am } \\ 10 & \text { what I am and how long how I handled the situation and how I do things in } \\ 11 & \text { my way } \uparrow \text { I never compete with anybody } \downarrow \text { I am not jealous } \downarrow \text { and I don"t } \\ 12 & \text { imitate or manipulate the accent to make people feel that I can speak } \\ 13 & \text { English } \downarrow\end{array}$

Dory highlights her homeland identity which includes her ethnic and linguistic identity, for example; her skin colour (brown skin) and her English accent ("Indian accent") to differentiate herself from New Zealanders and position herself as an Indian (line 6 and 7). She expresses that she is aware of this difference and accepts that, when she reports her own utterance, "come on $\uparrow$

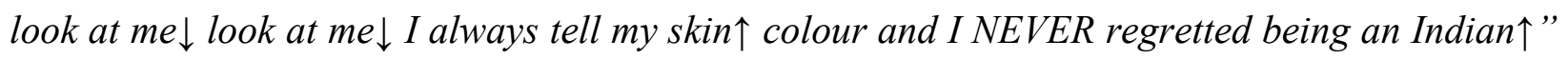
(line 5,6 and 7), "I might have that Indian accent $\uparrow$ and I am not ashamed of it $\uparrow$ "(line 7 and 8). Dory believes that her homeland identity is revealed through her "Indian accent". Further, she believes English accent is a marker which determines the speaker's homeland or host-land identity in NZ. This way, she indexes her homeland identity through her linguistic identity, positioning herself as an Indian in NZ. When she makes the comment that she is not ashamed of her Indian English accent, she reveals her awareness of a societal ideology regarding English in NZ: some English accents are preferred to others. Dory rejects this ideology by commenting that she is not ashamed of her accent even though it is different to the accent preferred in society.

Moreover, as shown in Excerpt 4.1, Dory thinks imitating the English accent (dominantly used in $\mathrm{NZ}$ ) is an attempt to show that one can speak English ("I don't imitate or manipulate the accent 
to make people feel that I can speak English"-line 11-13). There, she expresses her stance on English accents. She condemns the idea that one's English accent should be similar to New Zealanders' English accent in order to get accepted in the society as an English speaker. She challenges the ideology that English is owned by those who are from English speaking countries.

Dory always refers to her homeland (India) by narrating her lived socio-linguistic history (Barkhuizen, 2016) as a student and as a teacher. She narrated stories (both big stories and small stories) referring to her experience in India. This shows her homeland identity in India is related to the way she understands herself as an English teacher. Dory uses her "back in India" stories to show her teacher identity (Excerpt 4.2), her religious identity (Excerpt 4.3) and her identity as a working and studying mother (Excerpt 4.4). In Excerpt 4.2, Dory expresses her teacher identity in India.

\section{Excerpt 4.2-Dory's reference to her teacher identity in India (narrative interview)}

\begin{tabular}{lll}
\hline 1 & Dory: & yes teaching is my passion $(.$.$) as it is ($.$) and my (.$.$) the way I mean (.)$. \\
2 & & even though you know back in India we $(.$.$) being a teacher is like(..) it's the$ \\
3 & & most a $(.$.$) a ($.$) most professional what do I say ($.$) How do I put this (.) It's$ \\
4 & & the most [respect] \\
5 & Apsara: & [reputed]= \\
6 & Dory: & =reputed and respectable profession. If not I don't think anybody could hear \\
7 & & me when I am just standing in a street and talking (.) people may wonder \\
8 & & what is she up to (.) this is the place where people are sitting in a room and \\
9 & & listening to you $(. .$.$) it's a privilege you know \downarrow$
\end{tabular}

Dory uses the words "professional" (line 3) and "respectable" (line 6) to explain a teacher's socially assigned identity (Norton, 2013) in her homeland. She states that a teacher receives social recognition and respect in India. She also mentions how her voice was heard and given recognition in the society by being a teacher. However, when she uses the term "back in India" (line 2), it is suggested that this special social recognition given to teachers, is related to her identity in India. In addition to the teacher identity, Dory also expresses her religious identity (See excerpt 4.3) in her homeland.

\section{Excerpt 4.3- Dory's reference to her religious identity in India}




\begin{tabular}{lll}
\hline 1 & Dory: & you know people in India (.) or the church members (.) well they see "oh my \\
2 & & God! Pastor's daughter is doing that!" How come we can't do! you know so \\
3 & & that kind of a thing (..) So my mom was always "you can't do that you can't \\
4 & & do this" \\
5 & Apsara: & you are expected to be living \\
6 & Dory: & [living like a saint] \\
7 & Apsara: & [like a role] model
\end{tabular}

Dory reveals how she was expected to live in a socially and culturally determined frame because she was brought up in a strictly religious background. She was expected to be an example to the religious community as she was the daughter of a pastor. She mentions, that she had to maintain an assigned social identity to not be criticized by the "people in India", specifically "the church members". This way, she highlights her religious identity as a part of her homeland identity in India. Dory also explains her socio-economic struggles as a working mother while studying, to express her homeland identity (See Excerpt 4.4).

\section{Excerpt 4.4- Dory's reference to her identity as a hard working mother}

\begin{tabular}{|c|c|c|}
\hline 1 & Dory: & And second year of my graduation I gave birth to my daughter (.) and then I \\
\hline 2 & & continued studying and I was also working simultaneously (.) and I finished I \\
\hline 3 & & wanted to because in India the more you educate yourself the better position \\
\hline 4 & & you get(.) so as you know lots of competitions back in India(.) So, what I did \\
\hline 5 & & was I was like ok I have to finish this (.) Even though, I am married and have \\
\hline 6 & & a daughter I had to cope well with motherhood, life, education so I used to \\
\hline 7 & & work in a school in order to meet the financial needs even the milk powder \\
\hline 8 & & for my daugh[ter] \\
\hline 9 & Apsara: & [ok] so that's teaching (.) learning (.) and taking care of your child? \\
\hline 10 & Dory: & yeah $($.$) say all three things together$ \\
\hline
\end{tabular}

She expresses that she was required to study further to face the competition in the job market in India (line 4). She also depicts the importance given to education in her homeland (line 3). Moreover, she adds that her role as a mother also required her to be financially secured (line 7). Dory narrates how she faced hardships during her young age in India to reveal her determined nature in her hardworking past. It provides me insights into understand her homeland identity in India. 
As shown in the above excerpts, Dory expressed her homeland identity in India through many small stories in her narratives. These stories are micro fleeting aspects of her lived experience in India (Bamberg \& Geogakopoulou, 2008). According to Bamberg and Geogakopoulou (2008), small stories can be used to position oneself in doing identity during ongoing interaction. In addition, small stories can be small incidents narrated to back up or elaborate an argument in narratives. Dory uses these small stories to position herself as a hard-working and independent woman, from a religious background in India. She narrates these small stories in order to back up and elaborate her argument in positioning herself as an Indian who is different from homegrown New Zealanders.

Also, her repeated use of the phrases such as "in India" (line 3 in Excerpt 4.3), "back in India" (line 1 in Excerpt 4.3 line 4 in Excerpt 4.4), and "people in India" (line 1 in Excerpt 4.2) demonstrates how she expresses her homeland identity in India while interacting with me. Also, Dory's use of the phrase "you know" (line 2 in Excerpt 4.3), while talking about Indian context, suggests her reference to her shared socio-cultural knowledge with me. She actively and comfortably expresses her homeland identity in India while narrating her lived histories.

Dory also performed her home-land identity in NZ through her identity portrait (See Figure 4.1). Excerpt 4.5 is how she explained her homeland identity while drawing.

\section{Excerpt 4.5- Dory's homeland identity in identity portrait (recorded interaction)}

$\begin{array}{rll}1 & \text { Dory: } & \text { me (.) brown colour (colouring her face in brown) I want to show that my } \\ 2 & & \text { hands (@@@) } \\ 3 & \text { Apsara: } & \text { That's ok } \uparrow \text { good } \downarrow \text { And your face and neck } \\ 4 & \text { Dory: } & \text { I need my necklace }(.) \text { so I might have to put } \downarrow \text { a colourful necklace }(.) \\ 5 & \text { Apsara: } & \text { So does this necklace and all your ear rings represent something? } \\ 6 & \text { Dory: } & \text { my country } \downarrow \text { being an Indian I always dress like this (.) I wear my (..) ahh } \\ 7 & & \text { necklace } \\ 8 & \text { Apsara: } & {[\text { mmm] }} \\ 9 & \text { Dory: } & {[\text { and] I wear ear rings }(.)} \\ 10 & \text { Apsara: } & \text { mmm }\end{array}$

Figure 4.1- Dory's identity portrait 


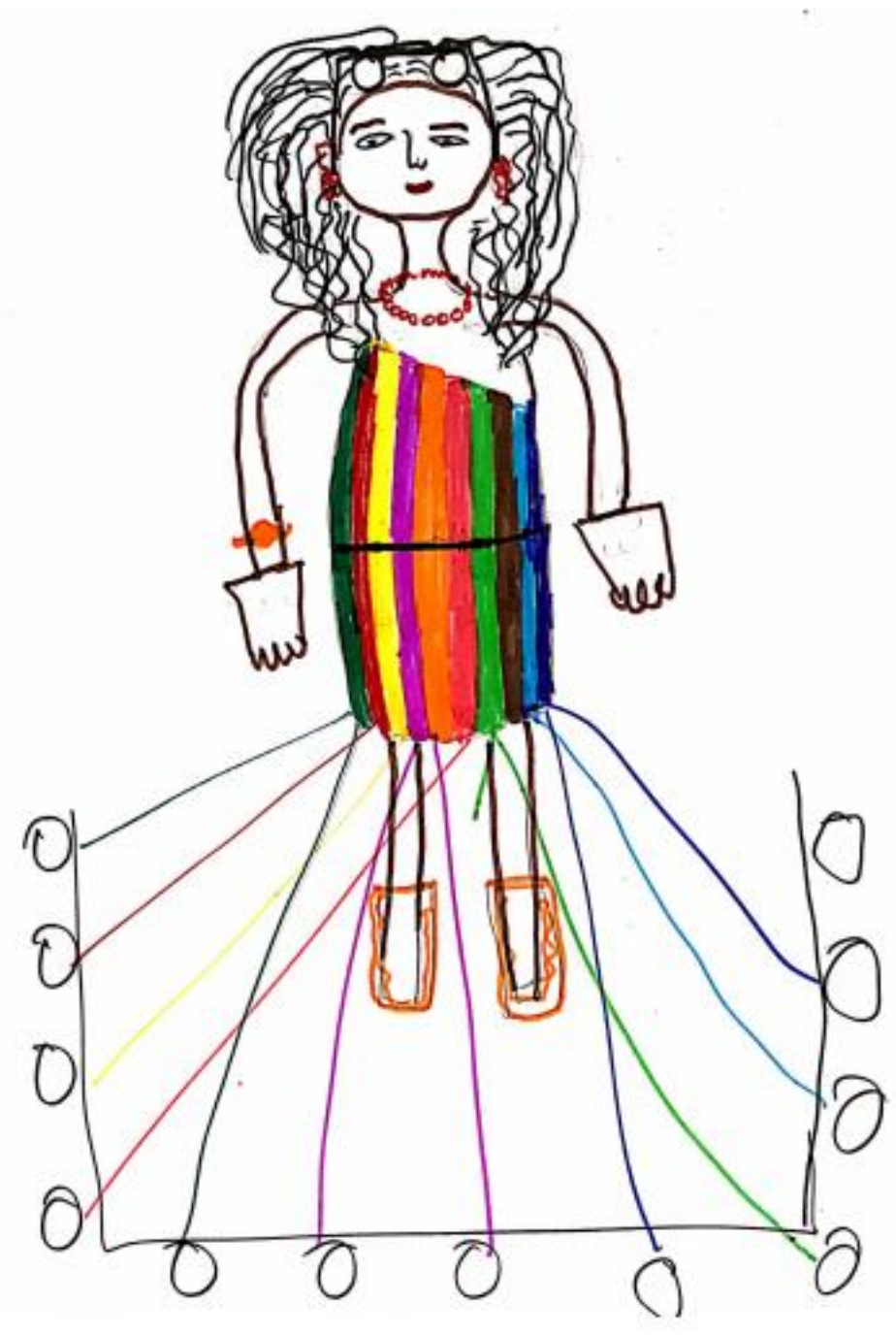

She drew and coloured her skin (face and hands) in brown and stated that "me brown colour" (line 1). This shows how she positions herself in NZ by her ethnic identity indexed through her skin colour. Moreover, she draws and colours that she is wearing a necklace and a pair of ear rings and adds that "being an Indian, I always dress like this I wear my necklace and I wear ear rings" (line 6 and 7 in Excerpt 4.5). She uses the jewellery, a part of her Indian culture, to index her homeland identity in NZ. Interestingly, she states "my country" (line 6) to refer to India but without mentioning India verbally. These instances illustrate how Dory performs her identity while interacting with me. Dory's performance of her homeland identity in NZ by indexing her ethnic and cultural identities while interacting with me, is her choice to express herself in 
opposition to the ideologies and societal norms in NZ which value Western and European friendly ethnic and cultural identities. Also, performance of Western and European friendly ethnic and cultural identities is expected from an English teacher because of monolithic language ideologies related to English language. Dory rejects this ideological and societal norm by performing her Eastern ethnic and cultural identities while interacting with me.

Excerpt 4.6 also provides evidence to argue on Dory's choice to perform her homeland identity in the host-land is an ideological choice.

\section{Excerpt 4.6- Dory's ideology on her homeland identity}

\begin{tabular}{rll}
\hline 1 & Dory: & I am who I am and that's it that's the story I don't want to (.) like my accent I \\
2 & & respect my accent and I DON'T $\uparrow$ regret at all for not able to be like a KIWI $\uparrow$ \\
3 & & Kiwis I don't $\uparrow$ that's not my way of $\uparrow$ thinking $\downarrow$ like whether I should match I \\
4 & & have to compete with them $\downarrow$ if they are there I need to be there (.) never $\uparrow$ \\
5 & & am what I am and I have my own pace \\
6 & Apsara: & you accept \\
7 & Dory: & [yeah] \\
8 & Apsara: & [yourself] who you are \\
9 & Dory: & I accept $\uparrow$ it $\downarrow$ and I am proud $\uparrow$ of it $\downarrow$ and I worked on my life and I already \\
10 & & know how I reached this place and I don't want to beat my drum and I want \\
11 & & to tell them I don't talk a lot about my achievements I don't want to tell I can \\
12 & & do this I can do that it's not me talking it's students talking. That's all I want
\end{tabular}

Dory states her ideological choice to perform her homeland identity when she mentions "I am what I am I have my own pace" (line 4 and 5) and to not negotiate her homeland identity to a host-land identity when she remarks "I don't regret at all for not able to be like a Kiwi" (line 2). These instances show how Dory decides to perform her homeland identity while interacting with me. She provides examples to state that she does not negotiate her homeland identity, revealed through her linguistic identity, in NZ. This shows how negotiation of identity and community membership in interaction is not neutral and it is a site of struggle over positionality (Rudolph et al., 2020). Dory's ideological choice to perform her homeland identity through her linguistic identity is a battle against the prevailing "idealized notions" (Rudolph et al., 2020) on English and English accents in NZ. Thus, she does not want to gain validity, authority and agency in the host-land by negotiating her linguistic identity. 
Even though Dory performs her homeland identity while interacting with me, she does not explicitly perform that in her classroom. Her teacher identity performed in the classroom is predominantly a multicultural identity. This will further be discussed in Section 4.3. Now I will discuss how Olga performs her homeland identity.

\subsubsection{Olga}

Figure 4.2 shows Olga's identity portrait followed by Excerpt 4.7 which illustrates how Olga describes her embroidery in the identity portrait to index her home land (Russian) identity.

Figure 4.2- Olga's identity portrait

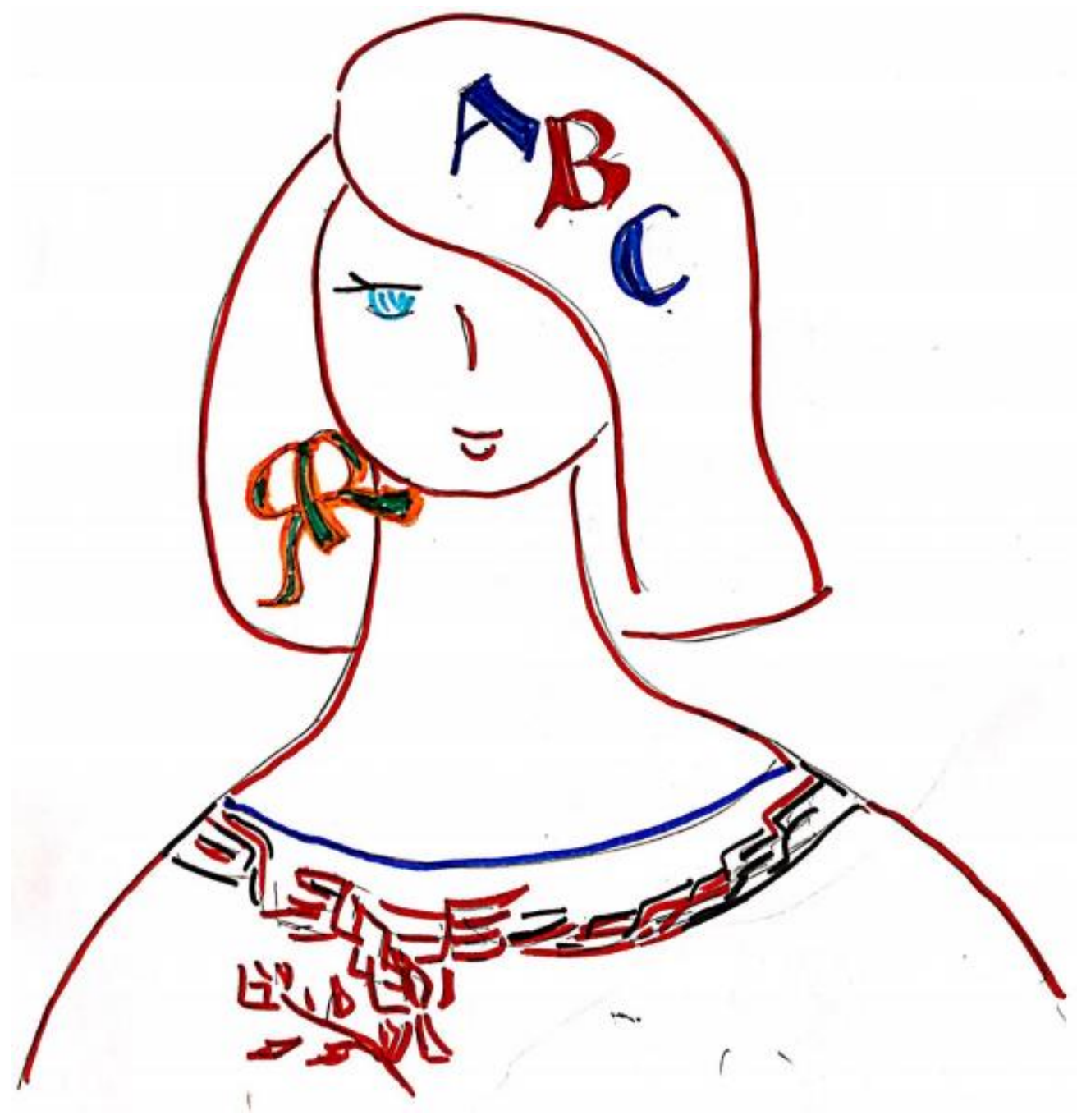




\section{Excerpt 4.7- Olga's embroidery in the identity portrait}

\begin{tabular}{rll}
\hline 1 & Apsara: & You are good at drawing $\uparrow$ [very nice] \\
2 & Olga: & [Yes I am] \\
3 & Apsara: & Have you done drawing before? \\
4 & Olga: & Yes I have taken some courses \\
5 & Apsara: & cool $\uparrow$ \\
6 & Olga: & mmmm $(\ldots .$.$) (thinking) ahh don't remember the embroidery \uparrow$. \\
7 & Apsara: & ok So that's the embroidery from $(.)$. \\
8 & Olga: & That's the embroidery representing my Russian identity \\
9 & Apsara: & I see very interesting \\
10 & Olga: & Yeah (draws) \\
11 & Apsara: & So in Russia, embroidery is famous? \\
12 & Olga: & mmm that's part of it $\downarrow$ so let's imagine that's embroidery $\downarrow$ \\
\hline
\end{tabular}

As shown in Figure 4.2, Olga indexes her homeland identity through an embroidery design in her dress which she refers to as a part of her Russian identity (See Excerpt 4.7). Even though she immediately decides to draw embroidery and starts confidently showing her skills in drawing (illustrated in my comments appreciating her drawing and her accepting it, further adding that she has learnt it), she had to take time to memorize the embroidery while drawing. She mentions that she does not remember the embroidery (line 6). Then she adds, "let's imagine this as embroidery" (line 12) indicating that she is not fully confident about her embroidery drawing. Despite the fact that Olga deliberately wants to express her homeland identity by indexing the embroidery, she demonstrates her disassociation with it by not being able to complete it the way she wants. Also, Olga does not make any comments to show that she wears embroidery clothes regularly in New Zealand unlike Dory who mentions that she always wears her jewelry as an Indian. Nofal (2020) remarks how his participants developed "semiotic links to generate more abstract meanings" (p.114) in their linguistic maps in order to construct multilingual and national or cultural identities. Similarly, Olga uses the embroidery in the identity portrait to express her homeland identity.

However, Olga indexes her homeland identity through the embroidery in the cloth as a part of her cultural identity, similar to how Dory uses jewelry in her identity portrait to index her homeland identity. It is interesting to understand how multilingual teachers index their homeland identity through their dress and accessories, which are part of their cultural identity. Furthermore, Olga suggested the pseudonym "Olga", to be used to refer to her in my thesis 
report stating that it is a common Russian name. She also refers to Russian culture during her classroom discussion about the New Year festival. (field notes-28/07) These instances illustrate how Olga performs her homeland identity while interacting with me as well as teaching English in the classroom.

\subsubsection{Cindy}

In contrast to Dory and Olga, Cindy does not actively perform her homeland identity during my research activities with her. For example, she neither narrates small stories about her homeland (Taiwan) while interacting with me nor she does make any reference to Taiwan in her identity portrait. However, there are two instances when I asked her about Taiwan and Taiwanese culture. The first is during our narrative interview when I asked her about her interest in movie (See Excerpt 4.8).

\section{Excerpt 4.8- Cindy's interest in movies (narrative interview)}

$\begin{array}{rll}1 & \text { Apsara: } & \text { ok good. And what are your interests? Like personal interests? } \\ 2 & \text { Cindy: } & \text { My interest(..) say(.) eeee(..) watching dramas(.) yeah(.) movies(..) } \\ 3 & \text { Apsara: } & \text { Can I know which dramas? What kind of movies? } \\ 4 & \text { Cindy: } & \text { Mostly American dramas [English] } \\ 5 & \mathrm{Me}: & \text { [So (..)] you are not watching your [local] (Taiwanese) } \\ 6 & \text { Cindy: } & \text { [No] no(.) umm just pretty much American Netflix all the good movies yeah } \\ 7 & \mathrm{Me}: & \text { Ok (.) So was that (..) from the beginning of your life? } \\ 8 & \text { Cindy: } & \text { yeah yeah } \downarrow \text { I think (.) It's probably because in Taiwan (..) we (.) the culture } \\ 9 & & \text { is really really deeply affected by the US American culture so that I leamed } \\ 10 & & \text { (.) It's both you know the pronunciation and the spelling all American } \\ 11 & & \text { English. So I am used to that (.) culture (.) Yeah }\end{array}$

Cindy corrected me to emphasize that she does not watch Taiwan movies or dramas, but American movies which she also introduces as "all the good movies" (line 6). This shows her interest in American culture. Interestingly, she mentions that the dramas she watches are "American" and immediately adds "English" (line 4). There, she remarks upon her interest on the American culture to which she links English language. Then I assumed that her interest in American culture is related to herself spending 2 years in the United States when she did her Master's in Teaching English (as she revealed in a previous narrative). Therefore, I asked her 
whether it was since her early life that she was interested in American movies. She makes the point clear by explaining Taiwanese culture is influenced by American culture. Her use of the words "really really deeply affected by American culture (line 9)" hints that she wants me to understand her cultural identity is also connected to the US culture. She also adds that her pronunciation and spelling are "all American English" (line 10).

Moreover, she uses the term "you know" when she moved on to talk about English to highlight our shared knowledge about English. She also positions her linguistic identity to be "American" by stating that she learnt pronunciation and spelling through these American movies, as similar to Dory naming her "Indian accent" to index her Indian national identity. This is another instance to show that teachers in my study claim national identities to be linguistic identities by indexing English and English accents to the gate keepers of the language.

Cindy finally concludes, "So I am used to that culture" (line 11) to emphasize her point as well as to clear my doubt. In this instance, she performs a negative homeland identity (Bucholtz \& Hall, 2005) by distancing herself from Taiwanese culture as well as making connections to US culture.

The second instance where Cindy clears my wrong assumption on representation of her homeland identity is while she was drawing her identity portrait (see Figure 4.3).

\section{Excerpt 4.9- Cindy drawing red flag in her identity Portrait}

\begin{tabular}{lll}
\hline 1 & Apsara: & Is red there in your flag? Taiwan? \\
2 & Cindy: & mmm(..) yes yes yeah it' red $\uparrow$ but about language I think \\
3 & Apsara: & You just took \\
4 & Cindy: & yeah. Not about my national flag but the language \\
5 & Apsara: & Mandarin \\
6 & Cindy: & Mm hmm \\
7 & Apsara: & why it's red? Why Mandarin is red? \\
8 & Cindy: & ahhh because Mandarin is Chinese (.) Chinese culture is red. The most \\
9 & & symbolic(..) symbolic colour \\
\hline
\end{tabular}

Figure 4.3-Identity portrait of Cindy 


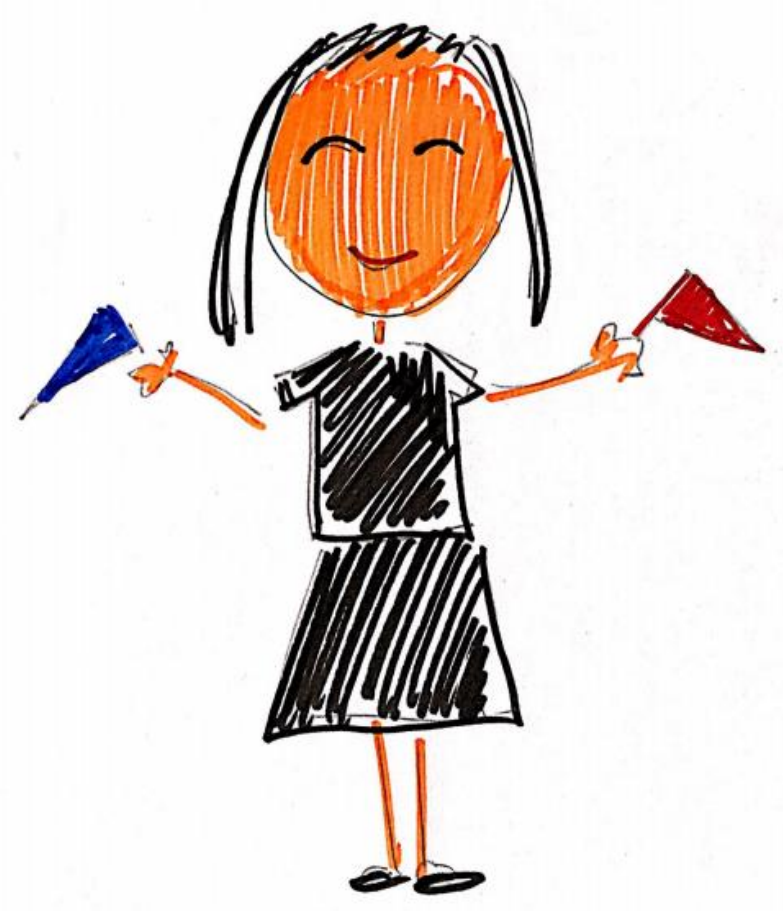

Cindy draws a red flag in her hand which I assumed to be an influence from Taiwanese national flag. Interestingly, when I asked her about the red flag, she accepts red to be a colour in the Taiwanese national flag but states that the red flag in her portrait does not refer to the Taiwanese national flag but it refers to her first language, Mandarin (See Excerpt 4.9) and adds that red is the "most symbolic colour" in Chinese culture (line 8 and 9).

In both instances depicted above, Cindy corrects my misunderstanding that she is performing her homeland identity as a Taiwanese. She distances herself from her homeland identity through negative identity practices (Bucholtz, 1999) and "discursively disaligns with concepts that index" (Barr \& Seals, 2018, p. 331) her homeland identity as Taiwanese. Furthermore, Cindy does not perform her homeland identity in her classroom. She seems to intentionally perform a negotiated (host-land) identity as an English teacher while interacting with me and conducting her classes. This will further be discussed in Section 4.3 during which I elaborate on host-land identities of the multilingual English language teachers. 
In this section, I discussed how MELTs performed their homeland identities in interactions with me through their narratives, identity portraits and classroom teaching. The discussion shows how Dory performs a positive homeland identity by positioning her ethnic, cultural and linguistic identities as an Indian. Olga attempts to make connections to her homeland identity by indexing her cultural and national identity through abstract meanings. Cindy performs a negative homeland identity through negative identity practices. I will discuss how they perform their hostland identities in the next section.

\subsection{Multiple host-land identities}

In previous section, I discussed how MELTs perform their homeland identities. In this section, I focus on their multiple host-land identity performance in New Zealand. Host-land identities of the MELTs in my study are multiple, dynamic, static and constantly being changed. Also, they negotiate their homeland identities to host-land identities, especially in the classroom. They also navigate their host-land identity through monolingual, multilingual, multicultural and multinational identities at times as English language teachers. In addition, they intentionally perform multiple host-land identities reflecting their understanding of the students.

\subsubsection{Negotiated host-land identities}

All three MELTs are current New Zealand citizens and they express and perform negotiated host-land identities on different occasions. Also, they have different ways of performing their host-land identities.

\subsubsection{Cindy}

Cindy's host-land identity performance is highlighted in many instances. Most of Cindy's identity portrait (See Figure 4.3.) is coloured in black (her clothes). She uses black to index people in Wellington while interacting with me during her identity portrait session. (See Excerpt 4.10)

\section{Excerpt 4.10-Cindy colouring her dress in black}

\begin{tabular}{lll}
\hline 1 & Cindy: & I think all those colours and flag is just because I am going to (..) black \\
2 & & people in Wellington whoever $\downarrow$ \\
3 & Apsara: & they are like black? \\
4 & Cindy: & mmm
\end{tabular}


Cindy's use of black to index people in Wellington can be understood by black being a prominent colour in Wellington as well as NZ. For example, black is associated with NZ's government work and Wellington is the capital in $\mathrm{NZ}$ and the centre of government work. This is the main reason why people point black clothes for Wellington. Also, black is a branded colour in NZ; the NZ Rugby team wears black and they are called "All Blacks", the national airline (Air New Zealand) uses black and white as their brand colour and black is also a prominent colour in traditional Maori flag along with red. Cindy colours herself in black stating "people in Wellington whoever" (see line 2) are represented by black. This way, in her identity portrait, Cindy indexes the identity of "people in Wellington". Thus, she makes connections to an imagined community (Anderson, 1991) of Wellington residents and identifies herself as a member of this community. Hence, Cindy performs a positive host-land identity in her portrait.

Cindy also performs her host-land identity in the classroom. She often takes examples from NZ; for example, while she was discussing a reading material with the students, she connected the scenario to relevant current issues in NZ. The class came across some information on the use of drugs in Holland in this reading material. Then Cindy explains about the referendum vote that was being scheduled in $\mathrm{NZ}$ at that time for legalizing marijuana for recreational purposes (field notes-04/06). Cindy also uses the Covid-19 pandemic situation in NZ for discussion. For instance, she played a video of one of the press conferences of the prime minister of NZ announcing the Covid-19 lockdown, as a listening lesson. The content of the video was discussed at the end of the video (field notes-08/06). She performs her host-land identity while supporting the migrant students to negotiate their migrant identities in the host-land-New Zealand. Thus, Cindy performs a negotiated host-land identity both in her identity portrait interactions with me and in the classroom with her students. In other words, Cindy illustrates practices of a positive identity through her "discursively aligning ideas, characteristics, etc that index [the host-land identity she wants to] embrace" (Barr \& Seals, 2018, p. 331).

\subsubsection{Dory}

Dory, in contrast to Cindy, performs both homeland identity and host-land identity as different occasions. For example, she narrated many big stories and small stories related to her student and teacher life in her homeland (India) as discussed in Section 4.1 as well as some small stories related to her teaching experience in NZ. Dory narrates small stories from her class to back up 
her arguments (Bamberg \& Geogakopoulou, 2008) about how and why she needs to highlight a host-land identity in the class. This is illustrated by the following small story which is an excerpt from her narrative interview with me. She is narrating a small story related to an incident that happened in the class with some students and how she responded to them (See Excerpt 4.11).

\section{Excerpt 4.11- Dory's negotiated host-land identity (narrative interview)}

\begin{tabular}{|c|c|c|}
\hline 1 & Dory: & Syrians $\uparrow$ oh my God $\uparrow$ They $\uparrow$ want to bring their culture $\downarrow$ and they want New \\
\hline 2 & Ansara. & (ब) \\
\hline 4 & Dory: & I am like "excuse me $\uparrow$ I scream (.) (...) \\
\hline 5 & & I said (.) "Look (.) I know I am Indian too $\uparrow$ I know you know how Indians \\
\hline 6 & & drive? They drive crazy $\uparrow$ have you seen you tube video about Indian traffic $\uparrow$ \\
\hline 7 & & But I am not bringing that here $\uparrow$ I have to change it myself this is what I tell \\
\hline 8 & & my Syrian students" Oh my God $\downarrow$ they sleep at $30^{\circ}$ clock in the moming they \\
\hline 9 & & don't come to the class at 8.45 . They say $\downarrow$ "teacher no it's ok teacher $\uparrow$ no \\
\hline 10 & & problem no problem" I say, "what is no problem there is a BIG problem \\
\hline 11 & & here†"@@@ \\
\hline
\end{tabular}

Dory comments on how her Syrian students have not been able to negotiate their homeland identities in the host-land-New Zealand when she remarks "Syrians oh my God. They want to bring their culture and they want New Zealand to follow that" (line 1). Dory herself being a migrant in New Zealand, believes that some aspects of the homeland identity of migrants should be negotiated when they are in the host-land. Therefore, she attempts to support her migrant students to negotiate their homeland identities by modeling how she negotiated her homeland identity through negative identity practices and host-land identity through positive identity practices in NZ. She uses the example of how Indians drive in India and how she cannot drive the same way in New Zealand even though she is an Indian.

Another example of a small story she narrates shows how she performs her host-land identity in the classroom. This is when she had to handle a situation where two students from two different countries started an argument in the class (See Excerpt 4.12).

Excerpt 4.12- Dory performing her negotiated host-land identity in the classroom 


\begin{tabular}{|c|c|c|}
\hline 1 & Dory: & You know these Columbian students are very loud people $\downarrow$ and Burmese \\
\hline 2 & & students are very quiet people $\downarrow$ when I am teaching when the Burmese people \\
\hline 3 & & can't understand hear me properly because at the same time some students \\
\hline 4 & & are talking (.) then one of the Burmese students said "shhh" (..) and then you \\
\hline 5 & & should see the Columbian (.) oh my God $\downarrow$ She got so angry she became red $\downarrow$ \\
\hline 6 & & I said what's happening $\uparrow$ "teacher, in my country we say "shh" to the dog \\
\hline 7 & Apsara: & $@ @ @$ \\
\hline 8 & Dory: & "I am not the dog" (Dory utters the student's word) \\
\hline 9 & Apsara: & $@ @ @$ \\
\hline 10 & Dory: & But in Burma, if a child is screaming, they say "shhh" \\
\hline 11 & Apsara: & even we say "shhh" \\
\hline 12 & Dory: & In India, "shuu" and then I had to after the class finished I had to meet the \\
\hline 13 & & students "hey look $\downarrow$, you need to understand (.) understand your culture is \\
\hline 14 & & different your culture is different but when you are in New Zealand please \\
\hline 15 & & don't bring that $\downarrow$ in to (.) you need to understand(.) he need (s) to say you are \\
\hline 16 & & talking in the class he was just trying to Shush you(.) but you thought $\downarrow$ your \\
\hline 17 & & mind straight away went to a dog $\uparrow$ But in his country it's not a dog $\downarrow$ you need \\
\hline 18 & & to respect that also" and then "yeah yeah yeah yes teacher yes teacher" shake \\
\hline 19 & & hand and go(.) This is the multilingual multicultural multiethnic all these \\
\hline 20 & & things come in to \\
\hline 21 & Apsara: & play in the class \\
\hline 22 & Dory: & Yeah and also teaching skills \\
\hline 23 & Apsara: & [You are] like a mediator \\
\hline 24 & Dory: & [oh yeah] pastoral care mediator I can't take sides I can't \\
\hline 25 & Apsara: & [be biased] \\
\hline 26 & Dory: & [You see] I can't give a (not clear) statement "oh you are right you are right" \\
\hline 27 & & BUT $\uparrow "$ "I think in your situation you are right in your situation you are right \\
\hline 28 & & but in New Zealand situation not in Dory's situation(.) in New Zealand (.) I \\
\hline 29 & & always tell them in New Zealand $\uparrow$ people don't care we need to do this \\
\hline
\end{tabular}

Dory narrates this small story to express how she performs her teacher identity in her multicultural English class supporting her students from different countries, to understand the need to negotiate their homeland identities in the host-land, NZ. She states, "understand your culture is different but when you are in New Zealand don't bring that" (line 13-15). Her utterance- "when you are in New Zealand" reminds the students their shift from homeland to the host-land. Her repetitive use of the word "understand" (line 14 and 16) emphasizes her intention to support her students to realize the need for their identity negotiation. However, she does not position herself to represent the host-land identity here even though she tells the students what their host-land identity should be. That is evident when she states, "but in New Zealand situation 
not in Dory's situation, I always tell them in New Zealand, people don't care we need to do that." ( line 28 and 29) She clearly differentiates her personal identity and New Zealand identity when she says, "not in Dory's situation" and "in New Zealand situation" to express that it is not her personal perspective. Dory neither performs a positive host-land identity nor negative host-land identity. Instead she performs a neutral host-land identity as a requirement of her teacher role in the class. However, she needs her students to understand that the nature of the host-land identity that they are expected to perform in New Zealand is a multicultural identity. How Dory herself performs her multicultural identity will further be discussed in Section 4.5.

\subsubsection{Multilingual identity of the MELTs}

Dory and Olga perform their negotiated multilingual identity during their narrative interviews with me, in their identity portraits and classroom teaching. Even though Cindy performs a multilingual identity in her narrative interview and identity portrait, she negotiates that to a monolingual identity in the classroom, as discussed further below.

Dory expressed that she speaks different languages including Thelungu, Hindi, Tamil, Urdu, English, Spanish and Arabic. However, she has known the former five languages since her childhood in India, whereas she acquired the latter two languages after coming to New Zealand. She mentions that she learned these languages (Spanish and Arabic) "for survival (as a teacher)" (Excerpt 4.13)".

\section{Excerpt 4.13- Learning Arabic and Spanish for survival (narrative interview with Dory)}

\begin{tabular}{lll}
\hline 1 & Dory: & Thelungu is my mother tongue (.) Hindi is our Second language (.) and I \\
2 & & picked up some Tamil with my Tamil friends and I also speak little Urdu \\
3 & & which is little closer to Arabic and Hindi (.) And it's one of the regional \\
4 & & languages from where I come from (.) And coming to New Zealand in order \\
5 & & to have students I started to learn Arabic and also Spanish yeah Spanish (.) \\
6 & & Arabic just starter I should say survival. I can understand but I can't get out \\
7 & & of a trouble using some of them \\
8 & Apsara: & Arabic or Spanish? \\
9 & Dory: & Spanish (.) Arabic you know I know Arabic. I can manage
\end{tabular}

This excerpt shows how Dory has negotiated her linguistic identity after coming to New Zealand. She specifically mentions that she learned Spanish and Arabic "to have students" (to be more qualified to teach English to learners who speak Spanish and Arabic) (line 5) and "I should 
say survival" (to survive in the class) (line 6). She has negotiated her linguistic identity by earning new linguistic capital (Bourdieu, 1977; Norton, 2013) in the new context which has also supported her to establish herself as an English teacher.

Interestingly, Olga also described a similar experience in negotiating her multilingual identity by learning the same languages in order to better suit her English language teacher identity in the classroom (See Excerpt 4.14).

\section{Excerpt 4.14- Olga picking up Arabic words from students}

\begin{tabular}{|c|c|c|}
\hline $\begin{array}{l}1 \\
2\end{array}$ & Apsara: & $\begin{array}{l}\text { What about your use of those languages in class? Do you get to speak any of } \\
\text { those languages in class or }\end{array}$ \\
\hline 3 & Olga: & oooh $\uparrow$ I need Arabic in class much more because lot of my students are from \\
\hline 4 & & Arabic speaking countries so (.) the students I currently work with they speak \\
\hline 5 & & Kurdish Arabic (.) Some of them speak ahh Burmese or other languages from \\
\hline 6 & & Myanmar so and I sometimes relate to their languages rather than the \\
\hline 7 & & languages I speak \\
\hline 8 & $(\ldots)$ & \\
\hline 9 & Apsara: & mmm how have you learnt all these languages? \\
\hline 10 & $(\ldots)$ & \\
\hline 11 & Apsara: & So these languages like Arabic languages? \\
\hline 12 & Olga: & The languages of my students I can't say I really know them just I have \\
\hline 13 & & picked up words from the students \\
\hline 14 & Apsara: & from the students \\
\hline 15 & Olga: & yeah yeah $\downarrow$ during conversations in class \\
\hline
\end{tabular}

Languages in Olga's repertoire before coming to New Zealand (Russian and French, and etc) are being rarely used in her class in New Zealand as there are fewer students who speak these languages. Therefore, her social capital loses its power in the host-land. On the other hand, Olga mentions that she needs Arabic in her English class because most of her students are from Arabic speaking countries (See line 3, 4 and 5). Hence, she "picked up [Arabic] words from students" (line 12,13) in order to use in the class. She further explains that she "relates to their [students'] languages" (line 6) in class. This shows how Olga has also negotiated her multilingual identity in New Zealand by earning new social capital in order to fit in her English teaching career.

Dory and Olga have similar experiences in negotiating their multilingual identities. This can be due in part to them teaching at the same institute which supports multiculturalism. In contrast, Cindy, who teaches at a different institute, does not perform her multilingual identity in the 
classroom even though she expresses her multilingual identity in her narrative interview and identity portrait. The following excerpt shows how Cindy expresses her multilingual identity in the narrative interview.

\section{Excerpt 4.15- Cindy's multilingual identity}

\begin{tabular}{|c|c|c|}
\hline 1 & Apsara: & Ok. What languages do you know? \\
\hline 2 & Cindy: & Mandarin Chinese(.) language My native(..) native language is Mandarin \\
\hline 3 & & Chinese(.) and my second language is English I don't know any other \\
\hline 4 & & languages. \\
\hline 5 & Apsara: & ok can you please tell me where and when you speak those two languages \\
\hline 7 & Cindy: & ahhh outside home(.) at home(.) Chinese because my husband is also from \\
\hline 8 & & Thaiwan so with my family(.) with my children $\uparrow$ I speak Mandarin Chinese \\
\hline 9 & & for one thing that's nature for me $\uparrow$ and the other thing is like because they \\
\hline 10 & & were born here they should learn Chinese(.) to speak(.) They can speak but \\
\hline 11 & & they have to be able to fastly read $\uparrow$ Chinese when they grow older \\
\hline 12 & Apsara: & So you want your children to be bilingual like you? or multilingual? \\
\hline 13 & Cindy: & yeah. Yeah. \\
\hline $\begin{array}{l}14 \\
15\end{array}$ & Apsara: & $\begin{array}{l}\text { Outside like where do you speak? Do you speak with any other friends or } \\
\text { [some] }\end{array}$ \\
\hline 16 & Cindy: & [yeah] if the friends from Taiwan (.) I do \\
\hline 17 & Apsara: & And English? \\
\hline 18 & Cindy: & Profession (.) Pretty much everywhere in New Zealand \\
\hline
\end{tabular}

Cindy claims her linguistic repertoire consists of two languages: English and Mandarin (See Excerpt 4.15). She mentions that she speaks Mandarin at home, and she wants her children to be multilingual. Also she says that she speaks Mandarin with her Taiwanese friends in New Zealand. Further, she expresses herself to be multilingual in her identity portrait (See Figure 4.3 in page 59 ).

\section{Excerpt 4.16- Cindy's multilingual identity (identity portrait session)}

\begin{tabular}{lll}
\hline 1 & Apsara: & What are those? (Pointing at the flags that Cindy is drawing) \\
2 & Cindy: & $\begin{array}{l}\text { Languages } \\
(\ldots)\end{array}$ \\
3 & & ok $\uparrow$ Why do you colour that flag in red? \\
4 & Apsara: & I think Mandarin is red $\uparrow$ \\
5 & Cindy: & ok \\
6 & Apsara: & English is blue $\downarrow$ I don’t know why but just that
\end{tabular}




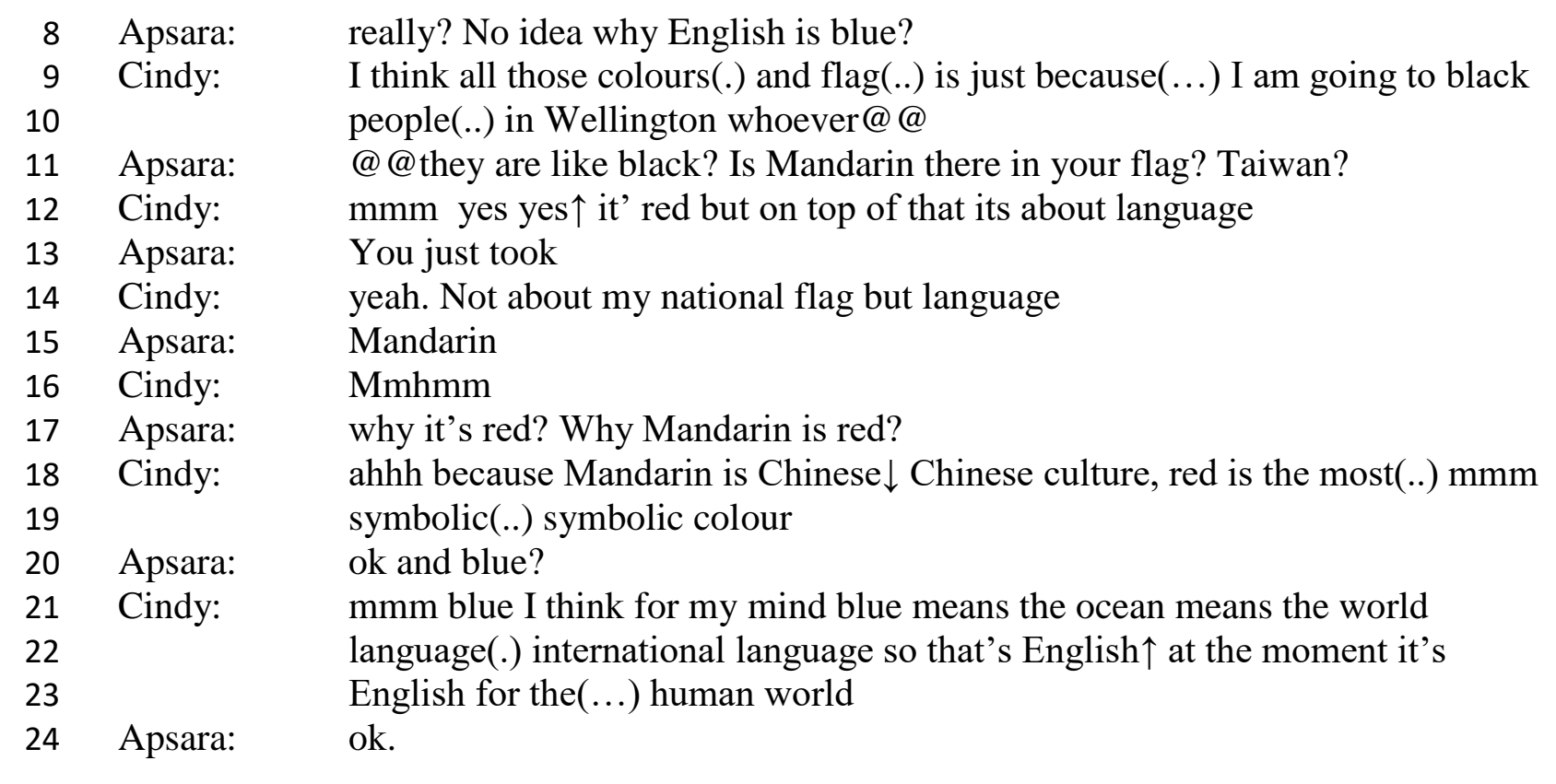

Cindy draws two flags in both her hands to represent the two languages she speaks: English and Mandarin. She uses the red flag to index Mandarin and the blue flag to index English. She explains the reason for using red for Mandarin is to symbolize the Chinese culture because red is the most symbolic colour for Chinese culture (See Excerpt 4.16). On the other hand, she expresses that she uses blue for English because it is the world/international language. Also, she uses blue to index the ocean and English to convey its spread all over the world and remarks " $I$ think for my mind blue means the ocean the world language" (line 21 and 23). Cindy demonstrates a positive ideology towards multilingualism in these instances highlighting that she wants her kids to learn their heritage language, Mandarin. She maintains multilingualism at home. Also, she herself talks to her Taiwanese friends in Mandarin (See Excerpt 4.15).

Although Cindy performs a multilingual identity (while interacting with me) indicating her positive ideology towards multilingualism (See Excerpts 4.15 and 4.16), she does not perform her multilingual identity in the classroom. She performs a monolingual identity in the classroom (field notes-04/06, 08/06, 09/06). This can be understood as a strategy used in order to fit in the monolingualism promoted at the institution she teaches at as well as her English teaching ideology. This can partly be due to multilingual teacher identities being challenged by institutional policies and social ideologies that value monolingualism and homogeneity (Canagarajah, 2016). As a result, sometimes, the MELTs can feel insecure about representing their multilingual identities in such English teaching contexts. 
Cindy has negotiated her multilingual identity to a monolingual identity in the English classroom in contrast to how other two teachers negotiated their multilingual identities by earning new linguistic capital, in the same macro context, New Zealand. This shows that the multilingual teachers perform negotiated multilingual identities in different ways in different teaching contexts in order to fit in to the requirements of the institutions they teach. Bucholtz and Hall (2005) argue that one's identity negotiation can be "in part a construct of others' perceptions and representations and in part an outcome of larger ideological processes and structures" (p.585). Cindy's performance of negotiated monolingual identity and both Dory's and Olga's performances of negotiated multilingual identities can partially represent the ideologies of the institutions they work at, in addition to their personal ideologies. The ideological and interactional functions that are served by these negotiated linguistic identities will further be discussed in Chapter 5.

\subsubsection{Multicultural identity}

Multicultural identity is one of the multiple host-land identities performed by the MELTs in my study. However, the way teachers perform multicultural identity is different from each other. For example, Dory and Olga perform their multicultural identities throughout the research process: in their narratives, in the identity portraits and in the classroom discussions whereas Cindy's teacher identity does not show any clear multicultural aspects in the classroom even though she expresses her personal interest in learning about new cultures. In this section, I will further elaborate upon how the MELTs perform their multicultural identities.

The most dominant aspect of Dory's identity portrait is the representation of the students from different countries, cultural groups and ethnic groups in her class. She recognizes all the groups and indexes all the different groups in her class through different colours for each group (See Figure 4.2. and Excerpt 4.17). She colours her dress in different colours to show that her students are from different cultures, ethnic groups and countries.

\section{Excerpt 4.17- Dory explaining multiculturalism in her class (identity portrait)}

\begin{tabular}{lll}
\hline 1 & Dory: & So what I am going to do I am going to select each colour represents (..) each \\
2 & & mm ethnicity in my class ok $\uparrow$ \\
3 & Apsara: & ok interesting \\
4 & Dory: & So green colour (.) Kadra (..) it's for Ethiopian ok
\end{tabular}




\begin{tabular}{|c|c|c|}
\hline 5 & Apsara: & Why green colour for Ethiopian? \\
\hline 6 & Dory: & because one of my students said Ethiopia is full of green or something \\
\hline 7 & Apsara: & ok \\
\hline 8 & Dory: & So green colour(colouring) just I want to represent each colour to each \\
\hline 9 & & ethnicity so yeah green and red colour for China \\
\hline 10 & Apsara: & So you have Chinese students ((colouring)) \\
\hline 11 & Dory: & yeah red colour for China ((colouring)) and yellow \\
\hline 12 & Apsara: & Yellow for whom? \\
\hline 13 & Dory: & Maybe India \\
\hline 14 & Apsara: & Ok why India is yellow? \\
\hline 15 & Dory: & Haldi Haldi you know like a bridal (.) bridal shower (..) we have Haldi \\
\hline 16 & Apsara: & ahh ok \\
\hline 17 & Dory: & So yellow is like bright like sun It has got so many $(.)$. \\
\hline 18 & Apsara: & So India (.) When you say India for you the sun comes to your mind \\
\hline 19 & Dory: & Yeah the bright colour it's sunny all the time (..) and I might [choose] \\
\hline 20 & Apsara: & [So do] you also have Indian students in your class? \\
\hline 21 & Dory: & yes I do yeah \\
\hline 22 & Apsara: & So does this represent your students or you or both \\
\hline 23 & Dory: & Both like I $\uparrow$ I am wearing a dress which represents all the other cultures also $\uparrow$ \\
\hline 24 & & it REFLECTS my way of when I teach I learn each (.) each(.) I learn \\
\hline 25 & & languages of my students \\
\hline 26 & Apsara: & hmmm \\
\hline 27 & Dory: & just to welcome you know like to greet (..) so I want to reflect $\uparrow$ my I mean I \\
\hline 28 & & want to tell them that no matter I might(.) you are from different ethnicity but \\
\hline 29 & & I can mix with your ethnicity \\
\hline 30 & Apsara: & ok to be multicultu[ral?] \\
\hline 31 & Dory: & [yeah] multicultural $\downarrow$ So my dress is going to be multicultural and multi \\
\hline 32 & & coloured(.) it's different identities staying on the same \\
\hline 33 & Apsara: & class? \\
\hline 34 & Dory: & yeah yeah and aaa for (.) Syrian students $\uparrow$ I want to go for this colour \\
\hline 35 & & $(($ magenta $))$ because I have seen some of my Syrian students wear this colour \\
\hline 36 & & a lot girls specially So I told myself they look beautiful in this colour(.) yeah \\
\hline 37 & & $(($ colouring $))$ so $(.$.$) and I will choose for Burma(..) I want to choose (.)$ \\
\hline 38 & & maybe orange colour with the mountains (.) with the military they are \\
\hline 39 & & painters most of them are painting painters \\
\hline 40 & Apsara: & Ahh $\uparrow$ painters painters here? \\
\hline 41 & Dory: & yes they get jobs as painters I want to use this colour to represent their skills \\
\hline 42 & & painting skills (colouring) and of course blue colour for Asyrians $\uparrow$ \\
\hline 43 & Apsara: & You told purple for Syrians \\
\hline 44 & Dory: & Syria $\downarrow$ this is Syria and this is ASYRIANS \\
\hline 45 & Apsara: & Ahh ok what is that? \\
\hline 46 & Dory: & Iraqi Iraqi one of the Iraqi community so I got this ladies beautiful ladies \\
\hline 47 & & ahhh I should go for this pink because they wear pink (colouring) \\
\hline 48 & Apsara: & And I want to choose Ethiopian culture I want to go for Ethiopian green \\
\hline 49 & & green colour because they say I said this one as a Sudan ohh sorry I think I \\
\hline 50 & & finished Ethiopia right \\
\hline
\end{tabular}




\begin{tabular}{|c|c|c|}
\hline 51 & Apsara: & yeah \\
\hline 52 & Dory: & so this is Sudanese so Sudanese students represent green because they are \\
\hline 53 & & farmers so some of them are from farming background so (..) I'll choose this \\
\hline 54 & & one for them(.) green colour so I want to use brown colour for Eritrea \\
\hline 55 & Apsara: & What is that? \\
\hline 56 & Dory: & Eritrean I have this beautiful lady Eritrean very tall actually Ethiopians and \\
\hline 57 & & Eritreans are very tall the men and women yeah so they work mainly in the \\
\hline 58 & & mountains they have lots of mountains so brown mountains I want to colour \\
\hline 59 & & them brown \\
\hline 60 & Apsara: & $\mathrm{mmm}$ \\
\hline 61 & Dory: & to show the landscape $\uparrow$ and then I have who are the other students I have ((to \\
\hline 62 & & herself)) mmm blue colour actually I have Argentinian student I think can I \\
\hline 63 & & ok ok let me go for the I'll go for the blue blue as boys colour \\
\hline 64 & Apsara: & ok \\
\hline 65 & Dory: & blue is for my Argentinian Messy boy \\
\hline 66 & Dory: & And then I have another Samoan Samoan student \\
\hline 67 & Apsara: & Samoan means from New Zealand? \\
\hline 68 & Dory: & No Samoa it's a small Island. I want to go for purple colour for Samoan \\
\hline 69 & & culture so the reason why I am choosing all these colours is my classroom is \\
\hline 70 & & colourful $\uparrow$ with all these different backgrounds \\
\hline
\end{tabular}

At the beginning of Excerpt 4.17, Dory mentions that she uses colours to represent ethnicities: " $I$ am going to [select] each colour represents each ethnicity in my class" (See line 1). However, later she refers to the countries of the students. For example, she uses green for Ethiopia, red for China, yellow for India, magenta for Syria, orange for Burma, light green for Sudan and blue for Argentina (lines 4, 9, 13 and 34 in Excerpt 4.17). While colouring, she mentions that she is using different colours to represent all the cultures (of the students in her class who represent different cultures). This is illustrated when she says, "I am wearing a dress which represents all the other cultures" and "yeah multicultural so my dress is going to be multicultural and multi coloured it's different identities staying on the.. [class]" ( lines 31 and 32).

Dory's knowledge about different cultures, countries and ethnic groups that she uses when assigning different colours to index different groups shows her close association with the different groups of students in her class. For instance, when I asked why she uses green to represent Ethiopia, she says, "because one of my students said Ethiopia is full of green or something" (line 6). This instance discloses that she discusses the countries with her students. She also mentions, "I will choose for Burma, I want to choose may be orange colour may be mountains with the military [background]" (line 37), which reveals her contextual knowledge about Burma. 
Furthermore, her selection of colours discloses her awareness of the students' socio-economic background. For example, she says, "Sudanese students represent green because they are farmers so some of them are from farming background" (line 53) and "they [Burmese students] get jobs as painters I want to use this colour to represent their skills painting skills" (line 39). This also reveals that Dory knows both the past and present lives of the students because she chooses green to index Sudanese students, relating to their farming background in Sudan, but she chooses orange to index Burmese students, relating to their current jobs in New Zealand.

Dory also indexes different gender groups in her class. For instance, she uses pink and magenta (a shade of pink) for indexing girls whereas she uses blue to index a boy. She states, "Syrian students I want to go for this colour [magenta] because I have seen some of my Syrian students wear this colour a lot. Girls especially so I told myself this is a beautiful colour" (lines 35 and 36) and "So I got this ladies beautiful ladies ahhh I should go for this pink because they wear pink" (line 46 and 47). She mentions the reason why she selects pink and magenta for girls is that these girls wear pink (line 47). However, using pink and pink shades to index women is a traditional way of representing gender groups. This is well indicated by Dory when she later uses blue to index a boy (Argentinian boy) in her class revealing the reason as "blue as boys colour" (line 63).

This way, Dory represents the multicultural aspects of her ELT class in New Zealand through her multi-coloured dress in the identity portrait. She uses her identity portrait to perform that her teacher identity in New Zealand is predominantly, a multicultural identity. Dory further remarks that she reflects upon her multilingual identity in her multicultural class, when she states, "it [her multi-coloured dress] reflects my way of when I teach I learn each each languages from my students" (line 24 and 25). Moreover, she explains her reason to learn her students' languages as to make everyone feels included despite the fact they are from different cultures, ethnicities and countries. For instance, she says, "I want to reflect my I mean I want to tell them that no matter I might [be from a different culture, ethnicity and country] you are from different ethnicity but I can mix with your ethnicity" (line 27-29). In other words, Dory wants to perform her multicultural identity in the class through her negotiated linguistic identity.

Olga also performs a multicultural identity that is dominant in her classroom. For instance, Olga uses New-Year festivals as a topic for classroom discussion (fieldnotes-28/07). She includes all 
the cultures represented by everyone (herself, students, volunteer teacher assistant and me) in the class. She first explains a Russian New-Year festival and asks students about Syrian, Iraqi and Ethiopian New-Year festivals. She also includes me in the discussion by inviting me to talk about Sri Lankan New-Year. Afterwards, she explains about "Matariki"-the Maori New-Year, to represent New Zealand culture. Olga interestingly navigates between different cultures in the class, making everyone feels included in the classroom discussion. Performance of multicultural identities by Dory and Olga aligns with Lisa Leoni's experience as an ESOL teacher in Cummins (2015). Cummins reports how Lisa Leoni expressed her process of identity negotiation-how she had to discover the linguistic and cultural background of each and every student stepped in her language classroom. This experience is shared by Dory and Olga in my study.

\subsubsection{Multinational identity}

In addition to multicultural identity, MELTs also perform multinational identity as a part of their language teacher identities. For example, Olga performs her multinational identity in her identity portrait (See Figure 4.3.) when she refers to Russia, Britain and New Zealand (See Excerpt 4.18.).

\section{Excerpt 4.18- Olga revealing her multinational identity (identity portrait)}

\begin{tabular}{rll}
\hline & Apsara: & Your hair ((in identity portrait)) is red Can I know why? \\
2 & Olga: & This this whole thing ((red, blue and white in the portrait)) is kind of because \\
3 & & it's multilingual identity I am using the colours of Russian flag here for my \\
4 & & personality \\
5 & Apsara: & ok \\
6 & Olga: & So it's kind of (..) so it's white and red and blue \\
7 & Apsara: & That shows your Russian identity \\
8 & Olga: & Yes this kind of this is also colours of British flag and New Zealand flag \\
9 & & these are mostly \\
10 & Apsara: & may be \\
11 & Olga: & complement each other \\
12 & Apsara: & yeah yeah yeah similar. So do you think you have both in you like New \\
13 & & Zealand Identity and Russian identity and British. \\
14 & Olga: & ahhh As an English teacher, definitely there is Both Russian and British $\uparrow$ \\
15 & & because that's where my English learming started like I studied British \\
16 & & English and British culture we didn't focus that much on American English. \\
17 & & And of course New Zealand because I am a New Zealander now Right
\end{tabular}


Olga starts explaining her use of colours: red, blue and white stating that she uses the colours from the Russian flag to represent her "multiingual identity" (lines 3 and 4). However, she is referring to national identities as well by using the countries' flags. She further adds that these colours also "complement" New Zealand and British flags (line 8). However, when I asked whether she thinks that she has all these New Zealand, Russian and British identities in her, she replies that "as an English teacher, definitely there is both Russian and British because that's where my English learning started like I studied British English and British culture" (line 15 and 16). Her emphasis on "as an English teacher", shows how she highlights her multinational identity as a part of her English teacher identity but not the "national identity" that she previously identifies as "Russian".

Olga also reveals interesting information about her belief of her association with a British national identity. She believes that she "definitely has a British identity" (in addition to the Russian identity) (line 14) in her because she learned "British English and culture" (line 16). Monolithic practices of using either American or British national identities to index English language are common among the MELTs in my study. For example, Cindy mentions that she uses "American English" and she is exposed to "the American culture" (See Excerpt 4.13). However, Dory claims her homeland identity (also Indian national identity) by indexing that through her "Indian [English] accent" (See Excerpt 4.5) Thus, Olga, Dory and Cindy positions themselves based on the variety of English that they speak.

According to Pennycook (2003) "it is not that people use language varieties because of who they are, but rather that we perform who we are by (among other things) using varieties of language" (p.528). All three MELTs in my study, in different instances, perform their identities using varieties of English they speak. In particular, Cindy and Olga perform their linguistic identities while drawing upon American English and British English revealing the influence of monolithic ideologies to do with English language. In contrast, Dory rejects the same ideology by highlighting her Indian English accent. Likewise, in line with Pennycook's (2003) argument, all three participants in my study use language varieties they speak in order to perform their national or/and multinational identities. 


\subsection{Conclusion}

In this chapter, I discussed how multilingual teachers perform their negotiated multiple identities through their narratives, small stories, identity portraits and classroom teaching practices. They perform multiple, positive and negative identities while positioning themselves whenever they feel necessary. Their identity performances were observed to be emergent in interaction and dependent on the context and the people they are interacting with at different times. The following paragraphs summarize each teacher's identity performance in brief.

Cindy performs a negative homeland identity positioning herself as a New Zealander. Also, she performs her positive host-land identity both in interaction with me and her students. However, she does not perform her multilingual identity as an English language teacher even though she maintains bilingualism at home with her family and friends. She rather performs a negotiated monolingual English language teacher identity supporting institutional ideologies.

In contrast to Cindy, Dory performs a positive homeland identity by narrating stories from her past student and teacher life in her home country, India. She also positions herself as an Indian in New Zealand by referring to her linguistic, ethnic and cultural identities. However, she has negotiated her linguistic identity to better suit her English language teacher identity in New Zealand. She further performs multilingual and multicultural identities in her ELT class by promoting multilingual and multicultural English teaching ideologies at her institution.

Olga who teaches at the same institution where Dory teaches, performs similarly negotiated multilingual and multicultural identities. In addition, Olga actively navigates between multicultural and multinational identities while interacting with her students as well as me. Also, she attempts to perform a positive homeland identity by making connections to national and cultural indexicalities related to her homeland, Russia.

In conclusion, the multilingual English language teachers in my study perform multiple negotiated identities in interaction with students and me. For example, they perform homeland identities which include both positive and negative identity practices while also performing hostland identities which include monolingual and multilingual, multicultural and multinational identities. However, the way they perform their homeland identities is more abstract drawing upon various cultural indexicalities and past memories. In contrast, they tend to perform more 
powerful host-land identities such as monolingual or multilingual, multicultural and multinational identities which have been negotiated in order to better suit their English language teacher identities in New Zealand. The ideological and interactional functions which are served by their negotiated identity performances will be discussed in the next chapter. 


\section{Chapter 5- Identity Negotiation of Multilingual English Language Teachers}

\subsection{Introduction}

In Chapter 4, I discussed how multilingual English language teachers perform their negotiated multiple identities in interaction with their students, peers, institutional bodies and myself, addressing the first RQ of the study. In this chapter, I present what ideological and interactional functions are served when MELTs negotiate their identities in the classroom, addressing the second RQ of my study. In Section 5.2, I discuss how MELTs invest in ELT through their (negotiated) identities, ideologies and capital. In other words, I argue how they earn new linguistic capital to negotiate their identities in ELT classroom. In Section 5.3, I present MELTs' identity negotiation as a pedagogical advantage showing what interactional functions are served when teachers negotiate their identities in ELT classroom. In this section, I elaborate on teachers' engagement in a shared Community of Practice with students in the classroom through their negotiated multiple identities: multilingual, multicultural, multinational and migrant identities. In addition, I discuss the negotiation of multilingual identities of the teachers as an interactional requirement in the language classroom by illustrating translanguaging practices of the teachers. In Section 5.4, I show the context dependent teacher identity negotiation, illustrating multilingual teachers' small stories on their practices in multicultural classroom settings and their experience during the Covid-19 lockdown period in New Zealand.

\subsection{Investment in ELT: Identity, Ideology and Capital}

Darvin and Norton (2015, p. 41) introduced the new model of investment consisting of capital, ideology and identity "to respond to the current shift of the world order" (p. 41). They state that the way power manifests itself materially in the practices of a classroom, workplace or community can be examined through an interrogation of ideology.

Bourdieu (1987) defines capital as power which extends from the material or economic, that is, wealth, property and income. Also, he states knowledge, educational credentials and appreciation of specific cultural forms as cultural capital. In addition, he mentions connections to networks of power as social capital. Agents, according to Darvin and Norton (2015), "are positioned in social space, based on the volume, composition and trajectory of their capital" (p. 44). Most importantly, the value of one's capital also shifts when it travels across time and space; therefore, either they acquire new material and symbolic resources as capital or transform their capital into 
valuable and recognized capital in new contexts. For instance, when people move from one border to another, the linguistic capital (languages, styles and registers), they bring can be "subjected to measure against a value system that reflects the biases and assumptions of the larger sociocultural context" (Darvin \& Norton, 2015, p. 45). This complex process of transformation and acquisition of capital has to be taken into consideration by the teacher in the teaching and learning process by "treating the linguistic and cultural capital of learners as affordances rather than constraints" (Darvin \& Norton, 2015, p. 45). Thus, the MELTs in my study, specifically Dory and Olga, have invested in earning new linguistic capital in the new social context, NZ, for teaching English. Furthermore, they consider linguistic and cultural capital of the students as resources in the ELT classroom by embracing multilingualism in English language teaching.

I argue how MELTs negotiate their identity with regard to whom they interact with and which context they are situated in are based on their English language teaching ideologies. Furthermore, the teachers earn new linguistic capital while negotiating their identities in order to invest in English language teaching. Based on their ideologies of language(s), they also encourage the students to use their existing linguistic capital as resources to acquire new linguistic capital by accepting and practicing multilingualism and translanguaging in teaching English. On the other hand, multilingual teachers who have a monolingual ideology towards teaching and learning languages constrain their learners in using their existing linguistic capital in ELT classroom believing it negatively affects students' learning. I observed multilingual teachers in my study carried either of the above mentioned language teaching ideologies. Also, I identified different ways that my participants positioned their English language teacher identities depending on their ideologies of monolingual and/or multilingual ELT practices.

\subsubsection{Ideology of monolingual practice in English language teaching}

As discussed in Chapter 4, Cindy expressed herself as a multilingual speaker in her narrative interview and identity portrait. She also revealed that she maintains bilingual language practices at home specifically because she wants her kids to be bilingual (See Excerpt 4.15 in Section 4.3.2). However, she practices a negotiated linguistic identity which is predominantly monolingual in her ELT class. For example, she encourages her students to use only English while interacting in the class. I first experienced this scenario while I was observing her class. A 
student from her class who is originally from Sri Lanka (where I am originally from) spoke to me in Sinhala, a language shared by both of us. I observed how Cindy was nervous hearing a different language in her class (field notes-09/06). Later, when I asked her about this incident in the stimulated recall session, she replied to me as follows.

\section{Excerpt 5.1 Cindy's monolingual language policy in the classroom (stimulated recall)}

\begin{tabular}{|c|c|c|}
\hline $\begin{array}{l}1 \\
2\end{array}$ & Apsara: & $\begin{array}{l}\text { I think you heard he was trying to speak to me in some other language. How } \\
\text { did you feel? }\end{array}$ \\
\hline 3 & Cindy: & It's (..) If it's not bothering to the whole class $\uparrow(.$.$) say if it's just a in a group$ \\
\hline 4 & & discussion $\downarrow$ the ((not clear)) incident that's fine yeah but if that happens and \\
\hline 5 & & then (.) it is disrupt other people differently seen we usually use English I \\
\hline 6 & & would probably not say stop I would say (..) umm I would just remind the \\
\hline 7 & & students that when you come to ((name of the institution)) you have to stick \\
\hline 8 & & yourself to English yeah I do have this happen in my afternoon class there's \\
\hline 9 & & this sisters in the class from the same family so they just forget \\
\hline 10 & Apsara: & maybe it's natural for them [to] \\
\hline 11 & Cindy: & [yeah] but that just disturbing for other students when that happens right \\
\hline 12 & & away I stop them \\
\hline 13 & Apsara: & Is this a rule in the institution or is this personal to you? \\
\hline $\begin{array}{l}14 \\
15\end{array}$ & Cindy: & $\begin{array}{l}\text { It's mostly very }(.) \text { pretty much everything teacher and the classroom has this } \\
\text { rule yeah they just need constant reminders }\end{array}$ \\
\hline 16 & Apsara: & ok \\
\hline
\end{tabular}

Cindy says speaking in other languages except English in class is a disturbance to other students in class. She also recalls another small story to prove that the other students are disturbed when someone speaks in a different language in the class. She thinks "constant reminders" to not speak other languages and speak only English are essential in the classroom (line 15). However, she also reveals that she "right away stop them" when she finds it disturbing to others (line 6). One might argue that this is a classroom management strategy used by the teacher. However, when she reveals that she reminds students when they come to class they "have to" speak English (line 7), it is implied that the institution maintains a monolingual policy. I asked her whether it's a rule in the institution (line 13). Cindy confirms that it's "everything" (line 14) including the teacher and the classroom, drawing on her institutional capital. Her use of "we" in line 5-"we usually use English" also suggests that it is a common practice in the institution, and she represents her institutional identity. 
Interestingly, my attempt to justify the use of other language by two sisters in her class (line 10) was immediately interrupted by her to emphasize that this disrupts other students as well as confirm her monolingual ideology towards teaching English. Mohamed (2020) states that the way in which a language teacher uses language "may serve to validate their membership within the teaching context or allow others to exclude them from affiliation” (p.138). Illustrating this aspect of language teacher identity, Cindy subjectively negotiates her multilingual identity (practiced at home) to a monolingual identity in her class to perform the linguistic identity favoured by the ELT institution that promotes monolingual ELT practices as well as her personal ELT ideology.

Cindy's performance of negotiated linguistic identity is an example to understand how English language teachers negotiate their identity to align with the ELT ideologies practiced in the institutions they serve. Moreover, Cindy' choice of performing different linguistic identities in interaction with different people in different contexts illustrates that teacher identity is negotiated and co-constructed in interaction with others (Connelly \& Clandinin, 1990; Mohamed, 2020).

\subsubsection{Ideology on Multilingual Practice in ELT}

In contrast to Cindy, Dory and Olga perform multilingual identities in their ELT classes and the remainder of this section will focus on them. However, they have negotiated their multilingual identities by investing in learning languages used by their students as discussed in Chapter 4. Their investment in new linguistic capital to use in their ELT classes reveals their multilingual friendly language teaching ideology.

Dory shows her interest in multilingual ELT from her early career in India. She narrates a small story to express how she first started being passionate about understanding the difficulties faced by speakers of other languages when they learn English.

\section{Excerpt 5.2: Dory's interest in multilingualism (narrative interview)}

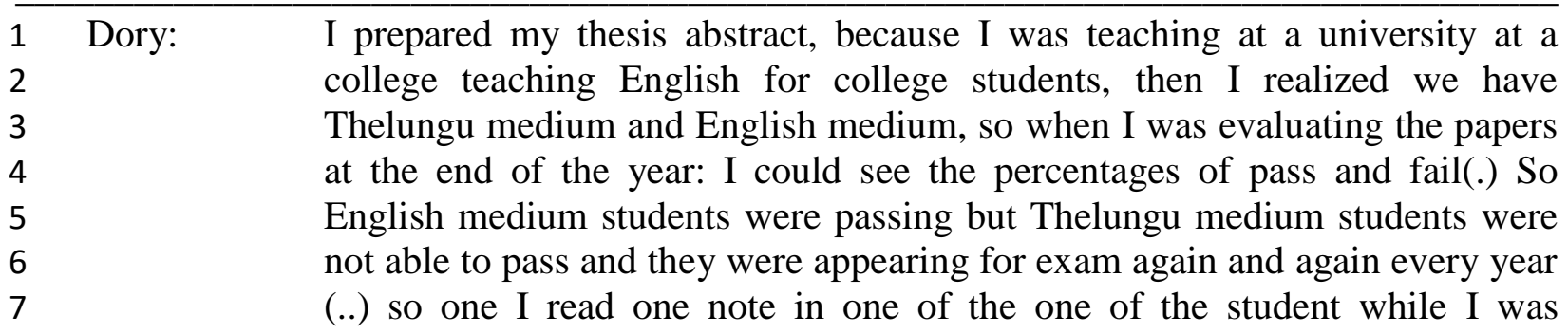


evaluating and she:: he or she, I think she, must be she(.) It said that "this is my $17^{\text {th }}$ time"

Apsara: $\quad$ Ohh

Dory: "And I pass all my other major subjects like optional subjects like physics, chemistry and some but I am not able to get 35 marks in English, So this is my $17^{\text {th }}$ time, And I am so stressed, I might commit suicide" (.) something like that. Generally they are not meant to write anything like that but that message touched me and I was like woow! so people who are smart in their optional languages optional subjects but not able to pass and go further just because of this English subject so I was thinking why Thelungu medium students, number of fail students who are failing this exam is more high, double the rate of the English medium students (.) so then I thought ok, I need to do some research why is this happening? How can we help? How they can learn? How they can get through this kind of test they need to pass what other things I was just going through I mean thinking of this girl who wrote this, this is only by chance I just got it but don't know how many of them they might not be writing, but they might be committing suicide because of they are not able to cope with this you know passing mark which is 35 they have to get 35 marks but most of them are getting 20273032 but still they are failed so this system in India is more memory based than you know. And then I was like ok I have to start thinking about doing some research that's how I started my topic was on how we learn English with the help of our mother tongue, So I did my PHD in this area (.)

Dory's interest in multilingualism for teaching English occurred in her early career in India. She narrates this story to reveal her intentions to support the students in using their first languages to learn English. Also, she studied incorporating multilingualism and translanguaging in teaching English (as revealed in her narrative interview) to speakers of other languages, in her Master's degree in New Zealand. Her personal interest and her educational background encouraged her to negotiate her linguistic identity by learning the languages spoken by her students in order to support them in acquiring English. Therefore, negotiation of her multilingual identity in New Zealand is a result of her personal ideology that she has developed throughout her teaching career, influenced and encouraged by her learning. Thus, teacher identity is "not just relational (i.e. how one thinks or expresses oneself or how others think or express about one), but also experiential (i. e. formed from one's lived experience)" (Mohamed, 2020, p. 137) and subjected to co-construct through learning. This also aligns with the conceptualization of LTI by Yazan (2018) indicating how language teachers negotiate teacher identity in relation to teacher learning. 
Olga's interest and investment in multilingualism has begun after she started her teaching career in New Zealand. It was revealed when she answered one of my questions during the stimulated recall session, as follows.

\section{Excerpt 5.3Olga's Ideas about Multilingualism in ELT (Stimulated recall)}

$\begin{array}{lll}1 & \text { Apsara: } & \text { How do you feel when they use Arabic for their communication in the class? } \\ 2 & \text { Olga: } & \text { Ok I can say that that my stance on that and my feelings have changed over } \\ 3 & & \text { the past two years at the beginning I ahh I felt a little bit, may be not irritated } \\ 4 & \text { but but bit unhappy because I want them to study English ahh and I keep } \\ 5 & \text { encouraging them to use English if they can but now I feel a bit more relaxed } \\ 6 & \text { about it because my primary goal is in this class to empower them and make } \\ 7 & \text { them happy so I know that my aim is to teach them English but this is not my } \\ 8 & \text { only aim my other goals are to keep them engaged like they enjoy their time } \\ 9 & \text { like if they using their language helps them then that's ok. So, I feel relaxed } \\ 10 & \text { as long as they also do English and sometimes I think it is important specially } \\ 11 & \text { when like today when we discuss complex ahh complex things like voting } \\ 12 & \text { and if their friends can help them, by explaining in their own language, I } \\ 13 & \text { think that's good. }\end{array}$

Olga clearly mentions that her ideology of multilingualism in teaching English has changed over time (lines 2 and 3). In addition, she reveals that her objectives as an English teacher are not only limited to teaching English but also empowering the students and ensuring that they are happy in the class. This indicates that she has understood the adult learner identities in her class and she uses a multilingual friendly teaching methodology that addresses her students' needs. Olga's views also show that employing a multilingual friendly teaching methodology helps keeping the students engaged in class. Olga's feelings towards students using other languages in class two years ago- "I felt a little bit, may be not irritated but but bit unhappy" (lines 3 and 4) were similar to Cindy's current feelings towards it. Their reactions to this were also similar. They keep reminding and encouraging the students to use English in the classroom. However, this excerpt also illustrates how Olga has negotiated her language teacher identity over time based on her transformation of ideology in teaching English. Her transformation of ideology aligns with her learning and the institutional ideology towards multilingualism as follows.

\section{Excerpt 5.4 Institutional Ideology towards multilingualism and translanguaging in ELT}




\begin{tabular}{|c|c|}
\hline Apsara: & $\begin{array}{l}\text { Ok, so what about, I mean from your institution's side what kind of } \\
\text { encouragement you get? Do you speak when you have meetings and all about } \\
\text { using their, learners' languages in class? }\end{array}$ \\
\hline Olga: & $\begin{array}{l}\text { I think that ((institutional ideology)) is also changing now, because they are } \\
\text { growing awareness in multilingualism and ahh we have (.) we have heard } \\
\text { about translanguaging in our ((name of a meeting)), they were having some } \\
\text { presentations who have been to conferences and heard about it so this } \\
\text { awareness is growing now and there is more encouragement to use that if } \\
\text { appropriate, so the policy is just stick to English in class as much as possible } \\
\text { but use other languages as it face(.) we use Te Reo for example a lot we are } \\
\text { encouraged to use Te Reo and we rely on students' language when we } \\
\text { discuss complex notions so that's what, how it is encouraged by the } \\
\text { management }\end{array}$ \\
\hline
\end{tabular}

This excerpt from Olga's narrative interview illustrates that the institutional ideology towards translanguaging and multilingualism in ELT is changing over time to a positive approach. This particular institution encourages the teachers to use a multilingual approach in teaching English while also encouraging them to promote using te Reo Maōri, the indigenous language of NZ. The current multilingual friendly language teaching ideology of the institution can also be a result of current national policies regarding employing heritage languages of students in education, implied in a recent strategy for languages in Aotearoa, New Zealand, 2019-2033 (Auckland Languages Strategy Working Group, 2018). However, the institutional policy of "stick to English in class as much as possible" (line 9) discloses that the monolingual friendly ELT ideology still remains in institutional policies despite them attempting to use multilingualism at the practical level.

In this section, I discussed how multilingual teachers negotiate their multilingual identities in ELT classrooms based on their ideologies involving on ELT. Cindy, for example, negotiates her multilingual identity to perform a monolingual identity in her class room to align with her monolingual ELT ideology which has also been bound and encouraged by her institution. Therefore, she neither uses other languages from her repertoire nor her students' repertoires, as resources in teaching and learning English. In contrast, Dory and Olga have negotiated their multilingual identities by earning new linguistic capital in order to better invest in their ELT 
classes. This is due to their multilingual friendly ELT ideologies which have also been encouraged by their institution.

Cindy's and Olga's ideologies about teaching English seem to align with the institutional ideologies with which they are affiliated. These institutions can also be introduced as Communities of Practice as suggested by Yazan (2018). When the teachers maintain membership in these CofPs, they naturally adopt the values, norms and ideologies of the institutions. Yazan (2018) through his framework on language teacher identity (See Section 2.5.2) argues that the negotiation of language teacher identities is based on CofPs. This is an instance where the identity negotiation of MELTs in my study aligns with Yazan (2018) framework on language teacher identity.

In this section, I presented what ideological functions are served when multilingual teachers negotiate their linguistic identities as English language teachers. In Section 5.3, I will further discuss what interactional and pedagogical functions are served when multilingual teachers negotiate their identities in ELT classrooms.

\subsection{Identity Negotiation: a pedagogical advantage}

MELTs in my study perform their negotiated identities as a pedagogical advantage in the language classroom. They negotiate their identities to be included in the classroom community as well as to encourage students to invest in maintaining their membership in the classroom community. Teachers attempt to create a Community of Practice (Wenger, 1998) in their language classrooms so that the students (migrant students from different backgrounds) feel included and enjoy the membership of the community. In addition, teachers perform their negotiated multilingual identities as a positive identity practice serving the interactional functions in the ELT class.

\subsubsection{ELT Classroom as a Community of Practice}

As I discussed in Chapter 2 of this thesis, a Community of Practice (Wenger, 1998, p. 4) is a group of people who shares "a concern, a set of problems, or a passion about a topic and who deepen their knowledge and expertise in this area by interacting on an ongoing basis". Nofal (2020) reviews how Trentman (2013) suggests that the CofP influences students' investment in language learning by granting them legitimacy or the "right to speak" when they move from periphery to full participation. The MELTs in my study negotiate their identities and perform 
negotiated multiple identities to model their membership in the CofP in the language classroom, as it encourages students to invest in learning the target language. The students and the teachers have a membership in a CofP which engages in achieving the shared instrumental goal (Holmes \& Meyerhoff, 1999) of learning English. The teachers and the students seem to commonly share the multilingual and multicultural identities as well as migrant identities. Moreover, students seem to appreciate this community membership, as they feel included and accepted. Also, teachers intentionally perform their negotiated multilingual, multicultural, migrant and second language learner identities to provide a comfortable space for the students in the ELT classroom.

The following example reveals how Olga is aware of the positive impact of her migrant identity in the class.

\section{Excerpt 5.5- Olga's multilingual and migrant identity in ELT class (narrative interviews)}

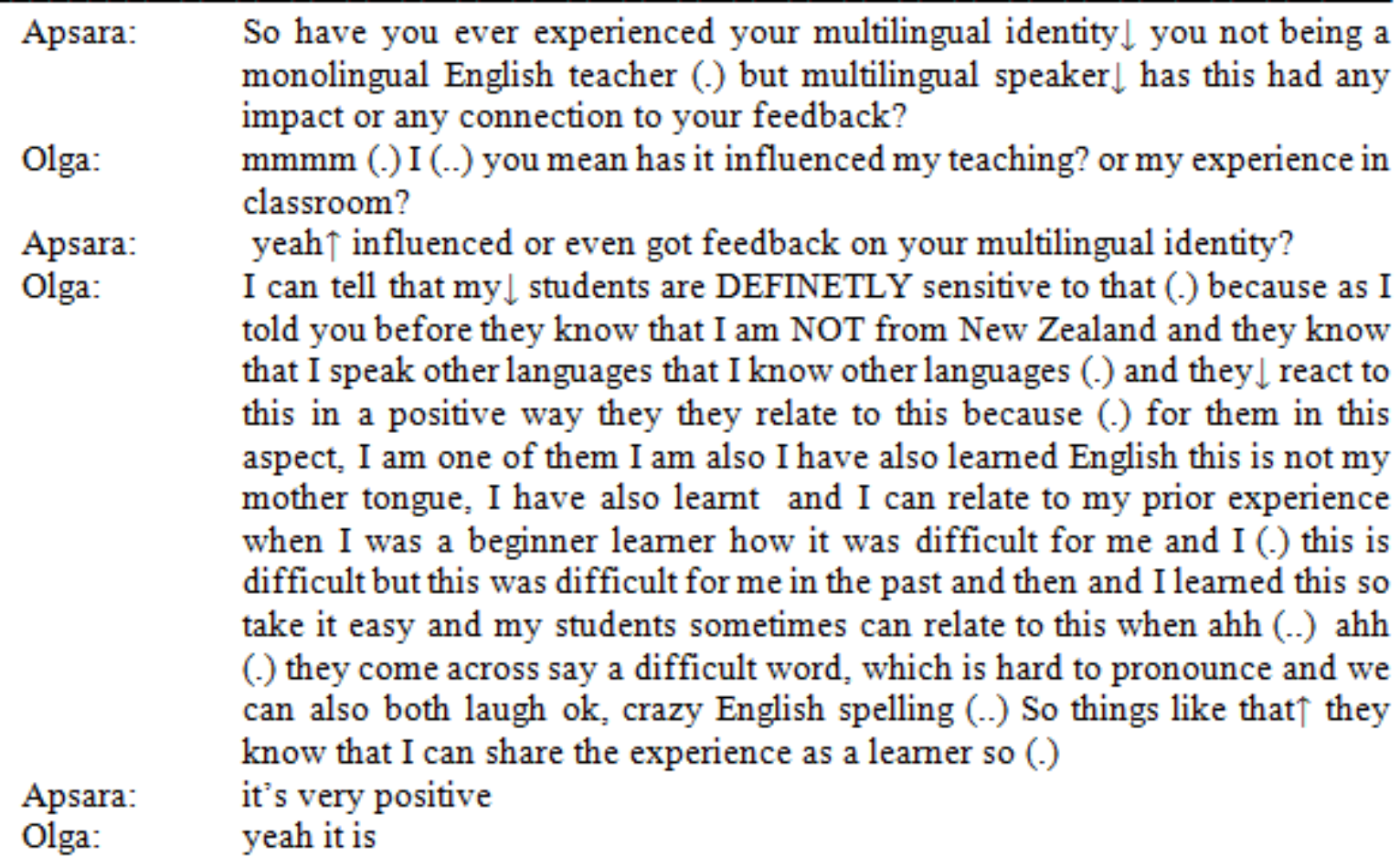

Olga here positions herself both as a multilingual speaker and a migrant. She says, "they (students) know that I am not from New Zealand" (line 8) to highlight her migrant identity whereas she mentions "I speak other languages" (line 9) to refer to her multilingual identity. I argue that she has performed multilingual and migrant identities in the classroom intentionally 
because she is aware that these two identities are well accepted by her multilingual students. Further, these identities allow her to perform positive identity practices (Bucholtz, 1999; Seals, 2017) in the ELT classroom context where the students share similar identities. She emphasizes this when she makes the statement, "I can tell that my students are definitely sensitive to that (to herself being a migrant and a multilingual speaker)" (line 7). She is extremely confident in performing her migrant and multilingual identity in the classroom because the students according to her "react to this [her migrant and multilingual identities] in a positive way" (line 9 and 10).

This was also evident in a classroom discussion when I introduced myself as a researcher to Olga's students; I also explained my research topic (field notes-27/07). Then I was required to explain the difficult words in my research topic. While I was explaining to them the word "multilingual", I asked them what languages their teacher (Olga) speaks because I assumed Olga is the best example of a multilingual speaker that the students are familiar with. The students enthusiastically answered that Olga speaks English, Russian and Arabic. They seemed to be very positive about Olga's multilingual identity, especially the fact that she knows some Arabic words, uses them in class and accepts students using Arabic in class (field notes-27/07). Olga's attempts to perform her multilingual and migrant identities in the classroom can be understood as her subjective decision to be included in the classroom CofP by performing similar identities to her adult female students.

Mohamed (2020) states that there is an impact from a teacher's past experiences as a language learner on his or her teacher identity and teaching practices. Mohamed (2020) further claims that the shifting nature of language teachers' identities can be a result of attitudes, emotions and feelings arouse during their past language learning experiences. Olga provides an example for this notion commenting on the pedagogical value of her multilingual identity (lines 11 and 12 in Excerpt 5.5). For example, she remarks that it is advantageous for her to be able to relate to her experience of learning English as a second language when she teaches students. This way, she feels she can understand the learner identities of her students. She also mentions that she is aware of students' difficulties in learning a second language. Moreover, she comments on how learning occurs in the language classroom by comparing vocabulary in different languages. Since both the students and teacher are multilingual speakers and second language learners and speakers of English, their attitude to English can be similar. For example, she remarks "we can also both 
laugh ok crazy English, spelling" (lines 17 and 18 in excerpt 5.5) This also implies that they can make shared classroom jokes about language without being offended, which might not be as likely to happen in a classroom where monolingual pedagogic orientation is promoted. This also indicates that the members of this classroom community share the same set of concerns, problems and a passion, learning English. They also have ongoing interactions through which they attempt to become knowledgeable in English language. The teacher intentionally performs similar identities to the other members of the group (students) so that she can encourage the students to better invest in the shared concern, learning English.

\subsubsection{Community of Practice: An advantage in the multicultural ELT classroom}

Language classrooms are settings where different social, ideological, political, and cultural representations exist in different forms. For example, students, teachers, teaching materials and language practices of students and teachers can be highly political when they are from different backgrounds. In such situations, language teachers are responsible for managing the classroom discussions in a neutral way so that the students feel included and comfortable, which in return encourages them to invest in learning the language. Norton (2013) remarks that teachers conceive of language both as a linguistic system and social practice in which experiences are organized and identities are negotiated. In addition, she argues that teachers offer learners, "multiple identity positions from which to engage in the language practices of the classroom" (p.17).

In Chapter 4, I discussed how Dory performs her negotiated homeland identity in the host-land, New Zealand, as a model for her migrant students to follow. In this section, I discuss how Dory performs negotiated multilingual and multicultural identities in her class to serve interactional requirements in the language class; for instance, she also depicts her multicultural class as a CofP. Dory gives priority to this aspect of her teacher identity through her identity portrait (see Figure 4.3). Dory represents her multicultural class in her identity portrait by indexing different cultures and countries using different colours as discussed in Chapter 4 (See Excerpt 4.17 in Section 4.3.3). She further explains that she draws a belt tying the dress that represents all her students therein expressing the inclusion of her students from different countries and cultures in her English language class. The following is an excerpt from when she explained her drawing. 


\section{Excerpt 5.6 Dory's teacher identity in her identity portrait (recorded interaction)}

1 Dory: $\begin{aligned} & \text { So the reason why I am choosing all these colours, is my classroom is } \\ & 2\end{aligned}$
3
colourful, with all these different backgrounds $\uparrow$ we respect each other's
culture and we (..) we, we tend to now that we are doing zoom classes we are
5
trying to like a chit chatting meeting place, so that they have to say " $\mathrm{Hi}^{\prime \prime}$ in
7
their language so we are all learning it is representing in my dress (..) I want
to maybe I should get black, I want to use this belt to keep all my (students)
9
tight so that they don't (they are not excluded) (...) so this is my belt, actually
10

Dory explains how she uses multilingualism in her multicultural class to make her students feel included. She mentions that she encourages her students to learn the languages of their peers. This was also evident when I observed her online classes via Zoom. Dory encouraged the students to memorize phrases from their peers' languages (field notes 07/09). This way, she attempts to create a welcoming classroom space for her students. Further, her multilingual friendly ideology towards languages is revealed when she comments that "I am teaching English but we also respect our own languages" (line 7). Using the conjunction "but" in this sentence refers to the monolingual friendly ideology norm in teaching English that exists in English speaking countries. She attempts to differentiate herself from that general English teaching ideology. Also, she avoids linguistic imperialism (Phillipson, 1992) in her language classroom by recognizing other languages spoken by her students. In addition, her comment, "we respect each other's culture" (line 1) demonstrates a shared norm of respecting other cultures practiced in her ELT class as a CofP. Moreover, the multilingualism that is encouraged in her class leads to employing translanguaging in teaching and learning English. The translanguaging practices in Olga's and Dory's classes will further be discussed in Section 5.3.3.

\subsubsection{Translanguaging through negotiated multilingual identity}

The MELTs in my study, specifically (Dory and Olga) revealed that they engage in multilingualism and translanguaging in the ELT classes as discussed in Section 5.2. In this 
section, I discuss what interactional and pedagogic functions are served when they engage in translanguaging in the ELT classes. The evidence related to translanguaging emerged both in narrative interviews and classroom observation data. Dory and Olga employ their negotiated multilingual identities in order to translanguage in the ELT classroom for meaning making, giving instructions and classroom management.

Dory explained how her interest in translanguaging began as well as how she uses that in ELT during her narrative interview with me. The following excerpt from her narrative interview demonstrates how she translanguages using Spanish and Chinese while answering my question in English.

Excerpt 5.7 Dory learning and using Arabic and Spanish for translanguaging in her ELT class (narrative interview)

1

2

3

4

5

6

7

8

9

10

11

12

13

14

15

16

17

18

Apsara: Ok so Dory Can you tell me where and when? For which occasions you speak these languages?

Dory: $\quad$ First language I learnt it at home in the university English I learned from kindergarten until now. I should say Arabic, I started learning Arabic when (.) one of the papers I was doing with ((name of the university in New Zealand where she studied for her Masters in TESOL)) teaching and learning vocabulary. So ((the name of the lecturer)) has asked us to he has given a task as an assignment cho:ose a language which you have never spoken and every day you have to learn 10 words or 50 words a week, And that made me to wow! This is so cool so that's how I started learning Arabic $\downarrow$ And Spanish $\uparrow$ I wanted to help my students, because I used to have a new arrivals with no English at all only Spanish(.) So in order to make them feel comfortable, I used to learn some survival classroom diction, vocabulary to make them understand what I wanted them to do if I learn that part that important parts of the language $\downarrow$ I could help them. You know like for example, if I ask them ok if I If I am ask helping them to fill a form, date of birth, they don't understand, but if I say happy birthday to you ((singing)) and then they know without any (..) so some tricks I use(..)

Apsara: $\quad$ You have your own [strategies]

Dory: [yeah] own strategies, I know Cumpleaños a ti ((singing)) That's in Spanish and Shēngri kuàilè: Something in Chinese, So I the tone (tune) itself is help will help them no matter the words they might not understand but the tune of the song. Oh! That is the happy birthday that's when my birthday. So they feel that. So I use all these strategies to make a survival in the classroom How and also you know adults are ((attention changed)) These are the languages I use if I see someone if I want to talk to them I start with their language, so 
44

that they feel comfortable, friendly, way of you know students I noticed because since I started teaching the other low level past ten weeks I was teaching very low level and they were like when I say a word in their language, if they answer me I say Gracias! That means thank you and then they will be like Yes! They know Gracias! In my thank you in my language and then they that that that you know when you are learning a language it's not always about a language but there are so many other factors

Apsara: Emotional?

Dory: $\quad$ Yeah

Apsara: $\quad$ When you hear your own language in a different country

Dory: $\quad$ And a different person using it, for example when someone, a Kiwi says Namasthe, I would be like wow $\uparrow$ you know and that that connection is so different you can't ignore that person, you want to pay attention you want to show some respect so that is what I feel, how I take, how I see a person to me in my language, not the whole sentence but one word is enough $\uparrow$ to make that bond between the student and the teacher, because they are: you know it's not easy to sit and listen to someone who is talking in a different language for three hours, so I respect that

Dory mentions that her interest in learning new languages began during her studies in New Zealand. However, she reveals that she further learned Arabic and Spanish to support her students in the English class (lines 10, 11 and 12). Therefore, negotiation of her linguistic identity by learning new languages was a pedagogical advantage. She further states that these languages are used as "a survival in the class" (line 23 and 24). This discloses that the new linguistic capital is also earned as an interactional requirement in the language classroom. Language teachers are compelled to learn and use the languages (that are not included in their repertoire) of their students for interactional and pedagogical purposes in the class especially when students are highly monolingual. Hence, negotiation of teachers' linguistic identity is important. Dory also explains the value of learning vocabulary in a new language in order to translanguage in class (lines 15, 16, 17). Interestingly, Dory engages in translanguaging while explaining this to me by singing "happy birthday to you" in two different languages. She then explains how she uses it in the class to translate the word "birthday" to the students. This highlights one of the pedagogical functions of translanguaging as meaning making in the ELT classroom.

Dory also refers to the emotional connection a person makes to his or her language. She says that she is aware of this emotional connection (line 27) students make when she speaks to them in 
their own language. She describes the situation taking an example of herself, how she feels when a foreigner speaks to her in her language. Dory claims that a person can gain the respect and attention of another by talking to the person in his or her language (lines 37-40). Also she states that students feel more comfortable when she speaks to them in their language. This way, she also uses translanguaging to gain approval and acceptance from her students in the class.

Moreover, Dory explains how she uses translanguaging to convince the students of important matters when it is necessary in the classroom (See Excerpt 5.8).

\section{Excerpt 5.8 Dory using translanguaging to convince adult students on sensitive matters}

\begin{tabular}{|c|c|}
\hline 1 Dory: & I tell them like here now this is a big $\uparrow$ no I do this action ((spreading hands to \\
\hline 2 & show big)) big $\uparrow$ no $\downarrow$ and then they think this girl is really getting annoyed a \\
\hline 3 & this is what it is, I have to teach them and you see so, "teacher no no no, \\
\hline 4 & good, New Zealand no good", I say "wait a minute, your ((name of a king)) \\
\hline 5 & killing people is he good or this one is good? No teacher no, house is n \\
\hline 6 & good smelly, I said "you need to calm down a bit here $\downarrow$ " I tell them, I \\
\hline 7 & some Arabic words, and I speak to them yeah even if I want to explain \\
\hline 8 & them something and if they don't understand, I have the Arabic to Engli \\
\hline 9 & dictionary, English to Arabic dictionary, I'll show the word I will show th \\
\hline & show them "oh y \\
\hline
\end{tabular}

Dory's investment in traslanguaging in classroom is evident when she explains how she uses a dictionary to refer to words that she needs to use in the class. Excerpt 5.8 also reveals that translanguaging is used for convincing students in a classroom discussion.

A similar situation to this was observed in Dory's online class. There was a communication barrier between Dory and a student where the student could not respond to Dory in English so that he started acting out something. Dory requested language assistance from another student and the latter student spoke to the former student and explained his response to Dory (field notes07/09). This is another instance of how interactional translanguaging is being used in language classes to overcome communication barriers and maintain the teacher-student rapport. These various instances illustrate how translanguaging functions in a variety of ways to support student-teacher interaction and rapport in addition to meaning making in an adult second/foreign language classroom. 
Olga also uses translanguaging in her classroom. She has assistance of a volunteer teacher (Salma) who is bilingual in English and Arabic. Classroom observation data reveals how Olga receives assistance from the volunteer teacher to give clear instructions to the students. She explains her instructions in English first, and whenever she feels that some students do not understand her clearly, she receives the assistance of Salma. The following excerpt from the classroom observation data shows how Olga requests translanguaging assistance from Salma to give instructions in the class.

Excerpt 5.9 Olga requests translanguaging assistance (Classroom observation- 28/07)

1

1 Olga: Salma, Can you ask these students, what they did yesterday in Arabic?

2 Salma: Yes. ((Salma explains that in Arabic, while Olga assists the students to write

3 the sentences in English.))

4 Student: I ((some Arabic))

5 Salma: I cook

6 Student: ((Answers in Arabic and writes words in English))

In Olga's class, translanguaging is employed more for pedagogical functions like negotiating meanings of the words and giving instructions (See Excerpt 5.9). Translanguaging for negotiating meanings of words was observed emerging in interactions among students and between Salma and students. Olga carefully observes the students' translanguaging to ensure that they are engaged in meaning making related to the classroom discussion. However, the adult female students in her class from similar backgrounds who share the same language, Arabic, communicated with each other using Arabic unless they talked with Olga.

Moreover, Olga explains that she needs Arabic in her class when they discuss vocabulary (See Excerpt 5.10)

\section{Excerpt 5.10 Olga's experience on translanguaging}

1 Apsara: What about your students' use of those languages in class, Do you get to 2 speak any of those languages in class or

3 Olga: $\quad$ oh $\uparrow$ I need $\underline{\text { Arabic }}$ in class much more because lot of my students are from 4 Arabic speaking countries so (.) the students I currently work with they speak Kurdish, Arabic some of them speak Burmese or other languages from 6 Myanmar, Vietnamese, so (.) and I sometimes relate to their languages rather 
than the languages that I speak because the languages I speak are:: occasionally, I can $\uparrow$ use Russian or French or any other in class for example, when we are discussing new vocabulary, and they say "ohh teacher this word is so difficult in Arabic it's bla bla:: and then we start comparing compare English words and Arabic word or another word of their language and I also give them Russian word and we discuss which word is longer which word sounds (not clear) so occasionally, yes(.)

Apsara: $\quad$ mmm how have you learnt, and all these languages I think you told here and there

Olga: aa yeah English in school, university ahh (.) Russian native native language Belarussian also in school and ... when living there French in university course aaa and other Slavic languages basically just spontaneous learning I didn't have any formal instruction in any of them

Apsara: $\quad$ So these languages like Arabic languages

Olga: $\quad$ The languages of my students $\uparrow$ I can’t say I really know them, just I have picked up words from the students

Apsara: $\quad$ from the students

Olga: $\quad$ yeah yeah

This excerpt shows that translanguaging and multilingualism in class are not limited to meaning making and giving instructions. Olga states that she uses other languages as resources in discussing new vocabulary. This can be another pedagogic value of translanguaging and multilingualism in language teaching. She uses other languages (in her repertoire and another official language of New Zealand) which are totally new to students' repertoire (neither the target language nor the first languages of students); for example, Russian, French (lines 7 and 8) and Te Reo Maōri (field notes 27/07) are used in the language classroom. This illustrates how various languages are used as resources by language teachers in order to make their classroom discussions more interesting and relevant for the students.

In Section 5.3, I discussed how English language teachers negotiate their linguistic identities by earning new linguistic capital with the intension of translanguaging in their ELT classroom. Moreover, the experiences of multilingual teachers, Dory and Olga revealed that they translanguage for meaning making, giving instructions, teaching new vocabulary and classroom management in adult language classroom as well as for receiving students' acceptance, approval and maintaining student-teacher rapport. This answers a part of my second RQ: what interactional functions are served when MELTs negotiate their identities in the classroom. In Section 5.4, I will discuss the context dependent nature of teacher identity negotiation. 


\subsection{Context dependent teacher identity negotiation}

In this section, I will discuss how MELTs express/perform their negotiated teacher identities in New Zealand through their small stories on most favourite and least favourite moments. Yazan (2017) reviews many studies on teacher identities, and identifies five main commonalities with reference to conceptualization of teacher identity: teacher identity includes teachers' conceptions and beliefs about themselves as teachers, involves others' expectations and social positioning, teacher identity is dynamic and evolves constantly, teacher identity is constructed and reconstructed in social contexts and interactions, and teacher identity develops through teachers' commitment to, participation, and investment in the profession. The following small stories narrated by Dory and Olga illustrate the commonalities of teacher identity introduced by Yazan (2017).

I present two small stories narrated by Olga, related to her classroom experience before and after the Covid-19 lockdown in NZ. Olga's teacher identity negotiation revealed in these two small stories aligns with Yazan's conceptualization of teacher identity. In addition, Olga constructs her English language teacher identity while choosing to tell the following two small stories (Bamberg \& Geogakopoulou, 2008) as answers to two of my consecutive questions. The first story, about the Master Chef cooking show in class (Excerpt 5.11) is to express her favourite moment in her teaching career, and the second, about online teaching during the Covid-19 lockdown in NZ, is to express the least favourite moment (Excerpt 5.12). She constructs a committed and a self-reflected language teacher identity through the interactional engagement between the two of us while telling these stories.

\section{Excerpt 5.11 - Olga's favourite moment in teaching}

\begin{tabular}{lll}
\hline 1 & Apsara: & Could you please tell me about a favorite moment in your English language \\
2 & & teaching career? \\
3 & Olga: & Favourite? Mmmm ((thinking)) I have a lot of favourite moments one of the \\
4 & & favourites I had this, not this semester last semester, (..) was when we studied \\
5 & & cooking (.) And I had, rather than talking about recipes and talking about \\
6 & pictures we decided to have a Master Chef show, so I went first I prepared \\
7 & guacamole So I brought guacamole ingredients and showed them how to do \\
8 & that and so I asked them to comment on my actions and they did successfully \\
9 & in the end and with recipe, and we had a tasting, and so I said ok your turn is \\
10 & next and then they following class one of the ladies brought Asian dish she \\
11 & brought the ingredients and then another lady brought a Syrian salad she \\
12 & brought sort of half prepared thing because she explained that it would be
\end{tabular}


little bit too long do it in class but she brought all the things neatly cut and prepared and she showed us what is this and she brilliantly described how she did it and we had a shared lunch We had series of classes like this. And I used this as an experience during the lockdown it was not always easy especially first because it was quite difficult for them to, make their transition to Zoom how to use this just not everyone and I used this for relaxation technique, ahh(..) I explained my experience how to make play dough at home so I had play dough ingredients in front of my computer, and I showed them how to make play dough and use that with the kids to keep the kids entertained because they had to stay at home

Apsara: $\quad$ yeah that's very interesting

This story shows that Olga's favourite moment in teaching is when her session succeeds with students actively engaging in and enjoying the lessons. Interestingly, she starts her story as "one of the favourites I had ...was when we studied cooking" (line 2). She uses the word "we" to refer to herself and the students, which indicates that teaching and learning for her is a collective engagement by the teacher and the students. Moreover, her words, "we studied" rather than "I taught" or "they studied" depict that classroom activities are both learning and teaching for her. This suggests that Olga's class is more of a CofP (Wenger et al., 2002) where the teacher and the students collaboratively practice for one goal.

This nature of a CofP in her class is also evident when she describes her class as "sort of a social $h u b$ " where the adult female students have some free time from family and household duties while having connection to a social network (line 10 in Excerpt 5.12). Olga's commitment to teaching is evident in her small story as she uses teaching methods and activities to suit the students she teaches. For example, she plans the language lesson to address her adult female students' interests. Her commitment to and investment in teaching is also visible in her second story related to her experience when she had to transform her face to face sessions to online sessions (See Excerpt 5.12).

\section{Excerpt 5.12- Olga's negotiation of teacher identity during the Covid-19 lockdown}

\begin{tabular}{lll}
\hline 1 & Apsara: & Could you please tell me about a least favourite moment in your English \\
2 & & language teaching career? \\
3 & Olga: & Mmm(...) that would be connected to the recent lockdown again because I \\
4 & & felt, when we had to transfer for online classes it went very different for my
\end{tabular}


Apsara:

Olga:

Apsara:

Olga:

Olga:

Olga:

Apsara:

Olga:

Apsara:

Olga:

Apsara:

Olga:

Apsara:

Olga:

two different classes English for work it went very smoothly and, the people were familiar with technology: they could use the smart phone to install Zoom and it went quite well, but the other group there were: students who told me that they didn't want online classes because they were too busy, they had family kids grandkids at home they couldn't find time at home to study because before the lockdown it was like sort of a social hub where they have some free time from family and household duties they had some fun the social network

yes they had friends

And this lost that connection and so the whole point was coming to class not for all but for some of them were getting together in one's place and [socialization]

[socializing and] learning some English on top of that and in when we had to transfer to online classes it was just mainly the learning, so they had to sit down somewhere at computer or with their phone and focus some learning, not everyone wanted that for various reasons and I felt that despite I lost $\uparrow$ lot of control over the situation because I could send them a task and get response from two students out of ten (.) And it was horrible experience I had to go through it and I had to I had to ammm calm down, and sing and reflect about it, so much it was not my fault because I wanted to take over keep working, keep teaching, and then I concerned on breathing and ok this was not because some of them do not and they openly told me they texted me or, in a phone conversation they told me that ok they are not happy with the whole situation of online learning and they do not want to continue with this because this is not what they light about learning fair enough and I had to calm down and situation and I (..) my students make sure they are all and they knew what's going on so I send them(..) little amm amm messages explaining in simple English the alert levels and what are the changes make sure that I gave them necessary information and just

you kind of postponed the [classes]?

[yeah] No I had the classes I had online classes with the couple of students who were able to

Those who are ok to

Yeah so there were at least two students who were fine with online learning so one or two or three sometimes three sometimes two they would turn up in Zoom classes They had a good learning it was almost like a one on one tutoring session which was very beneficial for them very good it's just the other group who (..) this incident and I just and I told to myself that they because I am bad or something it's because

Because of the country, the world

[yeah]

[pandemic]

And this situation these people need to just pause and take the time and spend more time with their family

And it's stressful to work

and that's fine so they will they will come back to classes after the situation 
51 Apsara: thank you

Olga's commitment to teaching is also evident throughout her narrative. She changes her teaching methods and activities to suit the different classes she teaches. For example, she plans language lessons related to her adult female students' interests. Furthermore, during her online classes, she demonstrates how to make play dough so that her students can use it at home to spend time with their kids during the lockdown. This instance illustrates that Olga attempts to adjust her activities in a way that her adult students can engaged with. This indicates that for some students in her class, learning English was not a priority. Olga herself confirms that when she says "we had to transfer to online classes it was just mainly the learning so they had to sit down somewhere at computer or with their phone and focus some learning not everyone wanted that for various reasons" (lines 17-20) and "they are not happy with the whole situation of online learning and they do not want to continue with this because this is not what they like about learning" (lines 27-29). Olga seems to have struggled between the mismatch of students' expectations and contextual factors that were beyond her control.

Olga further explains how she felt, reacted and finally negotiated her teacher identity when she realized that the situation was out of her control. She says "I lost lot of control over the situation" (lines 20-21), "it was a horrible experience and I had to go through it" (lines 22-23) to show how she felt when she found teaching online unsuccessful despite her attempts to adjust her sessions to the situation. She repeats that she had to calm down (lines 23 and 30) by singing, practicing breathing exercises and reflecting on the situation. Then she decides that it was not her fault as it was the contextual factors, and she tried to continue teaching despite the interruptions. Olga's teacher identity negotiation is a result of her emotional reactions to the contextual factors that had an impact on her teaching. This aligns with the conceptualization of teacher identity by Yazan (2018). Yazan argues how teachers negotiate their teacher identity with reference to their emotional reactions to different contextual factors.

Dory also mentions her experience of negotiating her teacher identity when she replies my question on her most favourite and least favourite moments in her career. Dory narrates this small story is similar to Olga's small story (See Excerpt 5.11) because Dory also positions herself as a committed teacher who makes her language classroom enjoyable to students, yet 
who undergoes emotionally affecting situations when adult students do not invest in the language classroom as per her expectations.

\section{Excerpt 5.13- Dory's most favourite and least favourite moments in ELT}

\begin{tabular}{|c|c|c|}
\hline 1 & Dory: & Sometimes it is when students listen when they pay attention I feel like yes! \\
\hline 2 & & I've done a good job yes I have to do more but sometimes it is like what is \\
\hline 3 & & happening I worked so hard I planned this lesson and I am delivering it but \\
\hline 4 & & they are not taking it \\
\hline 5 & Apsara: & Is that your least favourite moment? \\
\hline 6 & Dory: & Yeah sometimes I blame myself that is the worst thing I ever do and I am still \\
\hline 7 & & doing it If a student is out of 15 students if one student is not listening not \\
\hline 8 & & paying attention I go crazy wait a minute why he is not listening maybe the \\
\hline 9 & & problem is with me when out of 17 students 15 are listening and and 2 are not \\
\hline 10 & & listening why is this maybe I have to do something and when I went and \\
\hline 11 & & spoke my manager saying that hey look this is what happening oh no Dory \\
\hline 12 & & don't blame yourself maybe they are going through something else in their \\
\hline 1 & & life you see.. that's how I started to understand how it's not only the \\
\hline 14 & & classroom because they have their personal life some students are happy to \\
\hline 15 & & come to my class just to forget their problems because we have lots of fun I \\
\hline 16 & & love fun being giving happiness is the best thing ever you could do apart \\
\hline 17 & & from teaching you know so I say thank you for coming I know you must have \\
\hline 18 & & had a last night you might not be able to sleep but thank you for coming oh \\
\hline 19 & & my God yeah. She is thanking me so so I can see that there are certain things \\
\hline 2 & & you can feel some things you can just see some things you can like ahh ok \\
\hline 2 & & that student's attitude is not positive. So why would you blame yourself for \\
\hline 2. & & that I should respect the ones out of 15,17 people two people are not \\
\hline & & listening but I can't overlook the other people but I should respect them \\
\hline
\end{tabular}

Dory starts the story by expressing her different feelings based on her students' investment and success in learning. For example, she feels happy when the students understand the lesson and vice versa (lines 1-3). Dory says that she first thinks it is her fault when some students do not understand the lesson. Lines 6-9 reveal her reactions to students' not learning: "I blame myself that is the worst thing I ever do and I am still doing it", "why he is not listening may be the problem is with me". Even though she knows it is not her fault, she wants to get it confirmed by an outside party. Therefore, she reacts to her emotional response by seeking her superior to convince her that it is not her fault. This emotional reaction to students' responses in class was 
also experienced by Olga during her online classes. However, Olga negotiated her teacher identity by self-reflecting on the situation. Dory in contrast, sought her superior's support, acceptance and negotiation regarding a similar matter revealing her bond to the institution because she reports both positive and negative student behavior to her superior. In addition, she feels secured in reporting negative responses to the superior. That also allows her to express her own commitment to teaching despite students' not investing in learning. Thus, she positions herself as a committed teacher by narrating the story to me.

However, at the end of the scenario, Dory realizes the adult students' identities and their roles apart from the language classroom and attempts to not be affected by the unsuccessful performance of some of her students. She also adds that her classes are interesting for the students and some students come to her class to feel relieved from their personal problems. This was also common to Olga's students who considered the language class as a social hub. Also, Dory reveals that the majority of students who are happily investing in her class is a motivation for her to be positive about her own performance. Hence, this small story is another example to understand how MELTs negotiate their teacher identities depending on contextual factors (Yazan, 2018).

These small stories narrated by Olga and Dory illustrate how constant negotiations of teacher identity occur in relation to interactions with students and the context, aligning with Yazan's conceptualization of teacher identity (2018). In addition, these stories demonstrate how language teacher identities are dynamic and constantly evolving while being developed when they actively participate and invest in teaching (Yazan, 2017).

Finally, Dory narrates a small story that shows how she negotiated her teacher identity in interaction with her students from refugee backgrounds. She states that her role is not only in teaching but also in providing pastoral care to the students (line 6).

\section{Excerpt 5.14: Dory's teacher identity beyond teaching}


2

3

4

5

6

7

8

9

10

11

12

13

14

15

16

17
Dory:

Apsara:

Dory:

Apsara:

Dory:

Apsara:

Dory:

Apsara:

Dory:

Apsara:
My classes at the moment 18 to 19 students, and they are all from different backgrounds, I have eleven ethnicities in my class and some of them are migrants, Most of them are refugees, So: psychologically, emotionally, ahh:: physically, financially, and:: how do I put it the other way, they are all $\downarrow$ they have different backgrounds so: I need to, I have to leave the teacher role aside $\downarrow$ sometimes I have to do the pastoral care, that's very important, Some of them might have lost their family members in the civil war $\uparrow$ like Syria for example, I have students from Syria, and I have students from Colombia, they are: they have no, They don't have civil war but they have drug war, so they are traumatic(.) Burmese cross their boarders (...)

They tell you those stories in the class?

Yeah $\uparrow$ And I need to know because my job is not only teaching English but every student is different, One student is traumatized, one student, I had one student last year Palastinian man he is a civil Engineer but he was this is the Israel Palastinian boarder he was running away from his country,

From where?

From Palastine

To?

To the other border and it was the Israel, Egypt I think. So, he was just crossing this boarder and there was a bomb planted and the time he stepped in there, the same time the bomb exploded and he has got a plastic you know the artificial leg, and he is a computer Engineer. And he is sitting in a class to learn English (.) But I should not forget he was a civil Engineer, computer Engineer or electrical engineer. They have this beautiful life back in their countries but I need to respect. I ca:n't deny their past. I need to respect that for example, I am a PHD, and if I go to Another country and someone is treating you like a child and teaching me A B C or any other language A B C and me sitting there how do I take it you see that is I take it importance doing my class(.) I respect them I don't think that they don't know English but they have life skills they have I don't think I would have been a normal person like whatever problems through they went in the war losing people $\downarrow$ losing the family $\downarrow$ I don’t think I I would sit in a class (...)

without

psychologically

just you can't ignore it

Dory narrates this story of her refugee student to explain me about her class profile. She also highlights her empathetic approach to her students who are adult language learners that happen to learn a foreign language because they were compelled to the position of a refugee by the social system. According to Dory, these students' psychological, emotional and financial status 
has an impact on their language learning. Therefore, she negotiates her teacher identity in a way that she can provide "pastoral care" to her students. She clearly mentions that her role is not only teaching English (line 12). Dory explains that it is important to understand her students because they are different to each other. This shows her sensitivity to the diversity in her class. Dory's repetitive use of the word "respect" (lines 25 and 29) for the students' past lives highlights her attitude towards the refugee students in her class. She empathizes with the adult students who happened to be in her class rather than sympathizing them. By narrating this small story about students, Dory performs and positions herself as an understanding teacher who is aware of her students' backgrounds. This was also revealed in her identity portrait when she showed her awareness of her students' socio-economic backgrounds as I discussed in Chapter 4.

In Section 5.4, I presented how multilingual teachers, Dory and Olga negotiate their teacher identities based on contextual factors. Cindy keeps her focus on negotiated monolingual identity to align with her teaching context as discussed in Section 5.2. In Section 5.5, I will conclude Chapter 5, summarizing the discussion.

\subsection{Conclusion}

In Chapter 5, I addressed the second RQ of my study, discussing what ideological and interactional functions are served when multilingual teachers negotiate their identities in ELT classrooms. The major finding was the two different English language teacher ideologies: monolingual-friendly ELT and multilingual-friendly ELT. Cindy performs a negotiated monolingual linguistic identity in her English language classroom, encouraging students to use only English in the classroom. In contrast, Dory and Olga perform negotiated multilingual linguistic identities, earning new linguistic capital in order to cater the multilingual students in their classrooms. They also employ multilingualism and translanguaging in ELT classroom serving various interactional and pedagogical purposes; for example, meaning making, giving instructions and managing classroom through maintaining effective rapport between student and teacher. I also discussed how teachers negotiate their teacher identities based on contextual factors. In the next Chapter, I will conclude the thesis by presenting a final discussion of the findings and the implications of my study. 


\section{Chapter 6: Final Discussion and Conclusion}

\subsection{Introduction}

In previous chapter, I discussed what ideological and interactional functions are served when MELTs negotiate their identities. In the conclusion chapter, I present a brief summary of my findings in two sections: (1) identity performance of MELTs and (2) ideological and interactional functions served at identity negotiation of MELTs. In addition, I report the pedagogical implications of my study. I also mention the limitations of the study as well as recommendations for future research.

In this thesis, I discussed the identity negotiation of Multilingual English Language Teachers (MELTs) in New Zealand. My objectives were to explore how MELTs perform their negotiated identities and what functions are served when they negotiate their identities. I employed a multiple case study to explore identity performance and identity negotiation of English teachers who speak other languages in addition to English. I addressed two RQs: (1) how do multilingual English language teachers perform their negotiated identities? and (2) what ideological and interactional functions are served when MELTs negotiate their identities? The Poststructuralist view of identity theory (See Chapter 2) was employed in understanding MELT identities. More specifically, identity in interaction (Bucholtz \& Hall, 2005; Rudolph et al., 2020) identity as performance (Bucholtz \& Hall, 2005; Qin, 2019), constant, dynamic and multiple nature of identity (Norton, 2013) and positive and negative identities (Barr \& Seals, 2018; Bucholtz, 1999) provided insights into understanding theoretical bases relevant to the current study. In addition, the conceptual framework of language teacher identity developed by Yazan $(2017,2018)$ was used for understanding identities and identity negotiations of the MELTs who participated in the current study. Empirical research on language teacher identity; for example, by Varghese et al. (2005); Bliss (2016); Zhang (2016); Canagarajah (2016); Yazan (2017); Costa and Norton (2017); Rudolph (2018); Canagarajah (2016); Varghese (2004); Toohey (2016); Motha (2016); Kubota (2016) and Mohamed (2020) were used to explore how previous researchers have discussed language teacher identity.

The data collected used a multiple case study approach including three cases: three multilingual English language teachers in New Zealand. The data collection methods were semi-structured narrative interviews, identity portrait sessions, and classroom observations followed by 
stimulated recall sessions. These were utilized to generate discursive and semiotic data. Discourse analysis, narrative analysis and the small stories approach were used to analyze the qualitative data generated. Data from four different methods were triangulated to analyze how MELTs perform their negotiated identities. The following sections elaborate on the findings of the study in brief.

\subsection{Identity performance of MELTs}

MELTs perform multiple identities in context of interaction with different interlocutors; for example, with their students and with me as the researcher. Different data types illustrate MELTs' various identity performances in different contexts. In other words, the way they perform their identities in identity portraits and/or in narrative interviews (in interaction with me) is different from the way they perform their identities in the classroom. This shows how MELTs perform multiple identities and how they constantly negotiate their identities in interaction with students and other interlocutors. Thus, they perform negotiated multiple identities, including homeland identities, and host-land identities such as migrant, multilingual, multicultural and multinational identities. These identity performances support them to establish their ideological stances on their English language teacher identity as multilingual speakers at a context where English is the dominant language. For instance, Dory performs her homeland identity to challenge societal norms on multilingual linguistic identities of language teachers. Moreover, MELTs navigate between different identities to serve different functions as English language teachers.

Furthermore, MELTs perform positive and negative identities based on the context and interlocutors. For instance, Dory and Olga perform positive multilingual identities in their language classrooms. However, Cindy performs a negative multilingual identity in her language classroom in contrast to her own positive multilingual identity performance while interacting with me during her narrative interview and identity portrait session. This proves how MELTs' performances of positive or negative identities depend on the context and the interlocutors. In addition, their choice to perform positive or negative identities is based on their language teaching ideologies.

The findings of my study reveal how MELTs position themselves in interaction with different interlocutors. This is widely seen in the small stories narrated by the teachers. However, there are 
instances where they differently position themselves while interacting with the students in the class. The teachers position themselves to express how they need to be understood. Olga positions herself as a committed and self-reflected English teacher, a multilingual speaker, and an English as a second language learner and a speaker. Dory positions herself as an English teacher who is understanding and approachable to the adult students, a multilingual speaker, and as an Indian. Cindy positions herself as a teacher who is patient and understanding, a citizen in an urban city in New Zealand and as a speaker of American English.

Various indexicalities used by my participants to express themselves as MELTs reveal their identities and ideologies. Some of these symbols and concepts were connected to their cultures for example, clothes and accessories they drew in identity portraits. They also use different colours to index identity positions. For instance, Dory uses brown as a skin colour to position her ethnic identity both in her identity portrait and narrative interview. In addition, Cindy uses black to express her host-land identity as a citizen in New Zealand. Olga uses blue, red and white to represent the flags of Russia, Britain and New Zealand. This shows her multilingual and multinational identity positioning, which according to her is definitely important as an English teacher. Furthermore, this depicts her monolithic language ideology of English being owned by English speaking countries like Britain and New Zealand.

\subsection{Ideological and interactional functions served at identity negotiation of MELTs}

The current study provides insights to understanding how MELTs' identity negotiations serve various ideological and interactional functions; for example, promoting their ideologies as well as institutional ideologies of English language and English language teaching, fulfilling pedagogical requirements of language teaching in the classroom, and addressing the contextual changes and requirements of language teaching.

MELTs, Dory and Olga, have negotiated their linguistic identities by investing in learning new capital: the languages spoken by their students. This serves to perform multilingual identities that are welcomed by the multilingual students in their classes. Also, negotiating their linguistic identities to promote multilingualism in the language class illustrates their multilingual friendly ELT ideology. On the other hand, Cindy performs a negotiated monolingual identity in her ELT class to maintain her monolingual friendly ELT ideology, which is also promoted by her institution. 
MELTs' performances of negotiated multilingual identities support them in employing multilingualism and translanguaging for various pedagogical functions in the language class; for instance, meaning making, giving instructions to monolingual foreign language learners and classroom management (approaching students, convincing them and offering them an inclusive classroom environment).

Also, modeling the host-land identities in the language class offers the migrant students positive host-land identity options through which the students can take examples to negotiate their negative homeland identities (identified as negative identities in the host-land). For instance, MELTs perform multicultural identities that value a friendly and welcoming environment for everyone. This makes interactions easy in the language class as a micro social context. Thus, MELTs not only offer positive linguistic identities but also positive social identities for the students to follow in the host-land, New Zealand.

Negotiated multilingual, multicultural and migrant identities performed by MELTs also support promoting the language class as a Community of Practice. A language class that functions as a CofP fulfills interactional requirements of the class by offering students a more inclusive environment through offering membership into a new community in the host-land. In addition, it encourages them to invest in learning the language by attending the class regularly and using English to interact comfortably with other students and the teacher as members of the community.

Language teachers also negotiate their teacher identities based on contextual factors. This occurs when teachers actively participate in teaching and invest in the profession. They adjust their teaching methodologies to address the contextual changes and the students' responses to those changes. Sometimes, teachers even emotionally react to these contextual changes; however, they negotiate their teacher identities as a response to these changes and continue teaching. In addition, they change their ideologies of language and language teaching while negotiating their teacher identities. MELTs in my study illustrate how language teacher identities are developed while they are learning in different scenarios. Teacher cognition and teacher emotions have a significant impact on how language teachers negotiate their teacher identity. This is a constant process in language teachers' careers. 


\subsection{Epistemological value to the field of LTI research}

Findings of my study reveal that Yazan's (2018) conceptualization of language teacher identity (which he originally suggested for understanding identities of novice language teacher students) can also be employed in understanding teacher identities of experienced language teachers. This conceptualization was useful for understanding and interpreting identity negotiation of the MELTs who participated in my study. According to Yazan (2018), teacher identity and teacher learning are interrelated factors which results in the negotiation of teacher identity. Also, the development of teacher identity is relational to teacher biographies, teachers' participation in CofPs, teacher's emotions and cognition within different contextual factors. Biographies of the MELTs in my study explored through their socio-linguistic histories revealed in their narratives and small stories are significant in understanding their negotiations of identity in different phases of their lives as well as language teaching careers. These stories disclose socially assigned homeland identities of MELTs as well as the way MELTs use these stories to position themselves in their lived socio linguistic histories while interacting with me. In addition, teacher identity, teacher learning, teacher cognition, teacher emotions and teachers' participation in CofPs which are highlighted in the data depict how MELTs engage in constant negotiations of identity. Hence, Yazan's (2018) conceptualization of language teacher identity can successfully be employed in understanding language teacher identities and their identity negotiations.

However, my study also suggests how language teachers' ideologies of language and language teaching play a major role in their teacher identities adding possible extended discussions on LTI framework suggested by Yazan (2018). Specifically, this framework could also include teacher ideologies as a part of understanding LTI. This also has a significant impact on identity negotiation of MELTs. Teachers' ideologies of language and language teaching decides how, when and where to perform and/or to negotiate a particular identity. Language teachers' ideologies change when teachers learn, experience, self-reflect and participate in CofPs. These communities can be the CofPs in their language classrooms or the CofPs that consist of academic and professional communities with which they have ongoing relations.

The current research also contributes to the field of research on Language Teacher Identity (LTI) by presenting a qualitative research design that includes various research methods which can effectively be used for in-depth analysis of teacher identities in any context. For example, the 
narrative analysis method used in the current study is a blend of narratives (also known as big stories or canons) and small stories (See Chapter 3). Thus, the present study illustrates how teacher stories can effectively be employed in exploring identity performances, identity positioning and identity negotiation in teachers' lived socio-linguistic histories (Barkhuizen, 2016) and interactionally produced brief stories (Bamberg \& Geogokopoulou, 2008). Moreover, my study depicts how teachers do their identities while interacting (in interviews) with the researcher throughout the research process which emerges as a social practice rather than merely as participating in data collection (Talmy, 2010). The use of identity portraits and recorded interactions during the sessions, provide semiotic insights to explore how language teachers perform their identities as well as how they connect indexical meanings to their multiple identities. These indexicalities also reveal teachers' ideologies of language and language teaching. Therefore, the current research is evident that identity portraits can successfully be utilized as a data collection method in identity research to support the data generated in other qualitative methods.

In addition, the current study illustrates how classroom observations support the researchers to gain first-hand experience in language classroom realities while closely observing the identity performance of the teachers when they are in interacting with students. The stimulated recall sessions assist the researcher to clarify their observations with the teachers so that researchers can bring more validity and reliability to their findings. This way, the current study demonstrates a qualitative research design triangulated through a wide range of data for in-depth analysis of teacher identities.

\subsection{Pedagogical implications}

Understanding MELT identities is of utmost importance for language teacher educators and administrative and academic bodies of institutions who conduct English language teaching programmes because ideologies promoted by language educators and institutional bodies can influence teacher identities and their identity negotiations.

MELTs bring various resources to the language classroom through their multilingual, multinational and multicultural identities. The policies and conventions of the institutions should create platforms in which MELTs are encouraged to perform positive multilingual, multinational and multicultural identities to better invest in language teaching. 
Also, multilingualism and translanguaging have many positive contributions to language teaching and learning. Language teachers regardless of their linguistic identities (either multilingual or monolingual) can employ translanguaging as a language teaching method in multilingual settings. As shown in this study, a language classroom which practices multilingualism and translanguaging encourages multilingual learners to better invest in language learning by utilizing the other languages and language related knowledge they possess.

\subsection{Limitations of the study}

As an identity researcher, I attempted to avoid positioning and labeling English language teachers through their different identity categories unless they performed and demonstrated their identities. For instance, I selected the term Multilingual English Language Teachers (MELTs) rather than using a more binary term such as Non-Native English Speaker Teacher (NNESTs) (Dewaele et al., 2021) because I recognize multilingual identity as a resource for language teaching. However, the focus of the current study is only multilingual teachers and I could not include monolingual English language teachers, even though I believe their identities and identity negotiations in language classrooms are of utmost importance to be studied.

The current study focuses only the multilingual English language teacher identities. In adult multilingual language classroom, multilingual learner identities play a major role when they interact with peer learners and teachers. I could not focus on learner identities in my research due to the limited scope allowed for the requirement of my degree. However, this is a worthwhile area for future research.

Furthermore, the current study was conducted in an urban city in New Zealand with a purposive sample of three teacher participants who were recruited through the researcher's academic network. However, inclusion of more teachers from different urban and rural areas can provide broader insights about MELTs in New Zealand. Moreover, all the three participants of my study (recruited on availability) are migrants to New Zealand from different parts of the world. Multilingual English language teachers who are originally from New Zealand can possibly provide different insights into MELT identities. 


\subsection{Recommendations for future research}

Research that includes both multilingual and monolingual English language teachers can reveal comparisons between two teacher identities. This can also illustrate how teachers negotiate their identities in a setting where multilingual and monolingual teachers interact with each other.

An ethnographic study which allows the researcher to explore multilingual teacher and learner identities as well as identities of administrative bodies of the language schools will reveal identity negotiations of different parties in interaction. Moreover, such studies can disclose how identity negotiations of learners and teachers can influence on the change of institutional ideologies which in return can change the policies cater to language education.

\subsection{Final word}

This thesis reports the identity performance and negotiation of multilingual English language teachers (MELTs) in New Zealand. It provides insights to understand how MELTs perform their negotiated identities and what ideological and interactional functions are served when they negotiate their identities. The MELTs who participated in this study performed negotiated multiple identities: homeland and host-land identities as well as negotiated teacher identities. Their identity performance and negotiation emerged in interaction with students in the language classroom and myself during the research process. MELTs also positioned their identities through positive and negative identity practices based on the way they wanted to be understood in different contexts. Furthermore, their negotiated identity performances were relational to their language ideologies as well as language ideologies promoted by the institutions with which they are affiliated. In addition, MELTs negotiated their identities to support the interactional functions of the language classroom. Moreover, the MELTs who participated in my study demonstrated negotiated identity performances to suit the adult migrant student identities in their language classrooms. Interestingly, the negotiated identities performed by some of these teachers seem to have been well accepted, approved and welcomed by the adult second language learners in their classes.

All in all, this thesis reveals how multilingual teachers can bring their resourceful experiences into the English language classrooms in multilingual teaching contexts through identity negotiation. As shown in this thesis, their multilingual, multicultural and multinational identities can be beneficial for language learners. This supports academics and administrative bodies to 
understand positive trends of multilingual teacher identities in English language teaching, encouraging them to uphold opportunities for multilingual English language teachers in Aotearoa New Zealand and in other global English language teaching contexts. 


\section{References}

Anderson, B. (1991). Imagined Communities. Origins of Nationalism 48-59.

Asadi, L., Moody, S., \& Padron, Y. (2020). 'English is the commercial language whereas Spanish is the language of my emotions': An exploration of TESOL and bilingual teacher identity and translanguaging ideologies. In N. Rudolph, A. F. Selvi, \& B. Yazan (Eds.), The Complexity of Identity and Interaction in Language Education. Multilingual Matters.

Bamberg, M., \& Geogakopoulou, A. (2008). Small stories as a new perspective in narrative and identity analysis. Text and Talk, 28(3), 377-396.

Barkhuizen, G. (2016). Narrative Approaches to Exploring Language, Identity and Power in Language Teacher Education. RELC Journal, 47(1), 25-42. https://doi.org/10.1177/0033688216631222

Barr, S., \& Seals, C. A. (2018). He Reo for Our Future: Te Reo Māori and Teacher Identities, Attitudes, and Micro-Policies in Mainstream New Zealand Schools. Journal of Language, Identity \& Education 17:6 (6), 434-447. https://doi.org/10.1080/15348458.2018.1505517

Baxter, J. (2006). Positioning language and identity. In The Routledge Handbook of Language and Identity. Routhledge.

Baxter, P. E., \& Jack, S. M. (2008). Qualitative Case Study Methodology: Study Design and Implementation for Novice Researchers. The Qualitative Report, 3(4), 544-559. http://www.nova.edu/ssss/QR/QR13-4/baxter.pdf

Beijaad, D. (1995). Teachers' Prior Experience and Actual Perceptions of Professional Identity Development. Teachers and Teaching, 1(2), 281-294.

Bliss, D. (2016). ESOL Teachers Identities in a Flux: Identity Transformation throught a Career Massey University]. Aotearoa New Zealand

Block, D. (2006). Multilingual Identities in a Global City-London Stories. Macmillan.

Borg, S. (2003). Teacher cognition in language teaching: A review of research on what language teachers think, know, believe, and do. In A. Burns \& J. C. Richards (Eds.), The Cambridge guide to second language teacher education (pp. 163-171). Cambridge University Press.

Bourdieu, P. (1977). The economics of linguistic exchanges. Social Science Information https://doi.org/10.1177/053901847701600601 
Bourdieu, P. (1987). "What makes a social class? On the theoretical and practical existence of groups". Berkeley Journal of Sociology, 32, 1-17.

Bourdieu, P. (1991). Language and Symbolic Power (J. B. Thompson, Ed.). Basil Blackwell

Braine, G. (1999). Non-Native Educators in English Language Teaching. NJ: Lawrence Erlbaum Associates.

Bres, J. D. (2017). Singing is the first thing that came into my head: Emotions and Language maintenance among Filipino Migrants in New Zealand. In M. M. P. Warren (Ed.), LINGUIST AT WORK FESTSCHRIFT FOR JANET HOLMES. Victoria University press.

Bucholtz, M. (1999). "Why Be Normal?": Language and Identity Practices in a Community of Nerd Girls. Language in Society, 28(2), 203-223. https://www.jstor.org/stable/4168925 (Cambridge University Press)

Bucholtz, M., \& Hall, K. (2005). Identity and interaction: A sociocultural linguistic approach. Discourse Studies, 7(4-5), 585-614.

Burns, A., \& Richards, J. (2009). Second language teacher education. Cambridge University www.cambridge.org

Butler, J. (1988). Performative Acts and Gender Constitution: An Essay in Phenomenology and Feminist Theory. Theatre Journal 40(4), pp. 519-531. https://www.jstor.org/stable/3207893

Canagarajah, S. (1999). Resisting linguistic imperialism in English teaching. Oxford University Press.

Canagarajah, S. (2013). Negotiating Translingual Literacy: An Enactment Research in the Teaching of English, 48(1), 40-67. (National Council of Teachers of English)

Canagarajah, S. (2016). Multilingual Identity in Teaching Multilingual Writing. In G. Barkhuizen (Ed.), Reflections on Language Teacher Identity Research (pp. 60-66). University of Auckland Press.

Cenoz, J. (2013). Defining Multilingualism. Annual Review of Applied Linguistics https://doi.org/10.1017/S026719051300007X

Connelly, M., \& Clandinin, J. (1990). Stories of Experience and Narrative Inquiry. Educational Researcher, 15, 2-14. http://www.jstor.org/stable/1176100 
Costa, P. I. D., \& Norton, B. (2017). Introduction: identity, transdiciplinarity, and the good language teacher. Modern language journal, 101, 4-14.

Cummins, J. (2015). Identities in Motion: Rethinking Teacher-Student Identity negotiation in multilingual school contexts. Australian Review of Applied Linguistics, 38(3), 99-105. https://doi.org/10.1075/aral.38.3.01cum

Darvin, R. (2016). Investment and Language Learning in the 21st Century. Langage et Societe 157(3), 2038. https://doi.org/10.3917/ls.157.0019

Darvin, R., \& Norton, B. (2015). Identity and a Model of Investment in Applied Linguistics. Annual Review of Applied Linguistics, 35, 36-56. https://doi.org/10.1017/S0267190514000191

Davies, B., \& Harre', R. (1990). Positioning: The Discursive Production of Selves. Journal for the theory of social behaviour, 20(1), 43-63. https://doi.org/10.1111/j.1468-5914.1990.tb00174.x

Derrida, J. (1987). A Derrida Reader: Between the Blinds (ques ed.). Harvester Wheatsheaf. https://www.routledgehandbooks.com/doi/10.4324/9781315669816.ch2

Dewaele, J.-M., Bak, T. H., \& Ortega, L. (2021). Why the mythical 'native speaker' has mud on its face In N. Slavkov, N. Kerschhofer-Puhalo, \& S. M. Melo-Pfeifer (Eds.), Changing Face of the "Native Speaker": Perspectives from multilingualism and globalization. Mouton De Gruyter.

Dewaele, J.-M., \& Botes, E. (2020). Does multilingualism shape personality? An exploratory investigation. International Journal of Bilingualism, 24(4), 811-823. https://doi.org/10.1177/1367006919888581

Duff, P. (2014). Case study research on language learning and use. Annual Review of Applied Linguistics, 34, 233-255. https://doi.org/10.1017/S0267190514000051

Duff, P. A., \& Uchida, Y. (1997). The negotiation of teachers' sociocultural identities and practices in postsecondary EFL classrooms. TESOL Quarterly, 31, 451-486.

Edstam, T. (2001). Putting the "Pro" into TESL/TEFL Professionalism. ESL Magazine, 4(ERIC), 16-18.

Garcia, O. (2009). Bilingual Education in the 21st Century: A Global Perspective. Wiley/Blackwell.

Gardner, S., \& Martin-Jones, M. (2012). Multilingualism, Discourse, and Ethnography. Routledge. 
Gass, S. M., \& Mackey, A. (2000). Stimulated Recall Methodology in Second Language Research. Routledge. https://doi.org/10.4324/9781410606006

Greenbank, E. (2019). Discursive navigation of employable identities in the narratives of former refugees Victoria University of Wellington].

Harcourt, B. E. (2007). An Answer to the Question: "What is poststructuralism?" http://www.law.uchicago.edu/academics/publiclaw/index.html

Heller, M. (2007). Bilingualism as Ideology and Practice (M. Heller, Ed.) https://doi.org/10.1057/9780230596047_1

Higgins, C. (Ed.). (2011). Identity Formation in Globalizing Contexts: Language learning in the new millennium (Vol. 1). De Gruyter Mouton. https://doi.org/10.1177/0957926513486580c.

Higgins, C., \& Ponte, E. (2017). Legitimating multilingual teacher identities in the mainstream classroom. The Modern Language Journal, 101(S1), 15-28. https://doi.org/10.1111/modl.12372

Holmes, J., \& Marra, M. (2002). Having a laugh at work: How humour contributes to to workplace culture. Journal of Pragmatics, 34(12). https://doi.org/10.1016/S0378-2166(02)00032-2

Huang, I.-C., \& Varghese, M. M. (2015). Toward a composite, personalized, and institutionalized teacher identity for Non-Native English Speakers in U.S. secondary ESL programs. Critical Inquiry in Language Studies, 12(1), 51-76. https://doi.org/10.1080/15427587.2015.997651

Jenkins, J. (2017). Not English but English-within-multilingualism. In S. C. a. U. Wingate (Ed.), New Directions for Research in Foreign Language Education (pp. 63-78). Routledge.

Johnson, K. E. (1992). Learning to teach: Instructional actions and decisions of preservice ESL teachers TESOL Quarterly, 26, 507-535.

Johnston, B. (1997). Do EFL Teachers Have Careers? TESOL Quarterly, 31(4), Pages 681-712. https://doi.org/10.2307/3587756

Kramp, M. K. (Ed.). (2004). Exploring life and experience through narrative inquiry. NJ: Erlbaum.

Kramsch, C. (2009). The Multilingual Subject. Oxford University Press. 
Krumm, H.-J., \& Jenkins, -. M. (2001). Kinder und ihre Sprachen- Lebendige Mehrsprachigkeit: Sprachen portraights [Children and their language -Living Multilingualism: Language portraits. In Researching multilingualism-critical and ethnographic perspectives. Routhledge.

Kubota, R. (2016). Critical Language Teacher Identity. In G. Barkhuizen (Ed.), Reflections on Language Teacher Identity Research (pp. 175-178). Routledge.

Lasagabaster, D., \& García, O. (2014). Translanguaging : towards a dynamic model of bilingualism at school / Translanguaging: hacia un modelo dinámico de bilingüismo en la escuela. Cultura y Educación 26(3), 557-572. https://doi.org/DOI: 10.1080/11356405.2014.973671

Lave, J., \& Wenger, E. (1991). Learning in doing: Social, cognitive, and computational perspectives:Situated learning: Legitimate peripheral participation. https://doi.org/10.1017/CBO9780511815355 (Cambridge University Press)

Li, W. (Ed.). (2008). Research perspectives on bilingualism and multilingualism. Oxford.

Liu, J. (2012). Nonnative-English-Speaking Professionals in TESOL. TESOL Quarterly, 33(1), 85-102. https://doi.org/https://doi.org/10.2307/3588192

Mantero, M. (2004). Transcending Tradition: Situated Activity, Discourse, and Identity in Language Teacher Education. Critical Inquiry in Language Studies 1(3), 143-161 https://doi.org/10.1207/s15427595cils0103_2

McEntee-Atalianis, L. (2019). Identity in Applied Linguistics Research. Bloomsbury.

Mckinney, C., \& Norton, B. (2008). Identity in language and literacy education. In The Handbook of Educational Linguistics. https://doi.org/10.1002/9780470694138.ch14

Merriam, S. B. (1998). Qualitative Research and Case Study Applications in Education Jossey-Bass Publishers.

Mohamed, N. (2020). Who Am I and Where Do I Fit In: A narrative analysis of one teacher's shifting identities. In N. Rudolph, A. F. Selvi, \& B. Yazan (Eds.), The Complexity of Identity and Interaction in Language Education. Multilingual Matters. 
Motha, S. (2016). WHO WE ARE Teacher identity, race, empire, and nativeness (G. Barkhuizen, Ed. 9/16/2019 ed.). University of Auckland.

Nofal, M. Y. (2020). Multilingual Practices and Identity Negotiation among Multilingual Heritage Language Learners in New Zealand Victoria University of Wellington].

Norton, B. (1997). Language, Identity, and the Ownership of English. TESOL Quarterly, 31(3), 409-429 https://doi.org/10.2307/3587831

Norton, B. (2000). Identity and Language Learning: Gender, ethnicity and educational change. Pearson.

Norton, B. (2010). Identity, Literacy, and English-Language Teaching. TESL Canada Journal, 28(1). https://doi.org/https://doi.org/10.18806/tesl.v28i1.1057

Norton, B. (2013). Identity and Language Learning: Extending the conversation. Multilingual Matters. https://doi.org/https://doi.org/10.21832/9781783090563

Norton, B., \& McKinney, C. (Eds.). (2011 ). An identity approach to second language acquisition (Alternative Approaches to Second Language Acquisition ed.). Routledge.

Norton, B., \& Toohey, K. (2011). Identity, language learning, and social change. Cambridge journals, 44(4), 412-446. https://doi.org/10.1017/S0261444811000309

Ortega, L. (2013). WAYS FORWARD FOR A BI/MULTILINGUAL TURN IN SLA. In S. May (Ed.), The Multilingual Turn : Implications for SLA, TESOL, and Bilingual Education. Taylor \& Francis Group. http://ebookcentral.proquest.com/lib/vuw/detail.action?docID=1323290

Pavlenko, A. (Ed.). (2002). Poststructuralist Approaches to the Social Factors in Second Language Learning and Use. Multilingual Matters.

Pavlenko, A. (2003). I Never Knew I was a Bilingual: Reimagining Teacher Identities in TESOL. Journal of Language Identity and Education, 2(4), 251-268.

Pavlenko, A., \& Norton, B. (2007). Imagined communities, identity and language learning. In International Handbook of English Language Teaching (pp. 669-680).

Pennycook, A. (2003). Global Englishes, Rip Slyme, and performativity. Journal of Sociolinguistics 7(4). 
Phillipson, R. (1992). Linguistic Imperialism. Oxford University Press.

Plöger, S., \& Putjata, G. (2019). Embracing multilingualism in school through multilingual educational staff: Insights into the interplay of policies and practices. In C. Seals \& V. Olsen-Reeder (Eds.), Embracing Multilingualism Across Educational Contexts Wellington. https://doi.org/10.13140/RG.2.2.25805.49120

Qin, K. (2019). Performing Curriculum and Constructing Identity: small stories as a framework for studying identity and learning in classroom discourse. INTERNATIONAL MULTILINGUAL RESEARCH JOURNAL, 13, 181-195. https://doi.org/10.1080/19313152.2019.1623638

Revis, M. (2017). Family language policy in refugee-background communities: Towards a model of language management and practices Journal of Home Language Research (JHLR), 2, 40-62. http://hdl.handle.net/10092/14420

Rudolph, N., Selvi, A. F., \& Yazan, B. (2020). Introduction: The complexity of identity and interaction in language education. In N. Rudolph, A. F. Selvi, \& B. Yazan (Eds.), The complexity of identity and interaction in language education. Multilingual Matters. http://www.multilingualmatters.com/display.asp?isb=9781788927413

Ryan, J., \& Gass, S. (2012). Stimulated recall. In R. Barnard \& A. Burns (Eds.), Teacher cognition and practice: International case studies to illuminate methodological issues Multilingual Matters.

Seals, C. A. (2017). Positive and negative identity practices in heritage language education. International Journal of Languages' Education and Teaching, 15(4), 329-348.

Seals, C. A. (2021). Interactional Sociolinguistics in Language and Sexuality Research: Benefits and Challenges. In J. Angouri \& J. Baxter (Eds.), Routledge Handbook of Language, Gender and Sexuality Routhledge.

Seals, C. A., Pine, R., Ash, M., Olsen-Reeder, V. I., \& Wallace, C. (2019). The use of translanguaging to bridge socio cultural knowledge in a puna reo. In C. A. Seals \& V. I. Olsen-Reeder (Eds.), Embracing Multilingualism across Educational Contexts (pp. 23-39). Victoria University Press.

Selvi, A. F. (2018). Non Native English Speaking Teachers. TESOL Encyclopaedia of English Language Teaching.

Silverstein, M. (2003). Indexical Order and the dialectics of Socio-linguistic life. Language and Communication, 23 (3-4), 193-229. https://doi.org/10.1016/S0271-5309(03)00013-2 
Singh, G., \& Richards, J. C. (2006). Teaching and learning in the language teacher education course room: A critical sociocultural perspective. Regional Language Centre Journal 37(2), 149-175. https://doi.org/https://doi.org/10.1177/0033688206067426 (Sage)

Stake, R. E. (1995). The Art of Case Study Research. Sage Publications, Thousand Oaks.

Swan, A. (Ed.). (2015). Redefining English Language Teacher Identity Macmillan Distribution Ltd.

Tajfel, H. (1978). Differentiation between social groups: Studies in the social psychology of intergroup relations. Academic press.

Talmy, S. (2010). Qualitative Interviews in Applied Linguistics: From Research Instrument to Social Practice. Annual Review of Applied Linguistics 30, 128-148. https://doi.org/10.1017/S0267190510000085 (Cambridge University Press)

Talmy, S. (2011). The Interview as Collaborative Achievement: Interaction, Identity, and Ideology in a Speech Event. Applied Linguistics 32(1), 25-42. https://doi.org/10.1093/applin/amq027

Todeva, E., \& Cenoz, J. (2009). The Multiple Realities of Multilingualism. https://doi.org/10.1515/9783110224481

Toohey, K. (2016). TANGLED UP WITH EVERYTHING ELSE Toward new conceptions of language, teachers, and identities (G. Barkhuizen, Ed.). UNIVERSITY OF AUCKLAND

Trent, J. (2017). Discourse, agency and teacher attrition: exploring stories to leave by amongst former early career English language teachers in Hong Kong. Research Papers in Education 32, 84-105 https://doi.org/10.1080/02671522.2016.1144215

Tsui, A. (2007). Complexities of Identity Formation: A Narrative Inquiry of an EFL Teacher. TESOL Quarterly, 41 (4). https://doi.org/10.1002/j.1545-7249.2007.tb00098.x

Varghese, M. (2004). Professional development for bilingual teachers in the United States: Articulating and contesting professional roles. In J. B.-G. M. Varghese (Ed.), Re-writing bilingualism and the bilingual educator's knowledge base (pp. 130-145). Multilingual Matters.

Varghese, M., Morgan, B., Johnston, B., \& Johnson, K. A. (2005). Theorizing language teacher identity: Three perspectives and beyond. Journal of Language Identity and Education, 4(1), 21-44. 
Vine, B., \& Marra, M. (2017). The Wellington language in the work place project: Creating stability through flexibility. In M. M. a. P. Warren (Ed.), Linguist at WorkFestschrift for Janet Holmes (pp. 177-197). Victoria University Press.

Vygotsky, L. (1978). Mind in society. MA: Harvard University Press.

Waite, J. (1992). aoteareo speaking for ourselves: A discussion on the development of a New Zealand languages policy. M. o. Education.

Weedon, C. (1999). Feminism, theory, and the politics of difference. Blackwell.

Wenger, E. (1998). Communities of practice: Learning, meaning, and identity. Cambridge University Press. https://doi.org/10.1017/CBO9780511803932

Wenger, E., Arnold, R., McDermott, \& Snyder, W. M. (2002). Cultivating Communities of Practice: A Guide to Managing Knowledge. Harvard Business School Press.

Williams, C. (1994). Arfarniad o Ddulliau Dysgu ac Addysgu yng Nghyd-destun Addysg Uwchradd Ddwyieithog, [An evaluation of teaching and learning methods in the context of bilingual secondary education]. Unpublished Thesis University of Wales, Bangor].

Woods, D. (1996). Teacher cognition in language teaching. Cambridge University Press.

Yazan, B. (2017). "It just made me look at language in a different way:" ESOL teacher candidates' identity negotiation through teacher education coursework. Linguistics and Education, 40, 38-49.

Yazan, B. (2018). A Conceptual Framework for Understanding Language Teacher Identities. Journal of Second language Teacher Education, 1(1), 21-48.

Yin, R. K. (2003). Case Study Research-Design and Methods In Applied Social Research Methods Series. Sage Publications

Zhang, Y. (2016). Reviewing Non Native English Speaking Teachers' Professional Identity. International Journal of Languages' Education and Teaching 4(3), 320-335. https://doi.org/10.18298/ijlet.644 
